University of San Diego

Digital USD

2003-03-19

\title{
Employee Receptivity to Three Hundred Sixty Degree Feedback Systems as a Function of Employee Trust and Employee Commitment: An Exploratory Study
}

Gregory G. Stump EdD

University of San Diego

Follow this and additional works at: https://digital.sandiego.edu/dissertations

Part of the Leadership Studies Commons

\section{Digital USD Citation}

Stump, Gregory G. EdD, "Employee Receptivity to Three Hundred Sixty Degree Feedback Systems as a Function of Employee Trust and Employee Commitment: An Exploratory Study" (2003). Dissertations. 722.

https://digital.sandiego.edu/dissertations/722

This Dissertation: Open Access is brought to you for free and open access by the Theses and Dissertations at Digital USD. It has been accepted for inclusion in Dissertations by an authorized administrator of Digital USD. For more information, please contact digital@sandiego.edu. 
Employee Receptivity to Three Hundred Sixty

Degree Feedback Systems as a Function of

Employee Trust and

Employee Commitment:

An Exploratory Study

Gregory G. Stump

Dissertation

March 19, 2003

Dr. Dan Miller, Ph.D, Chair

Dr. Fred Galloway, Ed.D., Member

Dr. Lee Williams, Ph.D., Member

The University of San Diego

San Diego, California

Submitted in partial fulfillment of the requirements for the degree of Doctor of Education 


\begin{abstract}
The purpose of this quantitative exploratory study was to determine what affect, if any, employee trust, employee commitment, psychological androgyny (an employee sexrole inventory), and various demographic variables have on employee receptivity to 360 degree feedback (R360).

Two organizations participated in the study. The first is a large university located in New York; the second is a small consulting firm located in California. A total of 62 participants responded to the 77 -item Internet-based survey. The survey was composed of psychometrically adequate constructs developed in earlier studies. Employee trust, a 12item construct, consisted of 8 items that measured trust in supervisor and 4 items that measured trust in the organization. Employee commitment and R360 used a 7-item construct and 5-item construct, respectively.

Four independent variables were found to be statistically linked to R360. Employee commitment, employee trust, income, and level of education accounted for $37.5 \%$ of the variance in $\mathrm{R} 360(\mathrm{p}=.044, .027, .028$, and .008 . respectively).

The research findings could have consequential implications, particularly if broader studies find similar results. Specifically, organizational leaders and managers would be able to make informed decisions about possible implementation of 360-degree feedback systems depending on the organizational climate.
\end{abstract}




\section{Copyright}

(c) 2003

by

Gregory G. Stump

All rights reserved 
Dedication

This dissertation is dedicated to my parents,

Perry Sr. and Doris,

who continue to be my best source for learning. 


\section{Acknowledgements}

I give my deepest appreciation to my wonderful wife, Leigh-Anne, who was my principal proofreader and my greatest supporter. I could not have completed this project without her.

Many thanks to all who contributed to this work, especially the following:

To Dan Miller for helping me to identify and narrow the focus on this research, and for his continued guidance and support;

To Fred Galloway who opened my eyes to econometrics, and who was a teaching and writing inspiration;

To Lee Williams who provided critical and thoughtful guidance from the beginning of survey design through the final rewrite;

To Rod Napier for being a mentor in 360 design and implementation. Thank you for the training;

To Julie Roberts for helping me to identify potential organizations to take part in the study;

To Peter Stark, Roxana Bahar Hewertson, and Kathryn Burkgren for their continued support;

To Lynne Donahue for teaching me the nuances of Perseus software and HTML programming;

And, to Howard Twomey for being my long-distance collaborator;

Without all of you, the pieces of the puzzle would have never come together. Your encouragement and assistance will always be remembered. 
Table of Contents

Title Page $\quad$ i

Approval Page $\quad$ ii

Human Subjects Approval $\quad$ iii

Abstract iv

Copyright $\quad$ v

Dedication vi

Acknowledgements vii

Table of Contents viii

Chapter I: Introduction

I. Introduction

$\begin{array}{ll}\text { Background to the Study } & 1\end{array}$

Problem Statement 3

Purpose of the Study $\quad 5$

Chapter II: Review of the Literature

$\begin{array}{lr}\text { II. Overview } & 6\end{array}$

$\begin{array}{ll}\text { Evaluation Theory } & 6\end{array}$

$\begin{array}{ll}\text { Employee Performance Evaluation Systems } & 12\end{array}$

Employee Evaluation History $\quad 12$

Contemporary Performance Evaluation Systems 13

Ability, Motivation, and the Performance Environment 19

$\begin{array}{ll}\text { Feedback } & 23\end{array}$ 
Three Hundred Sixty Degree Feedback $\quad 26$

History $\quad 26$

Three Hundred Sixty Degree Feedback Theory 28

Review of 360 Studies $\quad 30$

The Future of $360 \quad 34$

Chapter III. Methodology

Research Hypotheses $\quad 36$

Participants and Research Sites $\quad 36$

$\begin{array}{ll}\text { Piloting } & 39\end{array}$

$\begin{array}{ll}\text { Constructs } & 39\end{array}$

$\begin{array}{ll}\text { Construct Overview and Scoring } & 40\end{array}$

$\begin{array}{ll}\text { Instrumentation } & 42\end{array}$

Data Analysis $\quad 42$

Multiple Regression Assumptions $\quad 43$

$\begin{array}{ll}\text { Multicollinearity } & 45\end{array}$

$\begin{array}{lr}\text { Outliers } & 45\end{array}$

$\begin{array}{ll}\text { Missing Data } & 46\end{array}$

$\begin{array}{ll}\text { Computer Software } & 48\end{array}$

Strengths and Limitations $\quad 49$

$\begin{array}{lr}\text { Strengths } & 49\end{array}$

$\begin{array}{ll}\text { Limitations } & 49\end{array}$

$\begin{array}{ll}\text { Ethical Issues } & 50\end{array}$ 
Chapter IV. Data Analysis

IV. Introduction

Data Analysis

Descriptive Statistics

The Sample

Organization 1

Organization 2

Combined (Aggregated Data from Organization 1 \& 2)

Inferential Statistics

Econometric Concerns

Analysis 1: Demographic Variables

Analysis 2: Employee Trust

60

Analysis 3: Employee Commitment

Analysis 4: Employee Trust \& Employee Commitment

Employee Trust \& Employee Commitment - A Relationship 63

Employee Trust \& Employee Commitment - Concurrent Validity?

Analysis 5: Employee Trust, Employee Commitment, \& Demographics 65

Missing Data 68

Organization Comparisons 70

Multicollinearity and Heteroscedasticity 71

Outliers 71

Data Analysis Conclusions 
Chapter V. Findings Recommendations, and Conclusions

V. Introduction

Findings 75

Employee Commitment and Employee Trust 76

A Comparison of Studies 77

Implications 78

Strengths and Limitations 81

Recommendations for Future Research 82

Conclusions 82

References 83

Appendixes

$\begin{array}{lll}\text { Appendix A Sample Performance Standard } & 93\end{array}$

$\begin{array}{lll}\text { Appendix B } & \text { Performance Determinants } & 94\end{array}$

Appendix C Possible Effects of Feedback 95

$\begin{array}{lll}\text { Appendix D } & \text { Research Webpage } & 96\end{array}$

$\begin{array}{lll}\text { Appendix E } \quad \text { Data Interpretation (Organization 1) } & 100\end{array}$

$\begin{array}{lll}\text { Appendix F } \quad \text { Data Interpretation (Organization 2) } & 105\end{array}$

$\begin{array}{lll}\text { Appendix G Psychological Androgyny } & 112\end{array}$

$\begin{array}{lll}\text { Appendix H Survey (Internet based) } & 115\end{array}$

$\begin{array}{lll}\text { Appendix I Multiple Regression Assumptions } & 138\end{array}$

$\begin{array}{lll}\text { Appendix J Multicollinearity and Heteroscedasticity } & 141\end{array}$

$\begin{array}{lll}\text { Appendix K } & \text { Testing for COMT = TRUS } & 146\end{array}$

Appendix L Determining Values for First-Order Correction 148 
List of Tables

$\begin{array}{lll}\text { Table } 1 & \text { Summary of Factor Analysis } & 65\end{array}$

Table $2 \quad$ Estimated Coefficients ( 3 methods for missing data) 69

$\begin{array}{lll}\text { Table } 3 \quad \text { Summary of t-tests } & 70\end{array}$

Table A1 Variable Nomenclature \& Measurement $\quad 150$

Table A2 Descriptive Statistics (Organization 1) 151

Table A3 Descriptive Statistics (Organization 2) 152

Table A4 Descriptive Statistics (Organizations 1 \& 2) 153

$\begin{array}{lll}\text { Table A5 } & \text { Pearson Correlation } & 154\end{array}$

Lists of Figures

Figure 1 Scatterplots- Homoscedasticity \& Heteroscedasticity 4

$\begin{array}{lll}\text { Figure } 2 \quad \text { Hypothetical } 360 \text { Success Model } & 77\end{array}$

Figure A1 Combined Frequency Distribution (R360) 155

Figure A2 Combined Frequency Distribution (COMT) 156

Figure A3 Combined Frequency Distribution (TRUS) 157

$\begin{array}{lll}\text { Figure A4 Scatter Plot (R360:TRUS) } & 158\end{array}$

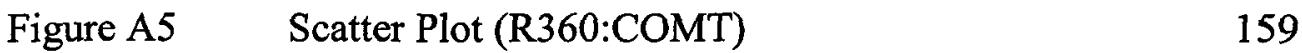

$\begin{array}{lll}\text { Figure A6 Scatter Plot (R360:INC) } & 160\end{array}$

$\begin{array}{lll}\text { Figure A7 } & \text { Residual Error Term Plot (COMT) } & 161\end{array}$

$\begin{array}{lll}\text { Figure A8 } & \text { Residual Error Term Plot (TRUS) }\end{array}$

Figure A9 Residual Error Term Plot (INC) 163 


\section{Chapter I}

Introduction

\section{Background to the Study}

Perhaps nothing in our professional lives consumes more effort than evaluation. Whether we are judging or attempting to improve, effective evaluation helps us to competently perform our day-to-day duties.

This study concentrated on one type of employee performance evaluation: 360 -degree feedback. This feedback system is characterized by the evaluation of an employee's performance by multiple evaluators (Mount \& Judge, 1998). Rather than having a single person (i.e., the supervisor) evaluate an employee, 360-degree evaluation systems provide feedback from a variety of sources including superiors, peers, direct reports, customers, and self (Edwards \& Ewen, 1996; Milliman \& Zawacki, 1994; Tornow, 1993a). A superior often does not have the luxury of observing employees who are engaged in daily activities. Three hundred sixty degree feedback, therefore, provides a more complete description of worker performance and behavior (Salam \& Cox, 1997).

Organizations implement 360-degree feedback systems in an attempt to increase employee performance and behavior. The underlying organizational assumptions are:

1) Three hundred sixty degree feedback will help employees better understand how others view them, and will therefore help them develop a more accurate sense of performance and behavior. 
2) Receiving feedback from multiple sources, rather than from only one source, will better identify employee strengths and areas needing improvement (Tornow, 1993b).

According to Dr. Julie Roberts (J. Roberts, personal communication, November 2, 2000), she and many of her organizational development colleagues use 360 to: ...open up the system to learning and change; help create a norm of improvement of behavior and gathering data; show impact vs. intention....and it gives people a choice (if you don't know where you are you can't change). Of course I use it in conjunction with other team building and cultural work to accomplish these goals.

The term 360-degree feedback (hereafter referred to as 360 ) was coined and registered in the mid-1980s-by-Teams, Inc. (Edwards \& Ewen, 1996). This evaluation process is also sometimes referred to as multi-source assessment, multi-rater feedback, and multi-rater assessment. Three hundred sixty degree feedback systems utilize feedback from many sources including direct reports, peers, superiors, skip reports, customers and suppliers internal and external to the organization, and self (Dunnette, 1993; Mount \& Judge, 1998; Tornow, 1993b; Waldman, 1997). The actual number of feedback sources varies from organization to organization. Upward feedback, an ancestor of 360, calls for ratings from several direct reports (London \& Smither, 1995).

The practice of 360 was not widely implemented until the early 1990 s. By 1994 , twenty of Fortune's thirty-two most admired companies had adopted 360 (Atwater \& Waldman, 1998), and by 1996, ninety percent of Fortune 500 companies had implemented some form of the system (Edwards \& Ewen, 1996). 
Three hundred sixty degree feedback' differs from traditional appraisal systems in two ways. First, 360 systems are most frequently used to enhance employee development and growth, rather than to determine salary adjustments, promotions, or other human resource actions (Tornow \& London, 1998; Waldman \& Atwater, 1998). Second, 360 feedback is generally offered anonymously (except by the supervisor) and is not accompanied by any type of two-way dialogue. This type of system generally increases the proclivity of evaluators to give honest feedback, thereby affording the employee being rated a more accurate assessment (Mount \& Judge, 1998).

Three hundred sixty degree feedback is generally reserved for managers and highlevel supervisors (Grote, 1996, Waldman \& Atwater, 1998), however, an increasing number of organizations utilize 360 for all employees (Tornow \& London, 1998). Although one of the original key purposes of 360 was to develop managers, it has evolved into a tool used for organizational change and improvement (Waldman \& Atwater, 1998). Additionally, 360 has been used to enhance team processes and interdependency among team members. One 360 system, the Campbell-Hallam team development survey (TDS), focuses specifically on teams. TDS allows team members, leaders, and outside observers to provide feedback to the team as a whole (Tornow, 1998).

\section{$\underline{\text { Problem Statement }}$}

The indirect and direct costs to design, implement, and maintain 360 systems are staggering. Employees are required to complete a questionnaire for each of several coworkers. Overall, 360 systems are approximately 10 times more expensive than standard performance evaluations that average $\$ 10$ to $\$ 25$ per employee (Romano, 1994). 
A small organization may spend upwards of $\$ 25,000$ annually in support of 360

(T.Bachus, personal communication, October 1999). It is estimated that in 1992

American companies spent $\$ 152$ million to implement and administer 360 systems

(Romano, 1994). New 360 computer programs, which are becoming more widely used, will somewhat reduce costs associated with the appraisal system. Additionally, such software expands the viability of 360 by increasing its versatility and ease of use (Coates, 1998).

A relevant question immediately comes to mind when comparing the costs and benefits of 360: "Is it worth it?" This question may be analyzed from at least two perspectives. First, is 360 a tool that can increase the effectiveness (e.g., performance) of employees? Despite the recent attention given to 360 , little is known about its affects on the employees who provide or receive feedback (Atwater, Waldman, et al., 2000). The studies that do exist indicate that 360 systems, and variants of 360 (e.g., upward feedback systems), which are correctly implemented and administered, generally act as a catalyst for increased employee performance (e.g., Hazucha, Hezlett, \& Schneider, 1993; Reilly, Smither, \& Vasilopoulos, 1996). Kluger and Denisi (1996), however, found that while feedback interventions generally improved performance, more than one-third of the interventions decreased performance. The decrease in performance was generally a result of inappropriate feedback intervention.

The second perspective, relating to whether 360 systems are worth the cost, relates to employee receptivity to 360 performance systems. If employees are unreceptive to the process of 360 evaluation and are unwilling to consider data generated from 360 systems, the effectiveness of the appraisal process may be negatively impacted (Bernardin, 
Dahmus, \& Redmon, 1993). Organizations composed predominately of employees who are not receptive to 360 , therefore, may be wise to consider providing appropriate interventions prior to implementing such a costly appraisal system. Or, such organizations may simply prefer to forgo adoption of 360 .

\section{Purpose of the Study}

The ability to predict whether individual employees will be receptive to 360 has major consequences. Human resource officials and organizational development consultants who are able to correctly make such predictions could promote 360 if it appears that the organizational culture is suited for such a system. Or, the same experts could prevent tens-of-thousands of dollars from being wasted on an evaluation tool that does not fit the employee culture. A third option, if receptivity to 360 is found to be relatively low, is for leaders to provide a workforce intervention intended to improve the organizational culture. Specifically, the proposed study could help experts determine whether 360 implementation is viable in a particular organization based on the composition of its workforce and the culture of the organization. 


\section{Chapter II}

Review of the Literature

\section{Overview}

This chapter is divided into subheadings that follow a logical progression. Three hundred sixty degree feedback is first discussed by building a conceptual framework of evaluation theory. Next, an overview of performance evaluation theory is introduced. Finally, 360 theory and analysis of associated studies are presented.

Evaluation Theory

The field of evaluation theory is vast. Hundreds of books and journal articles have been written chronicling the historical developments of evaluation theory, and providing new methodologies or theories for practitioners to consider. This section will provide a brief overview and some key concepts of evaluation theory that are the foundation of employee performance evaluation systems including 360-degree performance evaluations. Specifically, two key theories are considered: Fourth Generation Evaluation and Utilization-Focused Evaluation.

Evaluation, at some level, has been part of civilization for thousands of years. Evaluation as a field of professional practice, however, is relatively new. Guba and Lincoln's (1989) seminal work, Fourth Generation Evaluation, posits an accepted theoretical archetype of evaluation. 
According to Guba and Lincoln (1989), first generation evaluation involved measurement. The early influences of measurement related to schoolchildren. Tests had been commonplace in education for hundreds of years-students were tested to determine if they had mastered curriculum content. Content was based on an accepted "expert" or reference, e.g., Plato, the Bible, conventional concepts of math and science, etc. The primary responsibility of teachers was to teach current day facts. Schoolchildren were then required to recite these facts. Examples of first generation systems include the Stanford-Binet IQ, Army Alpha, and Scholastic Aptitude Tests. The role of the evaluator was purely technical—specify which instrument to employ and how to properly administer it.

Second generation evaluation relates to description. It began as educators realized the need for a change in curriculum after World War I. An influx of students, many whose parents had not continued education past sixth grade, flooded the secondary education system in 1919. These students, who desired to increase their social and economic status by continuing their education, were met with an ill-prepared education system. An increase in student population forced educators to develop new teaching methods and new techniques to evaluate their students.

During this period, the Carnegie unit system, which identified the types and numbers of units for high school graduation, was questioned. College and university officials became concerned that if the Carnegie system was superceded by another type of requirement process, unqualified freshmen would inundate higher levels of education. The Eight Year Study, designed to determine if alternative evaluation systems were viable, began in 1933 . The purpose of the study was to judge whether students who took 
part in a less traditional secondary education rote curricula could succeed in higher education.

One concern immediately surfaced as a result of the Eight Year Study. Specifically, the new curricula would not be able to pinpoint why students who passed the contemporary curricula in secondary education might fail at the college level. For example, might students who fail in college do so because the principle of the new curricula was inadequate, or because the curricula were inadequate in practice? Specifically concerning the new curricula, what was inadequate - the theory or the application of teaching?

During the same period, Ralph Tyler, a faculty member at the University of Ohio, developed tests that measured to what extent students learned what their professors had intended them to learn. Professors' desired learning outcomes were labeled objectives. Professor Tyler eventually took the Eight Year Study to a new level. The new studies were concerned not only with measurement (first generation evaluation), but also concentrated on refining the new curriculum to make it as effective as possible. This was the beginning of program evaluation. Program evaluation is concerned with identifying strengths and weaknesses of a program in order to improve it. This type of evaluation, i.e., second generation, relates to an evaluator describing the strengths and weaknesses of employees, groups, teams, programs, etc., in relation to stated objectives.

Next evolved third generation evaluation-judgment. It became apparent that an evaluator must not only measure, but he or she must also be able to judge using some type of external measure that may or may not be related to what he or she is assessing. Third generation evaluators, therefore, act as judges who are grounded in the theory and 
practice of what they are assessing. One predominant challenge associated with third generation evaluation is that a flaw may exist in the external measure. For example, an evaluator may accurately provide judgment based on a theoretical benchmark, however, the benchmark may be imperfect. Specifically, the theoretical benchmark may not be congruent with the practical threshold that separates acceptable and unacceptable standards.

Although each of the three preceding generations represented progress in the field of evaluation, Guba and Lincoln (1989) contended that a fourth generation was needed for more accurate assessment. Several potential flaws associated with the first three generations made this apparent. For example, key players within an organization may not share the same values when evaluating. Additionally, stakeholders may not be completely objective when performing evaluations due to bias or a conflict of interest.

An alternate approach to evaluation was first proposed by Robert Stake in 1975 . Stake referred to this alternate approach as responsive evaluation, and it determined the boundaries and parameters of evaluation through interaction of key players and negotiation among stakeholders. Who are the stakeholders? From an evaluation perspective, stakeholders include any person who has a vested interest in the evaluation findings. Possible stakeholders include program funders, staff, administrators, clients, program participants, or individuals who may be affected by the program or entity being evaluated (Mendelow, 1987). Guba and Lincoln (1989) labeled this alternative evaluation fourth generation. It is likely that Mendelow, Guba, and Lincoln did not realize in the late 1980s that their concept of including stakeholders in the evaluation process would cross over to employee appraisal systems, however, it has. Three hundred sixty degree 
performance appraisal systems include key stakeholders that may comprise supervisors, direct reports, peers, customers, and self.

Several experts have expanded the concept of fourth generation evaluation. A more recent interpretation, posited by Michael Patton (1997, p. 20), is utilization-focused evaluation. The premise of utilization-focused evaluation as Patton describes it is: [It] begins with the premise that evaluations should be judged by their utility and actual use; therefore, evaluators should facilitate the evaluation process and design any evaluation with careful consideration of how everything that is done, from beginning to end, will affect use. Nor is use an abstraction. Use concerns how real people in the real world apply evaluation findings and experience the evaluation process. Therefore, the focus in utilization-focused evaluation in on intended use by intended users.

Utilization-focused evaluators facilitate judgment and decision making by the intended user rather than acting as an independent judge. Utilization-focused evaluations frame the assessment by identifying the values of key stakeholders. Patton states, "[E]valuation use is too important to be left to evaluators."

It seems apparent that congruency exists between Fourth Generation Evaluation and utilization-focused evaluation. One association between the two types of evaluation is the people who are involved - the stakeholders who are or will be affected by the entity being evaluated, and subsequent action to create, modify, or eliminate policies related to that entity.

One final aspect of evaluation should be offered prior to discussing performance appraisal systems-evaluation types. At least three primary types of evaluation exist: 
summative, formative, and knowledge-oriented (Patton, 1997). Knowledge-oriented evaluation is primarily used to build theories, synthesize program patterns, make policy, and provide a foundation for academic publishing. It is used to affect the way that we generally think about issues (Rossi \& Freeman, 1985). This type of evaluation is important, however summative and formative evaluations are the frameworks used in performance appraisal systems and will be discussed in more detail.

Summative evaluation is used to judge the merit, worth, or value of something. Merit is the internal value of the entity, i.e., does the entity meet the needs of those for whom it is intended? Worth refers to the external value of the entity, i.e., does the entity meet the needs of individuals who are outside the entity, e.g., a larger community? A drug treatment facility, for example, would be considered to have merit and worth if it reduces the population of drug users through treatment, education, and prevention (internal value), and improve community life by reducing drug-related crime (external value). Examples of summative evaluation include audits, quality control, accountability, costbenefit analysis, accreditation/licensing, and decisions on a program's future (Patton, 1997).

Formative evaluation relates to improvement. Individuals who are involved with formative evaluation are less interested in passing judgment and more interested in improving a program or policy. Examples of formative evaluation include identifying strengths and weaknesses, quality enhancement or continuous improvement, managing/leading more effectively, and life-long learning (Patton, 1997).

The following quote provides a clear example of how summative and formative evaluation are related, "When the cook tastes the soup, that's formative; when the guests 
taste the soup, that's summative" (Scriven, 1991, p. 169). Additionally, Scriven's quote indirectly identifies the timing of both types of evaluation. Formative occurs during the process or program; summative occurs at a later point in time.

The theories associated with Fourth Generation Evaluation and Utilization-Focused Evaluation are key components that will be interwoven into the discussion of employee performance appraisal systems, and ultimately, 360-degree feedback performance evaluation.

\section{Employee Performance Evaluation Systems}

\section{Employee Evaluation History}

Measurement of employee performance has been a focus of applied psychologists for more than 50 years. The traditional employee rating scale still used by many organizations was introduced in the early 1920 s in an attempt to analyze characteristics of individual energy expenditure and effectiveness.

In the 1930s and 1940s, much research was focused on ascertaining the most effective format, method, and characteristics of performance measurement systems. At this early stage the question was not if employee performance would be measured, but how performance would be measured.

Robert Wherry drafted several reports for the U.S. Army in 1952 that discussed the rating process. Wherry concluded that observation, storage and retrieval of observation data, and judgment are all important elements of the rating process (DeNisi \& Williams, 1990).

Virtually no significant performance evaluation research was conducted from the mid1950 s through the 1970s. Researchers merely adjusted the evaluation scales, used letters 
rather than numbers, and altered the format of the report. After this period, a breakthrough occurred; the Behaviorally Anchored Rating Scale (BARS) (also referred to as the Behavioral Expectation Scale (BES)) (Smith \& Kendall, 1963) was introduced. Researchers spent more than a decade fine-tuning the BARS methodology in an attempt to evaluate employees in almost every profession. BARS evaluations attempt to combine trait ratings with the specificity required for objective and fair evaluations. Rather than using anchors such as, "works well with others", BARS employs a job analysis to determine specific behaviors and performance required by a particular job (King, 1984).

It became apparent to researchers that the methodology of BARS overlooked a key aspect of the evaluation system - rater characteristics and the mechanics associated with the rating process.

A change in the discipline of industrial psychology in the 1970s, and an eventual disappointment in BARS and BES, led researchers to examine dynamic variables associated with employee performance. This examination involved research toward understanding the notions of error, e.g., attribution error, implicit personality theory, and models of person perception (Landy, Zedeck, \& Cleveland, 1983).

\section{Contemporary Performance Evaluation Systems}

Today, the theories of employee evaluation continue to expand, and experts persist in debating the most effective performance appraisal model (Cleveland, Landy, \& Zedeck, 1983; Latham \& Wexley, 1981). A lack of consensus may exist among experts regarding performance evaluation models, however there is general agreement among psychologists on what defines a good appraisal instrument. A job analysis (e.g., traits associated with effective or ineffective job behavior) that yields a reliable and valid instrument are 
considered essential elements for an effective evaluation (Latham \& Wexley, 1981; Latham, 1990).

Job analysis, the first element in an effective evaluation, is an examination of the important work behaviors required for successful performance. A job analysis should focus on a task and the associated work behavior(s) required to complete the task (EEOC, 1978). Job analyses are completed to define the most critical aspects of a job (Whetzel \& Wheaton, 1997), specifically employee traits required by the job (Cummings \& Schwab, 1973; Henderson, 1984)

Job analysis is important for at least two reasons. First, it is an organization's framework that identifies expected behaviors and performance from employees. Organizations failing to provide such basic information to their employees could experience a sharp decline in effectiveness. Equally important, organizations failing to develop a job analysis run the risk of incurring legal challenges from employees who are terminated. Past employees who have brought suit against their respective organizations for wrongful termination have won when they could prove that the company had not provided a satisfactory job description (Laxley \& Wexley, 1981).

The second reason job analysis is important relates directly to the evaluation system as a whole. Job analysis can be used to determine the structure, process, and policy of an entire appraisal system. Job analysis, for example, can be used to identify the best sources to evaluate different components of job performance. Direct reports may be better suited, for example, to appraise certain components of a manager's performance while peers or supervisors may be more effective at evaluating other components (Bernardin \& Beatty, 
1984). An example of the output of a job analysis, i.e., performance standards, is provided in Appendix A.

The second and third essential elements of an effective evaluation, reliability and validity, relate directly to the psychometric characteristics of an evaluation. Reliability is the accuracy and consistency of ratings provided by an evaluator. Validity relates to whether a particular performance dimension measures what it purports to measure (Grote, 1996; Whetzel \& Wheaton, 1997). Developing valid and reliable appraisal systems is, in itself, a vast science and too broad to discuss herein, however various books and articles have been written on the subject (e.g., Cummings \& Schwab, 1973; Schmidt \& Hunter, 1977; Schmidt \& Hunter, 1981, Schmidt, et. al, 1985; Whetzel \& Oppler, 1997).

Experts tend to agree on the purpose of an evaluation system. Evaluation system purposes, which emphasize job requirements and performance expectations, include (Henderson, 1984; Levinson, 1970; Mohrman, Resnick-West, \& Lawler, 1989):

- Measure and judge performance

- Compare individual performance to organizational goals

- Nurture the increasing competence and growth of workers

- Help motivate direct reports

- Enhance communication among supervisors and direct reports

- Serve as a basis for human resource management decisions (e.g., promotion, salary, transfer, bonus, selection for education and training, etc.)

- Serve as a device for organizational integration

- Assist employees in career planning 
The purposes of evaluation relate directly to productivity (individual and organizational) and motivation. Additionally, as mentioned earlier, organizations use evaluation systems due to legal requirements that developed from the 1964 Civil Rights Act (Latham \& Wexley, 1981). This section, however, will concentrate on employee evaluations, specifically 360 -degree feedback systems, solely from a productivity and motivation perspective.

The concept of productivity in most organizations is related to at least three variables: technology, capital, and personnel. Some organizations have prospered by concentrating on and expanding technological resources and capital. Unfortunately, many of these companies have failed to maximize productivity by thwarting or by not pursuing the potential of their employees. Why do some organizations focus more on technology and capital than on employee performance? The primary reason is because it is easy for organizations to measure performance related to technology and capital by evaluating profits and costs. An accountant is able to quantitatively determine organizational effectiveness by measuring inputs and outputs. Measuring employee performance, however, is not as easy (Latham \& Wexley, 1981). Quantitative interpretation of human performance often overlooks rich data associated with employees.

Employee performance can be described in both quantitative and qualitative terms. Quantitatively, performance can be measured objectively in terms of what employees do on the job, e.g., attendance, accidents, turnover, and grievances. Additionally, organizations can measure what employees do not do. Employee practices such as tardiness, ceasing work early, and filling work requests incorrectly could cost a large company several million dollars. Qualitatively, performance may be measured 
subjectively (e.g., employee commitment, attitude, creativity, initiative, and motivation). This type of evaluation may be richer than objective standards, however, qualitative assessment may not be as precise as quantitative evaluation. The more qualitative measures can be made objectively, the stronger the data are for use in the appraisal interview and for human resource decisions (Grote, 1996; Latham \& Wexley, 1981).

Herein lies one inherent challenge in evaluating employees-accurately assessing employee performance. Such a challenge, however, can be overcome. One way is to separate the challenges associated with evaluation systems into parts.

Employee performance appraisal systems have two barriers-human and technical. Human barriers, which are the genetic and learned scripts that make it difficult for humans to accurately measure employee performance, may be extremely difficult to overcome: Technical barriers, however, are systematic in nature and are relatively simple to conquer. Human and technical barriers may be separated, however they are not mutually exclusive. They are related in the evaluation system.

Through proper design and implementation, the technical components of a performance appraisal system can reduce the problems associated with the human barriers. According to Henderson (1984), correct technical design of a performance evaluation system includes:

1. Accurate and thorough job descriptions.

2. Identification and weighting of performance dimensions and inclusion of performance standards.

3. Prioritization and allocation of resources that influence successful assignment completion. 
4. Inclusion of non-job related activities that influence organizational productivity.

5. Measurement processes and instruments that relate to the multidimensionality of work.

6. Use of raters who have observed, recognized, and measured performance.

7. Timing and scheduling of performance ratings.

8. Training of all involved personnel.

9. Use of an information system that can store, retrieve, analyze, and disseminate appraisal data to appropriate parties.

10. Monitoring and auditing programs that help identify and correct program deficiencies.

11. Establishment of an appeals process.

12. Development of performance improvement or action plans-(Kirkpatrick, 1982).

Challenges related to human barriers are not as easy to overcome due to complexities of genetic and learned human behavior. A variety of psychological, emotional, intellectual and physical problems combine in a multitude of permutations to neutralize the best-designed employee evaluation system. Some of the human barriers are universal-they affect anyone involved in the evaluation process, while other barriers affect the behavior of those involved in specific roles, e.g., evaluator, evaluatee, reviewer, user, or administrator. Examples of human barriers include employee reaction to being rated as average, concern of long term employee survival, an evaluator's desire to be accepted, and concerns of maintaining a healthy workgroup environment when unsatisfactory ratings are given to direct reports (Henderson, 1984). 


\section{Ability, Motivation, and the Performance Environment}

Three variables exist that will determine the performance of any employee: employee ability, employee motivation, and the performance environment (the organization). Two of the three variables, ability and motivation, relate directly to the individual who performs within the organization. The third, performance environment, relates to how the organization impacts individual performance.

The determinants employee ability and performance environment will be briefly discussed due to their technical nature. Motivation is a more complicated phenomenon and will be reviewed in greater detail. Appendix B, adopted from Cummings \& Schwab (1973), provides a graphical representation of the concept of performance determinants.

Ultimately, the responsibility of individual performance and behavior falls on the shoulders of the employee who works within the organization. It is, however, the organization that defines the nature of performance. Employees may have individual goals when they join an organization, however, individual goals generally must be set aside to strive for collective goals within the organization.

The performance environment includes the system and structure of the organization (e.g., employee selection and training), as well as its leadership. The affects of the performance environment are vast and are discussed in more detail herein.

Ability is an individual's capacity to perform a task or a set of tasks. The concept of ability encompasses a broad array of characteristics such as an individual's verbal, mathematical, and spatial skills, as well as personality traits that may be measured using various assessment tools including Myers-Briggs Type Indicator (MBTI) and Minnesota Multiphasic Personality Inventory (MMPI). 
Organizations are able to improve the ability and skill level of their workforce, through performance environment, in at least two ways. First, effective employee selection enhances individual ability level through a process of screening for appropriate abilities. Second, training, education, and development help organizations increase the ability levels of its workforce (Cummings \& Schwab, 1973).

An employee who has the ability to correctly perform a task, but is doing so unsatisfactorily, may lack sufficient motivation. Effective motivational strategies include four components: feedback, goal setting, team building, and incentives. Feedback allows an employee to learn how coworkers and the organization view his or her behavior. Goal setting identifies what the employee should be doing. Team building allows the employee to participate with coworkers in solving productivity challenges. Finally, incentives reward employees for good performance (Latham \& Wexley, 1981).

Motivation, compared to the other two performance determinants (i.e., employee ability and the performance environment) is perhaps the most difficult to fully understand. And, although many people assume that highly motivated employees will do well, this is sometimes not the case; "Simply swinging hard is not a guarantee that you will hit the ball" (Mitchell, 1983, p. 3). Nevertheless, the basic concepts of motivation are important when considering performance and performance evaluation.

Motivation falls into the ranks of behavioral, personality, and social psychology. The roots of motivation date back to ancient philosophy when scholars wrote about choices of goals and behaviors. Scientifically, researchers phrase a question in terms of what makes a person choose one goal over another. At least two elements appear to be necessary to answer this question; future outcomes and the anticipated value of a choice (Beck, 1990). 
Motivation involves the acting out of social behaviors such as striving for affiliation, power, or achievement. These social needs are included in Maslow's (1970) hierarchy of motives model, as belongingness and love (level 3), esteem (e.g. achievement) (level 4), and finally, self-actualization (fulfilling one's potential).

Perhaps there are as many definitions for motivation as there are for leadership. Technical definitions suggest that motivation, "[i]s the combination of psychological processes that cause the arousal, direction and persistence of behavior" (Mitchell, 1983, p. 41). Many researchers add a voluntary or goal-directed emphasis thereby making motivation a psychological process that causes arousal, direction, and voluntary actions that are goal directed.

Ford (1992) defines motivation as the organized patterning of an individual's personal goals, emotions, and personal agency beliefs (PAB). This definition may be represented as: motivation $=($ goals $) \mathrm{X}$ (emotions) $\mathrm{X}(\mathrm{PAB})$. In this definition, goals are the evaluation of the objective being pursued in terms of relevance and priority. Emotions are the state of readiness and arousal. The final component, personal agency beliefs, is the expectation about whether one can or cannot achieve a goal, based on both personal capabilities and support from the environment.

Additionally, Ford contends that there are three criteria that distinguish motivational processes from non-motivational processes. First, motivational processes relate directly to the person rather than to the context of the person (inner motivation versus motivation because of the situation). Second, motivational processes are present and futureoriented, rather than being associated with the past. Third, motivational processes are 
evaluative, i.e., they identify and quantify problems and opportunities but do not solve them.

Skinner (1938) determined that operant conditioning, i.e., human conditioning, is based on the principle that behavior produces consequences, the nature of which determines which specific behaviors are reproduced or relinquished. Behaviors that generate positive outcomes tend to be strengthened, and those that are followed by negative consequences tend to be avoided. Motivation principles based on these constructs are referred to as behavior modification and have been effective in changing behavior in various organizational settings (Petri, 1986).

Given the success of behavior modification in the field of psychiatry and psychology, organizational theorists (e.g., Luthans \& Kreitner, 1975; Nord, 1969) suggested that operant conditioning techniques might be applied to the workforce. The linking of valued rewards to desired behavior, i.e., reinforcement contingencies, could be designed to improve employee motivation, and ultimately, performance.

Luthans and Kreitner (1975) posited three principles to help guide the organizational modification process. First, managers should focus on observable behavioral events and performance, and not on attitudes, perceptions, or feelings. Second, behaviors and performance should be measured in terms of frequency, i.e., how often an employee repeats the desired behaviors and performance. Third, reinforcement contingencies should be established so the workforce is able to understand the relationship between behavior and performance, and subsequent rewards or lack thereof.

One concept appears to be certain about motivation-satisfied needs do not motivate. Unsatisfied needs are what motivate us. Next to physical survival, our greatest need is 
psychological survival - to be understood, affirmed, validated, appreciated, and respected (Covey, 1989).

$\underline{\text { Feedback }}$

Individuals and organizations function and operate on the basis of information received. Humans typically search for information to help guide the decision-making process, correct perceived errors, give direction, and confirm their beliefs. Individuals are information processors-receiving, filtering, and making decisions about behavior.

Organizations, similarly, gather and process environmental data and data about internal operations.

Given the relationship between the individual employee and an organization, it is important to consider the value of information as a tool for improvement for both the individual and the organization.

Data influences can ultimately change individual and organizational behavior in two ways. First, information can be a catalyst to energize or motivate behavior; it can arouse feelings and generate forces which can bring about behavioral changes. Information can create energy around events and issues, and in turn motivate action. For example, employee surveys may indicate that management is perceived as uncaring. The organization, subsequently, may take action to respond to the perceived discrepancy.

Second, data can be used to direct behavior once motivation has been induced. Information can be used to inform individuals, groups, or organizations of the types of behavior that will lead to certain results. In the above example, an organization may implement procedures to ensure that managers are perceived as more caring (Nadler, 1977). 
Feedback is a primary component of performance evaluation, and many studies have been conducted to better understand feedback in the context of employee appraisal systems. Nadler, (1977) provides six concepts that aid in understanding the premise of feedback in organizations:

1. Feedback is a basic component of self-regulating systems. This concept seems apparent, however it is easy to overlook. Virtually every employee is interested in knowing how he or she is performing on the job. The most effective way employees are able to determine how coworkers, including supervisors, perceive their on-the-job performance is through feedback. If employees do not receive feedback, they will often seek it (Ashford \& Cumming, 1983). Feedback has also been shown to help motivate employees and increase satisfaction (Hackman, 1980). Most decision-making models, and many motivational models, include some type of feedback loop to indicate that individuals learn, or in some cases do not learn, from the outcomes of their behavior and performance (DeNisi \& Kluger, 2000).

2. Feedback is information about the output of a system which controls the system input or transformation processes. Additionally, feedback is most effective when it is timed closely with the behavior to which it relates (Henderson, 1984).

3. Feedback is any information about the system which has the potential of being used to change the operation of the system.

4. Feedback is a necessary component, enabling the correction of errors, the adaptation to environmental change, and learning.

5. In social systems, such as work organizations, feedback does not automatically create change in the system's operation. Kluger and DeNisi (1996) found that feedback 
generally improved employee performance but more than one-third of the feedback interventions decreased performance. Regardless, the process of obtaining, interpreting, and using feedback information is important.

6. Organizations often ignore feedback or do not make an effort to use feedback effectively. Gioia \& Longnecker (1988) found that 40 percent of executives interviewed from a range of organizations indicated that they did not receive annual performance evaluations. Organizational development activities, therefore, serve an important function of facilitating feedback processes, thus helping organizations to correct errors, learn, adapt, and grow.

Nadler (1977) contends that eight elements exist for effective feedback:

1. Relevant. Information can only create energy if it relates to issues that are meaningful to the recipients. Information that is irrelevant will usually not create energy.

2. Understandable. Data are sometimes presented in a way that is difficult to interpret. Form, language, and symbols should be common to those involved in the process.

3. Descriptive. Feedback should include examples and illustrative detail so people can internalize the information.

4. Verifiable. Theory contends that people will respond more to data that they feel are valid and accurate. Data should be presented in a manner by which the receivers can validate the findings.

5. Limited. Information overload is a potential problem. Individuals have limits to the amount of information they can digest, therefore, limited data organized to prevent overload are more effective in creating and directing energy. 
6. Impactable. Provide feedback that is within the recipient's circle of control.

7. Comparative. Feedback should include data that can serve as comparison points. Receivers can then determine whether the comparison is valid.

8. Unfinalized. Feedback data that imply that data collection is completed, that all problems have been addressed, and that the process is over decreases energy. For feedback to be effective, the data should serve as a starting or continuing point for more in-depth data collection, problem identification, and problem solving.

Once feedback is provided to an employee, at least two factors influence how it is received. First, how the employee views the feedback plays a crucial role. Feedback interventions that are considered fair and accurate by employees, occur frequently, and are performed by supervisors who are familiar with the employee's behaviors and performance, tend to be received favorably (Landy, Barnes, \& Murphy, 1978). Second, the timing of feedback will influence how employees receive feedback. Feedback is most effective when it is provided soon after the observed behavior (Henderson, 1984). Appendix C, adopted from Nadler (1977, p. 146), identifies possible effects for individuals who receive feedback.

Three Hundred Sixty Degree Feedback

$\underline{\text { History }}$

Three hundred sixty degree feedback evolved from at least five systems: total quality management (TQM), organizational surveys, developmental feedback, performance appraisals, and multi-source assessment (Edwards \& Ewen, 1996).

Quality guru Dr. Edwards Deming pioneered TQM in the 1950s as an organizational improvement system that was based on data (i.e., statistical control methods). Data was 
collected from customers and suppliers, and analyzed to determine the strengths and weaknesses of the products and services supplied. Organizations, in the spirit of continuous improvement, continued processes and procedures that produced desired results and made changes to systems that produced unacceptable results (Atwater \& Waldman, 1998; Edwards \& Ewen, 1996; Napier \& Gershenfeld, 1999). Deming took continuous improvement one-step further and applied it to individual employees. Criticizing traditional top-down appraisal systems, Deming promoted the notion that employees who work side-by-side are more likely to provide accurate assessments than their managers (Grote, 1996).

A second ancestor of 360 is organizational surveys. Common in the 1970 s and 1980 s, these surveys targeted employees' satisfaction with their immediate supervisor or manager. As organizational surveys were implemented in increasingly smaller groups, the scores became a measure of leadership quality. Organizations including American Airlines, United Parcel Service, and Whirlpool used the results from organizational surveys to recognize and reward effective leaders (Edwards \& Ewen, 1996). Additionally, organizational surveys included various attitudinal dimensions such as job satisfaction, work conditions, and benefits (Atwater \& Waldman, 1998).

Developmental feedback, a third predecessor of 360, was popular in the 1980s. Developmental feedback was implemented as a formative evaluation tool, designed to provide employees with feedback that would not be used as a basis for negative human resource action (e.g., termination). This system aided employees in avoiding career derailment resulting from mistakes in style, skills, knowledge, or abilities (Edwards \& Ewen, 1996). 
Performance appraisal systems, another foundation of 360 , began in the late 1800 s as the industrial age evolved and production was mechanized. This period led to the perspective of "man as machine" and the desire to improve individual effectiveness (Edwards \& Ewen, 1996; Latham \& Wexley, 1994). A more comprehensive description of the evolution of performance evaluation is provided in the previous section.

The final forerunner to 360 is multi-source assessment. Multi-source feedback, as described earlier, is the process by which performance evaluations of an employee are collected from multiple sources (e.g., direct reports, peers, and supervisors) (London \& Smither, 1995).

Although the term 360-degree feedback was officially coined and registered in the mid-1990s, it was actually developed much earlier. In 1975, the Napier Group, a small consulting firm in Philadelphia, Pennsylvania, developed a process that was labeled “Executive Role Counseling”. Executive Role Counseling focused, “...on helping good leaders use their time more effectively, motivate others, conduct better meetings, deal with conflict or handle specific troubling problems" (J. Roberts, personal communication, November 2000).

\section{Three Hundred Sixty Degree Feedback Theory}

Three hundred sixty degree feedback focuses the collective wisdom of those closest to the employee, i.e., the supervisors, peers, direct reports, and internal and external customers (Grote, 1996; Mohrman et al, 1989). These groups provide multiple perspectives for employee evaluation including assessing critical competencies, specific behaviors, and skills of a particular employee. Employees generally view this multisource feedback as fair, accurate, credible, and motivating compared to evaluations from 
a single source. Employees are often motivated to change their work behaviors to become more harmonious with their coworkers (Edwards \& Ewen, 1996). Additionally, 360 provides the multiple sources of comprehensive assessment that employees who strongly value achievement may desire (Waldman, 1997).

By embracing concepts of high involvement, organizations increase employee ownership and buy-in. Ownership and buy-in generate an empowerment-rich environment which delivers proven benefits such as: increased motivation, a shift to a "work smarter- not harder" mentality, and decreased job stress (Howard, 1996).

The rationale behind using a 360-degree evaluation system to improve an employee's leadership and management practices relates to the notion of self-perception. It has been determined that feedback usually increases the accuracy of self-perception (Atwater \& Waldman, 1998). Additionally, feedback allows an individual to learn how others view him or her from a behavioral and work performance perspective. This awareness affords an employee the opportunity to self-reflect based on input from multiple perspectives. If the employee seldom or never receives feedback, or receives feedback from only one source that may be inaccurate, the employee does not have the opportunity to make the necessary behavior modifications (Atwater \& Waldman, 1998).

Organizations that do not provide the opportunity for employees to gain a more accurate understanding of how coworkers view them run the risk of helping to derail the careers of their workers. Van Velsor, Taylor, and Leslie (1993) found employees with inflated self-perceptions were considered by their coworkers to be poor performers. Bass and Yammarino (1991) found that United States Naval officers whose self-evaluations 
were more closely aligned with their direct reports generally attained higher ranks (London \& Smither, 1995).

It is unrealistic to require an employee to self-evaluate and subsequently make necessary changes to his or her behavior. Research suggests that humans have difficulty accurately performing self-evaluation. Self-ratings of behavior, personality, and other job performance categories are generally unreliable and biased (Mabe \& West, 1982). Hence, the apparent need for one or more effective tools to increase self-awareness and selfperception.

\section{$\underline{\text { Review of } 360 \text { Studies }}$}

Research is inconclusive as to whether upward feedback (which can be one element of 360) improves performance (London et al.,1995; Reilly, Smither, \& Vasilopoulos, 1996). Kluger and DeNisi (1996) posited evidence that individuals who are provided with feedback, and nothing more, do not automatically improve performance. In this study, Kluger and DeNisi found that more than $1 / 3$ of respondents experienced a decrease in performance after receiving feedback. Hazucha, Hezlett, and Schneider (1993) found considerable variance among the performance and behavioral changes associated specifically with 360 . Whether or not upward feedback prompts individual change depends on at least two factors: employee attitudes, and follow-up behaviors by the supervisor (Hazucha et al.,1993; Kluger \& DeNisi, 1996; Waldman \& Atwater, 1998). Another key factor of 360 success, that is perhaps more fundamental than employee attitudes and supervisor follow-up, is the design on the system itself. If 360 is implemented without defining the mission and scope of the system, it is doomed to failure. If 360 is not designed to ameliorate work behavior or performance, it is unlikely 
that the employees and organization will experience any improvement. Employees, as a result, would likely become frustrated and disenchanted with the system (Antonioni, 1996).

One recent longitudinal study did find that there was a significant increase in the performance of managers who were initially rated poor or moderate over the five-year period when they received upward feedback (Walker \& Smither, 1999). Managers and supervisors also drastically increased performance in years that they discussed the upward feedback with their direct reports compared to years they did not. Additionally, there is a direct correlation between supervisor commitment to a subordinate and the subordinate's upward feedback to the supervisor, and vice versa (Atwater et al, 2000). This finding is congruent with the Pearce and Porter (1986) study that found negative feedback increases negative attitudes.

According to field experts of 360 , the following elements are essential in effective implementation and execution of 360 systems:

1. Peer appraisals should not to be considered for human resource actions (summative evaluation, e.g., termination, pay increases, etc.). Rather, they should be used as formative evaluation tool and seen only by the employee being evaluated (DeNisi \& Kluger, 2000; McEvoy \& Buller, 1987; Rogers et al., 2002). One pioneer of 360, Dr. Rod Napier, however, contends that 360 can be useful as a summative evaluation tool. Using 360 as a formative versus summative evaluation tool, Dr. Napier contends, will not motivate an employee to change his or her performance or behavior. An employee who knows that his or her supervisor will not be privy to the results of the data associated with 
the employee's appraisal may have no reason to change (R. Napier, personal communication September 2000).

2. Organizations should have available, and encourage employees to use, human resource experts or highly trained coaches to help interpret the feedback that they receive. Additionally, the human resource experts should help employees develop action plans that will help them improve performance and behavior, based on the results that are received from 360 evaluations (Cosentino \& Nemeroff, DeNisi \& Kluger, 2000; Hegarty, 1974; Rogers et al., 2002). Hazucha, Hezlett, \& Schneider (1993) and Antonioni (1996) found that 360 is helpful in aiding employees to improve their performance and behavior, however, the critical factor in improving work skills is the development of an action plan based on the feedback.

3. Three hundred sixty degree feedback should be provided anonymously, especially when given by a direct report. Feedback submitted by direct reports who are required to include their name is generally higher than feedback provided anonymously by direct reports (Antonioni, 1994). Additionally, evaluators should be careful not to make comments in the evaluation that would easily lead to their identification (Antonioni, 1996).

4. There is a good chance that many employees will receive negative feedback during some point in their career. Therefore, it is important for workers to receive training on how to receive both negative and positive feedback (Antonioni, 1996).

5. Discrepancies between supervisor ratings and direct report ratings should be carefully considered. One study relating to leadership and evaluation found that many leaders who challenge the organizational status quo might receive low marks from 
supervisors and high marks from direct reports (Salam \& Cox, 1997). Leaders who fall into this category should not become disillusioned, rather, they should ponder if the organization's culture is ready for visionary thinkers.

6. The 360 system should be aligned with the organization's business plan or strategic plan. Additionally, employee competencies should be tied to the dimensions being measured. As with any organizational program, the return on investment should be measured and evaluated by senior management (Rogers, 2002).

7. Finally, adequate resources must be provided to ensure success. An appropriate human resource staff with a sufficient fiscal base is critical. Additionally, senior management must be 360 champions and users of the system (Rogers, 2002).

Of the relatively few studies relating to 360 that exist, two are closely linked with this study. The first was conducted by Bernardin, Dahnum, and Redmon (1993) and focused on supervisor attitudes toward direct report appraisals. The study was not a 360 -feedback study per se, however, it utilized one form of feedback that may be applied to multisource feedback, i.e., upward feedback (direct reports evaluating superiors). In this study three groups were utilized, all comprised supervisors. Group 1 received feedback from both managers and direct reports. Group 2 received feedback from managers only. Group 3 received feedback from direct reports only. The study found that supervisors in all three groups generally supported direct report appraisals, however, the first group tended to be more supportive of upward feedback compared to the other two. The Bernardin et al. study (1993) used a receptivity construct that was the model for the Funderburg and Levy (1997) study. 
Funderburg and Levy (1997) found that individual and contextual factors accounted for 37 percent of the variance in attitudes toward multi-source feedback. Individual variables relate to personality attributes and include self-esteem, the propensity to seek feedback, and locus of control. Contextual variables relate to factors that are associated with the organizational and appraisal climate and include the supervisory style of an employee's direct supervisor, organizational citizenship behavior (defined as organizational pro-social behavior), the cost in seeking feedback (the amount of discomfort associated with asking for feedback), and the feedback environment (the degree of difficulty to find a feedback source). The respondents $(n=75)$ of the Funderburg and Levy (1997) study were selected from two organizations. In addition to generating regression models with a best R-Squared value of .37 , the study found that contextual (organizational) factors appeared more important than employee personality in determining 360-degree attitudes.

Funderburg and Levy (1997) found three variables that met a 5\% level of significance threshold, and all were measured on a 5-point Likert scale. Each variable is negatively related to the dependent variable (360 attitude). Perceived costs of seeking feedback $(\beta=$ -.35) is the emotional and psychological sacrifice that an employee feels when attempting to gain feedback related to work performance (a higher score indicates higher perceived costs to seek feedback). Organizational citizenship behavior $(\mathrm{OCB})(\beta=-.47)$ is the degree an employee helps his or her coworkers (the higher the score, the greater the propensity of an employee to help others). Supervisor style $(\beta=-.30)$ measures the degree of supervisory autocracy (the higher the score, the more the supervisor practices participatory behavior). 
The future reference section of Funderburg's and Levy's 1997 study stated (p. 233): More research needs to be done regarding the components of an organization's 'readiness' for alternative performance feedback systems. Researchers should investigate macro issues such as culture and climate as well as dyadic issues such as trust and communication.

\section{The Future of 360}

Management and human resource trends such as management by objectives, zero defects, total quality management, etc. come and go. No one can accurately predict if 360 will be one of the trendy concepts that slowly fades away, or if it will be part of organizations for years to come. Considering the competitive nature of business, however, it seems that organizational improvement is vital for private, public, and notfor-profit prosperity. Three hundred sixty degree feedback systems are not a panacea, however, as with many tools, if properly used, they could increase the health of organizations. 
Chapter III

Methodology

This study investigated one particular leadership and management tool: 360 -degree performance evaluation systems. Specifically, this study was designed to predict employee receptivity to 360 -degree feedback.

The following research question guided the study:

1) Is it possible to predict employee receptivity to 360 ?

\section{Research Hypotheses}

The following null hypotheses $\left(\mathrm{H}_{0}\right)$ provided a focus for the study:

$\mathrm{H}_{01}$ : A relationship exists between the demographics (e.g., age, level of education, gender, race, income level, etc.) of an employee and his or her receptivity to 360 .

$\mathrm{H}_{02}$ : A relationship exists between the leadership style (i.e., psychological androgyny, a sex-role inventory) of an employee and his or her receptivity to 360 .

$\mathrm{H}_{03}$ : A relationship exists between employee trust and an employee's receptivity to 360.

$\mathrm{H}_{04}$ : A relationship exists between employee commitment and an employee's receptivity to 360 .

Participants and Research Sites

The population for this study included all organizations that utilized any form of 360 feedback and had completed at least one evaluation cycle using the multi-rater system. 
Additionally, organizations that employed 360 systems for at least one cycle, and subsequently discontinued use of the appraisal system, were included in the population. Three hundred sixty degree feedback, defined for this study, is an employee appraisal system that uses a minimum of two rater types, e.g., supervisor and direct report. The sampling frame comprised organizations located in California and any Northeastern state. Ultimately, the sample included the only two organizations that agreed to participate in the survey. The first organization, Organization 1, is a small consulting firm located in southern California. Organization 2 is a large university located in New York.

Unfortunately, this dissertation became an exploratory study due to the limited number of organizations that agreed to participate. Two factors appeared to contribute to the lack of interest shown by organizations. First, the September 11, 2001 terrorist attacks apparently changed the way organizational leaders dealt with outside requests that were not directly related to their world of work. Several leaders or managers who were contacted stated that their organization was not going to offer any additional burden to their employees' workload. Second, while the author was soliciting organizations to participate in the study, the economy experienced a significant plunge. A substantial drop in the stock market and highly publicized scandals within several organizations (e.g., Enron, WorldCom, and Tyco) exacerbated a substantial drop in consumer confidence. Consequently, organizations solicited to participate in this study were simply attempting to maintain focus on business and eliminate outside distractions. Several managers, in fact, mentioned that many organizational development projects were stalled or terminated due to the economic crisis. The sole reason the author was able to survey Organization 2 
was because of personal connections with two organizational development consultants who were closely connected to the organization.

The author contacted a number of human resource officials whom he met at conferences hosted by the Society for Human Resource Management (SHRM) and Linkage, Inc. Additionally, the author cold called and mailed solicitations to more than sixty organizations. Finally, the author developed a website (Appendix D) soliciting organizations to participate in the study in exchange for a no-cost organizational climate report. Sample climate reports were provided on the website. Organizational climate reports for Organization 1 and Organization 2 are included as Appendix E and Appendix F, respectively. The website soliciting organizational participation was registered with the search engine Google.

The author attempted to obtain a minimum of 258 observations. Tabachnick \& Fidell (2001) recommends that the ratio of cases to independent variables should be at least $N \geq$ $8(I V)+50$, where IV $=$ the number of independent variables. The initial regression model used 26 independent variables (a majority of which were binary), therefore, $N \geq 8(26)+$ $50=258$.

The author had direct contact with all employees who worked at Organization 1, and the organization netted a $100 \%$ response rate. Unfortunately, due to security reasons, the author was not allowed access to employees at Organization 2. Contact with workers employed at this university was through one of the university's human resource specialists. The specialist forwarded the author's research solicitation email to all employees involved with 360 . A follow up email was forwarded to the specialist 
encouraging employees who did not participate to consider completing the online survey. The follow up email increased the response rate from $10 \%$ to $19 \%$. $\underline{\text { Piloting }}$

This survey was piloted using employees of PBS \& Associates, six organizational consultants, and 4 human resource professionals. Participants in the pilot were provided a brief explanation of the instrument and were asked to complete the survey. Pilot group members were also asked to complete an associated comment sheet that requested answers to various questions such as the time required to finish the survey and problems that were encountered. As a result of the pilot, two primary edits were made to the survey. The terms "subordinates" and "superior" were changed to "direct reports" and “supervisor", respectively. The pilot took place from September 2000 to March 2001.

\section{Constructs}

Four constructs were used in this study. One, receptivity to 360 , relates directly to the research question and was used as the dependent variable. Three constructs were initially considered as independent variables: employee trust, employee commitment, and an employee sex-role inventory (psychological androgyny). Additionally, demographics were used as independent variables in the regression analysis. Psychological androgyny is a dimension of leadership style anchored by feminine and masculine characteristics. The feminine anchor relates to an interactive leadership style that focuses on team, nurturing, and enhancing self-worth, whereas masculine leadership is characterized by aggressiveness, power, and command-and-control ( $\mathrm{Li}$ et al., 1997). The psychological androgyny construct was eventually deleted (Appendix G). 


\section{Construct Overview and Scoring.}

The dependent variable, receptivity to 360 feedback, used a 5-item construct and a 7point Likert scale. The survey was designed so that the respondents rated all appraisers who provided feedback. For example, if three rater levels (e.g., supervisors, peers, and direct reports) evaluated a particular employee, the respondent would complete 15 items (3 rater levels X 5 items/construct $=15$ items). A sample item is, "The appraisal data I received from my rater level (e.g., direct reports, supervisor, etc.) will help improve my performance." This construct, originally implemented by Bernardin, Dahmus, and Redom (1993), consisted of ten items and was designed to measure attitudes of supervisors toward appraisals provided by subordinates. The construct was redesigned for a 1997 study (Funderburg \& Levy) to measure attitudes toward the future use of 360-degree feedback systems within the employee's organization. The construct was reduced to five items for the 1997 study (Funderburg \& Levy) and used a 5-point Likert scale ranging from "strongly agree" to "strongly disagree" (alpha $=.97)$. This study used a construct similar to the Funderburg and Levy study (1997), however a 7-point Likert scale was used which coincided with the scale for employee trust and employee commitment.

The independent variables of employee trust and employee commitment were chosen to determine if there is a relationship between organizational culture and receptivity to 360. Psychological androgyny was selected as the attitudinal construct because the author had observed a tendency of leaders possessing a feminine leadership style to be more open and receptive to new systems and procedures, compared to employees who possess a masculine leadership style. The final independent variables relate to education, age, years of service in the current organization, etc. (i.e., demographics). 
The first independent variable, employee trust, used a 12-item scale that was developed by Nyhan \& Marlowe (1997). The scale consisted of 8 items that measure employee trust in supervisors and 4 items that measure trust in the organization as a whole. The trust in supervisor subscale represents employee trust in what may be one of the most critical mediators of organizational complexity, an employee's immediate supervisor. The 4-item organizational subscale is designed to identify attitudes of trust toward the entire organization. The 7-point Likert-type format ranges from 1 ("Nearly Zero") to 7 ("100\%"). One example from the construct of supervisor trust is, "My level of confidence that my immediate supervisor is technically competent at the critical elements of his or her job is ___." An example of an organizational trust item is, "My level of confidence that this organization will treat me fairly is __." This 12-item scale was tested in seven organizations, with a total sample size of 779 individuals, and was found to be reliable (Cronbach alphas, ranging from .92 to .96 ) and valid (construct accounted for more than $78 \%$ of the variance across the two pretest groups). Scoring was calculated by totaling the responses of the 12 items that comprise the scale.

The second independent variable, employee commitment, relates to the stability and intensity of employee dedication to the organization (Eisenberger, Huntington, Hutchison, \& Sowa, 1986). Employee commitment was measured using a 7-item scale designed by Wayne, Shore, \& Linden (1997). The scale was originally designed as a 9item scale by Porter, Steers, Mowday, and Boulian (1974). A factor analysis of the condensed 7-item scale was conducted and the instrument was found to be psychometrically adequate (factor analysis netted a .87 Cronbach alpha). A 7-point Likert index was used and ranged from 1 ("Strongly Disagree") to 7 ("Strongly Agree"). One 
example of the employee commitment scale is, "I am willing to put in a great deal of effort beyond that normally expected in order to help this organization be successful." Scoring was calculated by totaling the responses of the 7 items that comprise the scale. Leadership style (psychological androgyny) is the final construct that was originally included as an independent variable. Appendix G provides an overview of the construct of psychological androgyny and an explanation of why it was deleted.

\section{Instrumentation}

The length of the original survey was 106 items. Organizational leaders were hesitant to allow their employees to participate in the survey because of reasons described in the Participants and Research Sites section of this chapter. The original survey was streamlined to 77 items after the psychological androgyny construct was eliminated. The condensed survey is provided as Appendix $\mathrm{H}$.

\section{$\underline{\text { Data Analysis }}$}

Multiple regression was the primary quantitative method for data analysis. Multiple regression was used because it accurately assesses the degree to which a dependent variable (employee receptivity to 360 ) is related to a set of independent variables (employee trust, employee commitment, and demographics) that have been combined to create a new composite variable (Tabachnick \& Fidell, 2001). Multiple regression allows the consumer of statistical data to predict or generalize outcomes associated with a dependent variable based on a change of one independent variable, keeping all other independent variables constant. It is a powerful mathematical model that allows a consumer to determine the degree of effect each independent variable has on a dependent 
variable, the model's level of significance, and the percentage of variance and variation that the model explains.

Multiple regression analysis generates estimated coefficients that are the most efficient, linear unbiased estimators of their population values. These estimated coefficients include the intercept of the regression line ( $\alpha$ or $\left.\beta_{0}\right)$ and the various slopes $\left(\beta_{1}, \beta_{2}, \cdots, \beta_{\mathrm{k}}\right)$ associated with each independent variable. The slopes are calculated by minimizing the sum of least squares (i.e., minimizing the errors between actual data points and the fitted regression line, $\hat{Y}$ ) (Greene, 1990; Katz, 1982; Pindyck \& Rubinfeld, 1991).

\section{Multiple Regression Assumptions}

The concept of multiple regression producing the best linear unbiased estimators compared to all other linear unbiased estimators is proven by the Gauss-Markov Theorem. Six statistical assumptions are required for this important result to hold. Problems may arise if the assumptions are not met, i.e., the regression model may no longer produce the best linear unbiased estimators if the assumptions are found to be violated. A brief explanation of the assumptions follows (Appendix I provides a thorough overview of the assumptions).

Three assumptions, accounted for by design, are very difficult to violate if sound regression practices are followed. The first simply assumes that the average vertical distance between the regression line and data points is zero (i.e., the regression line is fitted so the average distance between points above the line is equal to the average distance between points below the line). The second assumption describes how to write 
the regression equation (i.e., $Y_{i}=\beta_{0}+\beta_{1} X_{1}+\beta_{2} X_{2}+\cdots+\beta_{K} X_{K}+u$ ). The third assumption is that the mean of the population error term, $\mathrm{u}_{i}$, is zero.

The fourth assumption relates primarily to longitudinal studies — no relationship exists between errors from one point in time to the next point in time. This study is crosssectional in nature, hence the fourth assumption is not pertinent for this project.

The fifth assumption in multiple regression analysis is no exact relationship exists between independent variables. A researcher, for example, would not include the independent variables "monthly wage" and "annual salary" because there is an exact relationship between the two.

The final assumptions, homoscedasticity, relates directly to this and other crosssectional studies. The multiple regression model assumes that the variability of the data points around the regression line is relatively constant. This constant range of data points around the regression line is called homoscedasticity. Heteroscedasticity, the opposite of homoscedasticity, violates the Gauss-Markov Theorem. Figure 1 provides an example of homoscedasticity and heteroscedasticity. 


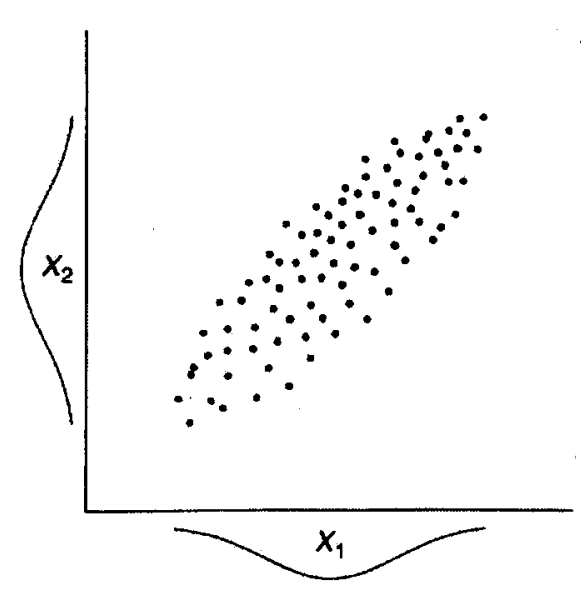

(a) Homoscedasticlity with both variables normally distributed

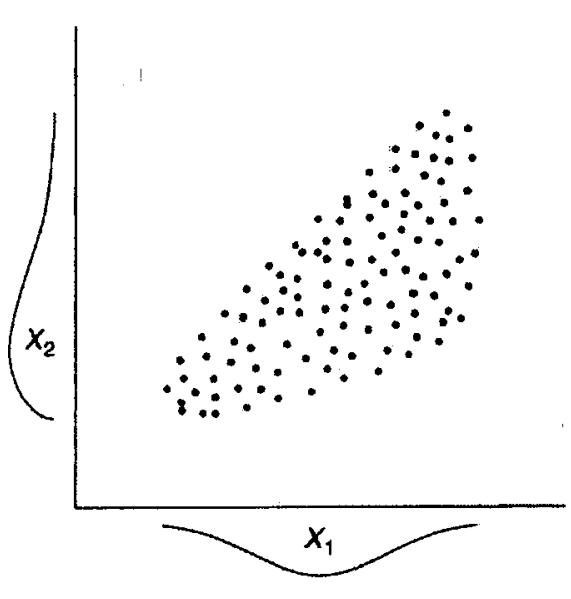

(b) Heteroscedasticity with skewness on $X_{2}$

Figure 1. Scatterplots showing homoscedasticity and heteroscedasticity (Tabachnick \& Fidell, 2001, p. 79). The band of data points in (a) is relatively constant whereas the band in (b) becomes wider.

Several tests for heteroscedasticity exist including Goldfeld-Quandt test and the Breusch-Pagan test (Greene, 1990; Johnson et al., 1987; Katz, 1982). Researchers, however, are not generally overly secure in using any particular test. All heteroscedastic tests require considerable judgment to determine which independent variable is the source of the problem. Additionally, more than one independent variable may be at fault, requiring a significant amount of time to isolate those variables that create a heteroscedastic situation (Johnson et al., 1987).

This study utilized the Goldfeld-Quandt test. This test was used because it allowed the researcher to test one variable at a time. The Breusch-Pagen test is similar to the Goldfeld-Quandt test, however it considers several independent variables simultaneously (Johnson et. al, 1987). The Breusch-Pagen test may be more parsimonious with regard to the researcher's time, however, the author decided to focus on each independent variable separately in an attempt to fully appreciate the associated affects of all variables. 
Chapter 4 and Appendix $\mathbf{J}$ provide a thorough explanation of homoscedasticity as it relates to this study.

\section{Multicollinearity}

Although not an assumption related to multiple regression analysis, the problematic phenomenon of multicollinearity occurs when two or more independent variables have a strong but not an exact relationship. During regression analysis, the multicollinear variables compete against one another. One problematic result associated with multicollinearity is the generation of estimated coefficients with extremely large standard errors. This problem is quickly resolved simply by omitting all but one of the multicollinear variables. Two tests for multicollinearity were utilized as described in Appendix J.

\section{$\underline{\text { Outliers }}$}

All data points with z-scores greater than or less than three (i.e., data points with values that were greater than or less than three standard deviations from the average) were identified for further consideration. A standard score of three was chosen because a $99 \%$ probability exists that all values would fall within this range. Standard scores were calculated for all continuous variables.

\section{Missing Data}

There is no universal best method for treating missing observations, therefore, missing data was considered using all three missing data methods: excluded (or dropped) cases listwise, zero-order correction (also referred to as zero-order regression), and firstorder correction (also referred to as first-order regression (Greene, 1990)). In the exclude cases listwise approach, only those observations with all values intact were utilized. Data 
associated with completed questionnaires with missing data were excluded for the analysis. When using the zero-order correction method, the sample mean for a particular item was substituted for any missing observations (Pindyck \& Rubinfeld, 1981). Finally, in the first-order correction method, the researcher replaced missing data by regressing known data and then estimating the missing observations by fitting a new regression line. Specifically the missing independent variable became the dependent variable and was regressed on the remaining independent variables (Pindyck \& Rubinfeld, 1991). In firstorder correction, only the observations with intact data are used to generate the first-order regression model which ultimately allows the researcher to predict the missing data.

If data is missing in a random order in the excluded cases listwise method, eliminating observations with missing data is reasonable. If there in a non-random order relating to missing data, dropping observations will maintain an unbiased and consistent set of estimators $\left(\beta_{1}, \beta_{2}, \cdots, \beta_{K}\right)$, however a loss of efficiency (i.e., an increase in variance) will result (Pindyck \& Rubinfeld, 1981). In the zero-order correction method, the estimated coefficients remain unbiased, however, there is a loss of precision (similar to the first method). The third method, first-order correction, may introduce bias and a forecast error, however, it produces a more efficient set of estimated coefficients. Because there is no best way to deal with this issue, this study employed the three most common methods to handle the challenge of missing data.

Closely related to missing survey data is the problem of unusable surveys. For example, a returned survey with only 10 out of the 77 items completed yields little value. Surveys with less than $95 \%$ of the items answered (i.e., 73) were not considered. Fortunately, all completed surveys had a minimum of 74 items completed. 


\section{Computer Software}

SPSS software, version 10.0 was used to calculate all regression models. The initial regression model shown below was used to calculate estimated coefficients, adjusted $\mathrm{R}$ square values, and p-values for the dependent variable, $Y$. The dependent variable, employee receptivity to 360 feedback, relates to the research hypotheses presented in this chapter. The backward elimination method was used, for the reasons outlined in the next paragraph, when building the regression models. This procedure considers all independent variables and eliminates them, one at a time, in order to maximize adjusted $\mathrm{R}$ square values and t-values (e.g., eliminating independent variables with a t-score $<1$ ).

Three common choices to build regression models were available to the researcherbackward elimination, forward selection, and stepwise selection. The foundation for forward selection and backward elimination is identical, however, forward selection adds variables, one by one, based on F-statistics and p-values, whereas backward elimination deletes variables based on the same calculated statistics. In reality, therefore, a researcher may choose either procedure, both of which will generate the same results (in reverse order). Backward elimination, therefore, was chosen simply because of the researcher's preference to review the overall affect of each removed variable on the model (versus examining the affect of adding variables). Stepwise selection was not considered because of the problems associated with the procedure (e.g., adjusted R-square values that are biased high, inaccurate p-values, etc.) (Derksen \& Keselman, 1992). 


\section{Strengths and Limitations}

\section{$\underline{\text { Strengths }}$}

This study was developed using sound principles of survey methods. A sophisticated data analysis methodology, multiple regression, was used to interpret the data. The combination of painstaking research design, careful data collection, and extremely thorough statistical analysis generated results typically found in much larger studies.

\section{$\underline{\text { Limitations }}$}

As with virtually all studies, limitations exist. First and foremost, the sample size was extremely small $(n=62)$ and potentially creates the phenomenon of over-fitting. Overfitting occurs when the ratio of sample size to independent variables is relatively low, which in turn provides a sample fit that may not be representative of the population (Tabachnick \& Fidell, 2001). In other words, this problem severely limits the confidence of accurate predictions or inferences made for a population based on the sample. Second, the limited number of organizations that participated (i.e. two) further exacerbated the problem of over-fitting.

Third, the response rate was extremely low. The response rate for Organization 1 was 9 of $9(100 \%)$, however, the rate of response for Organization 2 was a paltry 53 of 280 (19\%). The overall response rate was $21.5 \%$. Survey findings, therefore, may be biased because it is impossible to determine if the respondents' attitudes are different than the employees who elected to forgo the survey.

Fourth, response bias could have artificially increased or decreased the relationships between receptivity to 360 and the dependent variables. For example, employees who are 
astute enough to understand the foundation of the survey could have selected responses that would increase or decrease their receptivity score.

Fifth, respondents may not have closely read all survey items, in an attempt to complete the survey as quickly as possible, which could have decreased the accuracy of certain survey items and ultimately an entire construct.

Sixth, a large number of independent variables, primarily binary variables, were utilized which increased degrees of freedom.

Seventh, missing data may not have been random thereby decreasing the efficiency of the estimated coefficient (see the section relating to missing observations).

Eighth, with regard to data analysis, it is not possible to determine the direction of causality in this study. For example, does a person's commitment influence receptivity to 360 , or does 360 receptivity influence employee commitment? Causality can be determined only by experimentation and use of logic (Tabachnick \& Fidell, 2001). Ethical Issues

As with any study, potential benefits and risks exist. The primary potential benefit of this research is the development of a model that will allow organizations to calculate how effective implementation of a 360 -evaluation system would be, based on their current employee demographics and organizational climate (i.e., level of trust and employee commitment). This could help companies save tens of thousands of dollars. Another benefit may be employee self-reflection after participating in the survey.

Few risks, if any, existed for the participants. The greatest threat to respondents could have been the experience of mild fatigue during survey completion. The threat was low for participants, and confidentiality was maintained. Inferred consent (i.e., voluntary 
participation) did not require a consent form. Rather, participants who completed a survey conveyed consent. In case of any questions or concerns, respondents were provided with the researcher's name and phone number.

The greatest risk for the organization was the required employee downtime to complete the survey. An organization could potentially lose hundreds of employee-hours depending on the number of respondents who participated in the survey. 


\section{Chapter IV}

\section{Data Analysis}

\section{$\underline{\text { Introduction }}$}

The primary purpose of this study was to determine if a statistical and practical relationship exists between employee receptivity to 360 feedback and four independent variables. The independent variables considered are employee trust, employee commitment, psychological androgyny (this variable was ultimately omitted from the study) ${ }^{1}$, and several demographic variables including gender, age, income, ethnicity, etc. If a relationship exists between employee receptivity to 360 and the aforementioned independent variables, managers may survey their workforce to determine if the organizational climate is culturally mature enough to accept the multi-rater feedback tool. If it is determined that the organizational climate is ripe to introduce to 360 , managers may be better prepared to make a decision on how best to proceed with 360 .

Assume, for example, that employee trust and receptivity to 360 are related. A manager who determines that his or her employees have low trust levels could theoretically provide an intervention to increase employee trust prior to implementing 360. If a subsequent survey administered six or twelve months later indicates that

\footnotetext{
1 The variable psychological androgyny was omitted for two reasons. First, it increased instrument length by 36 items; consequently managers were hesitant to allow employees to participate in the survey. Second, the 12 items comprising the variable's three factors (femininity, masculinity, and neutral) were not sufficiently related (see Appendix G).
} 
employee trust is at an acceptable level, the manager could then implement 360 with greater confidence of potential success.

The primary benefit of ensuring that an organizational climate is ripe for 360 relates to the probability of the success of the system. Employees who are not receptive to 360 may comply with the system, however they will likely lack commitment. Employees may reluctantly complete the process of providing and receiving feedback, however individual performance and behavior may not ultimately be influenced by 360 feedback to the same degree as employees who are psychologically committed to the improvement endeavor. Three hundred sixty degree feedback systems are extremely expensive to implement. If employees are not receptive to 360 , it may not be wise to invest resources (fiscal and human) to impose the feedback intervention. If, on the other hand, employees are proven to be receptive, 360 may be a very useful tool.

$\underline{\text { Data Analysis }}$

Multiple regression was the primary method used to analyze data. This type of analysis is beneficial because it allows predictions to be made about a general population based on data taken from a sample of the population. A backward elimination method was used to determine the independent variables that shared a statistically significant relationship with the dependent variable, employee receptivity to 360 -degree feedback. A rationale for using the backward elimination method is provided in Chapter 3 under the Computer Software section.

$\underline{\text { Descriptive Statistics }}$

Descriptive statistics are included to provide a macro perspective of the sample. It should be noted from the outset that the number of observations for this study is 
extremely limited $(n=62)$. Several independent variables were found to be related to employee receptivity to 360 , however, due to the small sample size, broad generalizations and inferences will not be made based on the information contained herein.

Table A1 provides an overview of variable nomenclature and variable measurement. The Sample

\section{Organization 1}

Organization 1 is a small consulting firm located in Southern California. Employees of this organization completed the survey during a four-week period beginning in early May 2001. Organization 1 employed nine full-time personnel, each of whom participated in the survey (100\% response rate). The organization was composed of eight females and one male, all of whom are white. Descriptive statistics for Organization 1 are provided in Table A2. Frequency distributions for employee receptivity to 360 , employee commitment, and employee trust are not provided to ensure confidentiality.

\section{Organization 2}

Organization 2 is a large university in New York State. The sample frame consisted of 280 employees. A total of 53 respondents (19\% response rate) participated in the survey from mid-June through July 2002. Twenty-eight respondents were male, 25 were female, and only four were non-white. Descriptive statistics for Organization 2 are provided in Table A3. 


\section{Combined (Aggregated Data from Organization 1 and Organization 2)}

Aggregated descriptive statistics for both Organization 1 and Organization 2 are included in Table A4. Associated combined frequency distributions (generated using data gathered from Organization 1 and Organization 2) for employee receptivity to 360 , employee commitment, and employee trust are provided in Figures A1, A2, and A3, respectively. A Pearson's correlation matrix is provided in Table A5. Inferential Statistics

This study was designed to measure one dependent variable (employee commitment to 360 feedback), two attitudinal independent variables (employee trust and employee commitment), and demographic independent variables (e.g., age, income, ethnicity, education, etc.). The author of this research was highly sensitive of the primary problem (over-fitting) associated with the limited number of observations $(n=62)$.

A total of five categories of analyses were developed to determine the independent variables that were statistically related to the dependent variable, employee receptivity to 360-degree feedback (R360). Specifically:

1. First, demographic variables were considered independently of employee commitment and employee trust. It is very difficult, or impossible, for employees to change certain demographic characteristics such as age, gender, and ethnicity.

Nevertheless, it is important to understand if such variables affect the dependent variable (R360).

2. The 12-item variable, employee trust, was considered next. Employee trust is comprised of two dimensions - employee trust in manager (eight items) and employee trust in the organization (four items). Employee trust total (TRUS) is the average of 
employee trust in the manager (TRUSMG) and employee trust in the organization (TRUSOR).

3. Next, employee commitment was considered. Employee commitment (COMT) is a straightforward construct comprising 7 survey items.

4. The next analysis combined number 2 and number 3 above; i.e., the analysis considered employee trust (i.e., TRUS or the components of TRUS (TRUSMG and TRUSOR)) and employee commitment (COMT).

5. Finally, all variables in the preceding analyses were combined to determine which variables generated regression models with statistical and practical significance.

In order to parsimoniously select the variables with the greatest influence on employee receptivity to 360 -degree feedback, a backward elimination process was used. Specifically, all independent variables were considered in the first regression model and variables were removed, one at a time, in the order of influence on the dependent variable (R360). The independent variable with the lowest level of significance (pvalue) was removed first, the independent variable with the next lowest $p$-value was removed next, and so on, until only independent variables with p-values of .1 or better remained.

\section{Econometric Concerns}

To avoid the econometric problem of multicollinearity, employee trust (TRUS) was never used interdependently with employee trust in manager (TRUSMG) and employee trust in organization (TRUSOR). 
A second potential econometric problem is heteroscedasticity ${ }^{2}$. Heteroscedasticity weakens data analysis, but does not invalidate it (i.e., it produces standard errors that are greater than they would be in a homoscedastic scenario) (Johnson \& Johnson, 1987). Tests for heteroscedasticity were performed and results are discussed in Appendix J.

\section{Analysis 1: Demographic Variables}

The first of three null hypotheses follows:

$\mathrm{H}_{01}$ : A relationship exists between the demographics (e.g., age, level of education, gender, race, income level, etc.) of an employee and his or her receptivity to $360(\mathrm{R} 360)$.

Of the 14 regression models generated, one produced p-values at the 10 percent or better (lower) level. That particular model contained only one variable-a binary variable relating to education. Specifically, the variable was the highest level of education achieved. A bachelor's degree appeared to be statistically significant—all other highest levels of education were not. The $12^{\text {th }}$ regression model, however, generated three variables all with p-values at the 18 percent level or better. These variables are years working for present employer, income, and highest level of education (bachelors degree). The p-value threshold is 10 percent; consequently all variables not meeting the 10 percent level of significance for this model were ultimately dismissed. A liberal $p$-value limit of 10 percent was chosen to allow for more flexibility and latitude during data analysis for this exploratory study. Although there doesn't appear to be a

\footnotetext{
${ }^{2}$ One of the assumptions of the population error terms is that they are homoscedastic. Specifically, the range of error terms remains constant throughout the dataset. If the range of error terms is not constant (i.e., heteroscedastic), it creates a non-fatal problem. Specifically, data analysis is weakened, but not invalidated (Tabachnick \& Fidell, 2001). Several tests for heteroscedasticity exist (e.g., Goldfeld-Quant, Breusch-Pagan, etc), however, a researcher should not become overly confident when using the tests (Lebreton \& Peguin-Feissolle, 2002). Heteroscedasticity was evident in the final and preferred regression model generated for this study (see Appendix I).
} 
tremendous level of statistical confidence when all three variables are included, it is valuable to briefly discuss the possibilities associated with the predictive power they have on employee receptivity to 360 (R360), especially if future studies find the variables significant.

The number of years working for present employer (YRSWK) was found to be positively correlated with $\mathrm{R} 360(\mathrm{p}=.18)$. This makes reasonable sense because one could hypothesize that as an employee becomes part of the ongoing legacy of an organization, he or she feels less threatened by perceived negative consequences. Employees, for example, who have worked for an organization for ten or twenty years will likely have experienced tremendous organizational change during their tenure, and may ultimately realize that the implementation of 360 is simply another human resource management tool. An employee who is relatively new to the organization, on the other hand, might see this new tool as a threat because he or she has not forged the bond that develops through years of employment.

The next variable, income (INC) $(\mathrm{p}=.18)$, is negatively related to $\mathrm{R} 360$, i.e., the greater an employee's income, the less receptive he or she will be to 360 . One possible explanation is that an employee who makes more money than his or her colleagues may believe that income equals success. Such high-paid employees could contend, therefore, that 360 is superfluous because they receive their report card on a weekly or bi-weekly basis, in the form of a paycheck, and are making high marks.

Finally, the binary variable of highest education level, i.e., bachelor's degree (EDBS), was found to have both statistical and practical significance $(p=.065)$. A possible explanation of EDBS significance is that employees who are above or below 
the bachelor's degree level may simply be reticent to participate in 360 . Perhaps employees with a lower level of education (compared to EDBS) may not understand the importance or value of 360 . Employees with a higher education level may have similar beliefs and feelings as employees whose income levels are greater than average. Specifically, it is possible that these higher educated employees have more selfconfidence and may doubt that multi-rater feedback will provide them with information that is not already self-evident.

Although the above model did not produce adequate statistical results (it fell below the 10 percent significance level for two of the three independent variables), it is interesting to at least consider the associated regression equation that follows ( $t$-stats in lower parentheses):

$$
\mathrm{R} 360=5.027+(2.05 \mathrm{E}-02) \mathrm{YRSWK}-(3.55 \mathrm{E}-03) \mathrm{NC}+(.453) \mathrm{EDBS}
$$

In order to understand the model fully, it is important to remember the scales used for each variable. $\mathrm{R} 360$ is measured on a 7-point Likert scale (lowest receptivity $=1$, highest receptivity $=7$ ). INC is measured in $\$ 1,000$ s. This model may be interpreted as follows:

1. For each additional year an employee works for his or her present employer, the employee's R360 score will be predicted to increase by .0205 points (keeping all other independent variables constant).

2. For each thousand-dollar increase in salary, an employee's R360 score will be predicted to decrease by .00355 points (keeping all other independent variables constant). 
3. Finally, if the highest education level attained is a bachelor's degree, an employee's R360 score will be predicted to increase by .453 points (keeping all other independent variables constant).

For this particular model, only one variable, EDBS, is found to have both statistical and practical significance.

\section{Analysis 2: Employee Trust}

The second null hypothesis driving this study relates to employee trust.

$\mathrm{H}_{02}$ : A relationship exists between employee trust and an employee's receptivity to 360 .

Employee trust comprises two elements-employee trust in manager (TRUSMG) and employee trust in organization (TRUSOR). A composite construct, employee trust total (TRUS) is calculated by averaging TRUSMG and TRUSOR.

A total of three regression models were generated for the trust construct.

1. Trust in manager (TRUSMG)

2. Trust in organization (TRUSOR)

3. Trust total (TRUS) (average of TRUSMG and TRUSOR)

In each model, TRUS is shown to be strongly related to R360. Both TRUSMG and TRUSOR are positively correlated to 360 . The variable TRUS generated an estimated coefficient that was $30 \%$ greater than the estimated coefficient for TURSMG and TRUSOR considered singularly.

It is possible that employees who trust their manager and organization believe they have little to fear when developmental tools such as 360 are used. Or, perhaps 
employees subordinate their concern of possible consequences associated with constructive 360 feedback to the idea of improving professionally and personally.

The Pearson's correlation between R360 and TRUS (as well as R360 and TRUSMG, and R360 and TRUSOR) is significant: .48 at the less than 1 percent level of significance. R360 regressed on TRUS yields the following (t-stat in lower parentheses; adjusted R-square $=.221$ ):

$$
\operatorname{lnR} 360=2.651+(.484) \ln T R U S
$$

This regression model is in the from of $\log$-log which enables the reader to more easily understand how changes in the independent variable affect the dependent variable. In this particular model, a 1 percent increase in TRUS equates to a .484 percent increase in R360.

\section{Analysis 3: Employee Commitment}

The third null hypothesis driving this study is employee commitment. Specifically: $\mathrm{H}_{03}$ : A relationship exists between employee commitment and an employee's receptivity to 360 .

Employee commitment (COMT) is a relatively basic variable. The construct is comprised of a seven-item scale and there are no sub-constructs. A strong, positive relationship exists between R360 and COMT. It is possible that committed employees are more concerned with organizational improvement, and are less focused on sheltering their individual egos. Subsequently, they may be more inclined to welcome the notion of self-improvement.

Statistically speaking, the level of practical and statistical significance between R360 and COMT is nearly identical to the relationship between employee receptivity to R360 
and TRUS. Specifically, Pearson's correlation yielded .46 at the less than 1 percent level o f significance. Regressing R360 on COMT generated the following (t-stat in lower parentheses; adjusted R-square $=.202$ ):

$$
\operatorname{lnR} 360=2.635+(.464) \operatorname{lnCOMT}
$$

The equation predicts that for every 1percent increase in COMT, R360 will increase by .464 percent.

Analysis 4: Employee Trust and Employee Commitment

Employee trust and employee commitment are attitudinal dimensions that may be easier to develop or improve upon compared to certain demographic variables. Additionally, it is possible that employee trust (TRUS) and employee commitment (COMT) have a significantly greater influence on employee receptivity to 360 (R360) compared to demographic variables. Assuming this to be true, organizations would be wise to focus on improving the organizational culture and developing human resource programs and policies to ensure high levels of employee commitment and employee trust.

Analyses 2 and 3 regressed R360 on TRUS and R360 on COMT, respectively. Results from both analyses clearly indicate a statistical and practical significance between R360 and the independent variables TRUS and COMT. Intuitively, therefore, one would correctly surmise that combining employee trust and employee commitment would produce a model that predicts an even greater impact on R360 compared to TRUS or COMT considered separately. The following multiple regression was generated (t-stats in lower parentheses; adjusted R-Square $=.247)$ : 


$$
\begin{gathered}
\ln \mathrm{R} 360=2.127+(.257) \ln \mathrm{COMT}+(.315) \ln \mathrm{TRUS} \\
(1.746)
\end{gathered}
$$

This multiple regression model predicts that for every 1 percent increase COMT, a corresponding .257 percent increase will occur in the R360 score (keeping TRUS constant). Additionally, it is predicted that for every 1 percent increase in TRUS, R360 will increase by .315 percent. It is clear that COMT and TRUS are strongly related to R360, and this relationship has practical significance.

\section{Employee Trust \& Employee Commitment - A Relationship}

During the course of data analysis, it was found that TRUS and COMT are closely related. In fact, they have the greatest level of correlation $(.657 ; p=<.01)$ of any bivariate relationship found in this study. In order to exhaust the possibilities of this relationship, tests were run to determine if the estimated coefficients TRUS and COMT have the same affect on R360.

Two separate tests were executed to determine if the associated null hypothesis is true, i.e., TRUS $=$ COMT. In both tests, the calculated t-stat at the 1 percent confidence level was less than $t_{\text {critical, }}$ i.e., it was not possible to reject the null hypothesis of TRUS = COMT (Appendix K provides a thorough overview of each test). This finding does not suggest employee commitment equals employee trust, rather, offers the possibility that the variables TRUS and COMT have a similar affect on employee receptivity to 360 .

This finding may be relatively consequential. Specifically, a $99.9 \%$ probability exists that TRUS $=$ COMT. If the estimated coefficients of TRUS and COMT are equal, then it is possible that the constructs of employee trust and employee commitment are equal. If this were the case, organizations could develop an intervention to improve employee trust, and if successful, it is likely that employee commitment would improve as well, 
and vice versa. Unfortunately, however, there may be a conflict in the data. It would be assumed that if TRUS actually equaled COMT, the correlation coefficient would be much higher than .657 . This may be due to the extremely small sample size.

\section{Employee Trust and Employee Commitment - Concurrent Validity?}

If future research finds that employee trust equals employee commitment, one could argue that concurrent validity existed between the two constructs in this study. Specifically, a case could be made that both constructs are actually measuring the same attitudinal component. It appears, however, that although the constructs are highly related, they may actually measure two different attitudinal dimensions. A factor analysis generated a rotated component matrix (see Table 1) that appears to group several elements that are exclusive to TRUSMG, TRUSOR, or COMT. For example, the 8 items that comprise the construct TRUSMG, and no other, are grouped together (matrix scores (Varimax rotation) range between .718 and .849 ). Two of the four variables that comprise the variable TRUSOR are grouped (rotated matrix scores equal .81 or greater). Finally, five of the seven variables that comprise COMT generated matrix scores that were .81 or greater.

Analysis 5: Employee Trust, Employee Commitment, and Demographic Variables

The final analysis considered the amalgamation of employee trust, employee commitment, and the three demographic variables previously discussed (YRSWK, INC, EDBS).

Although a rather limited relationship appears to exist between employee receptivity to 360 and demographic variables, it would be negligent not to include the three variables found to have moderate influence (and limited statistical significance). These 
Table 1

Summary of Factor Analysis- Employee Commitment (COMT), Employee Trust in Manager (TRUSMG), and Employee Trust in Organization (TRUSOR): Rotated component (Varimax)

\begin{tabular}{|c|c|c|c|c|}
\hline Item & & Com & & \\
\hline & 1 & 2 & 3 & 4 \\
\hline COMT1 & $3.78-02$ & $1.78 \mathrm{E}-02$ & $2.79 \mathrm{E}-02$ & .920 \\
\hline COMT2 & -.304 & .345 & $5.39 \mathrm{E}-02$ & .655 \\
\hline COMT3 & .275 & .814 & .112 & $-9.29 \mathrm{E}-02$ \\
\hline COMT4 & .112 & .843 & .214 & .206 \\
\hline COMT5 & .120 & .812 & .218 & .240 \\
\hline COMT6 & .213 & .648 & .319 & .357 \\
\hline COMT7 & .260 & .837 & .212 & $-6.35 \mathrm{E}-02$ \\
\hline TRUSMG1 & .718 & .462 & .111 & -.302 \\
\hline TRUSMG2 & .849 & .331 & .102 & $3.89 \mathrm{E}-02$ \\
\hline TRUSMG3 & .754 & $-4.45 \mathrm{E} 02$ & $5.25 \mathrm{E}-02$ & .131 \\
\hline TRUSMG4 & .719 & .492 & $7.59 \mathrm{E}-02$ & $66.75 \mathrm{E} 02$ \\
\hline TRUSMG5 & .793 & .390 & .270 & $-9.20 \mathrm{E}-02$ \\
\hline TRUSMG6 & .793 & .118 & .231 & $-6.40 \mathrm{E}-02$ \\
\hline TRUSMG7 & .788 & .284 & $5.92 \mathrm{E}-02$ & $-6.11 \mathrm{E}-02$ \\
\hline TRUSMG8 & .849 & $-1.18 \mathrm{E}-02$ & .177 & $-5.19 \mathrm{E}-02$ \\
\hline TRUSOR1 & .266 & .549 & .583 & $4.68 \mathrm{E}-02$ \\
\hline TRUSOR2 & .249 & .467 & .648 & .195 \\
\hline TRUSOR3 & $4.29 \mathrm{E}-02$ & .109 & .854 & $-3.64 \mathrm{E}-02$ \\
\hline TRUSOR4 & .268 & .261 & .813 & $4.58 \mathrm{E}-02$ \\
\hline
\end{tabular}


variables, presented in the Analysis 1: Demographic Variables section of this chapter include the number of years working with present employer (YRSWK), income (INC), and the binary variable of highest level of education, bachelor's degree (EDBS).

A backward elimination multiple regression analysis was generated and only years working with present employer (YRSWK) did not meet the specified significance level. That variable was excluded from the final model. The variables COMT, TRUS, and EDBS were found to have a positive relationship with R360, and INC was found to be negatively related to the dependent variable. This finding is congruent with previous analyses. All off these variables were statistically significant at the 5 percent or better level. Additionally, the binary variable EDBS generated a large estimated coefficient (.571). The variables TRUS and COMT were shown to be strong predictors of employee receptivity to 360 . The following regression model was generated ( $t$-stats in lower parentheses, adjusted R-Squared = .375):

$$
\begin{aligned}
& \mathrm{R} 360=1.970+(.330) \mathrm{TRUS}+(.275) \mathrm{COMT}+(.571) \mathrm{EDBS}-(4.85 \mathrm{E}-03) \mathrm{INC} \\
& \text { (2.279) (2.067) (2.781) }
\end{aligned}
$$

In order to fully understand the significance of this model, it is important to consider the scales of each variable. R360 was measured using a 7-point Likert scale (1 equals lowest receptivity to 360,7 equals highest receptivity). Similarly, TRUS and COMT use a 7-point Likert scale (1 lowest; 7 highest). INC is measured in thousands of dollars. This formula is interpreted as follows:

1. Every 1-point increase in TRUS equates to a predicted .33 increase in R360, keeping all other variables constant.

2. Every 1-point increase in COMT equates to a predicted .275 increase in R360, keeping all other variables constant. 
3. If an employee's highest level of education is a bachelor's degree, the model predicts an increase of .571 in R360 score. If an employee's highest level of education is not a bachelor's degree (i.e., if he or she has achieved a degree that is higher or lower than a bachelor's degree), this variable does not change the R360 score.

4. For each thousand-dollar increase in salary, an employee's R360 score is predicted to decrease by .00485 points, keeping all other variables constant.

According to this equation, one could predict that an employee, for example, who scored 5.5 on TRUS, 5.8 on COMT, earned a $\$ 75,000$ income last year, and whose highest level of education is bachelor's degree would produce a R360 score of 5.59 (i.e., $1.97+(.330) 5.5+(.275) 5.8+(.571) 1-(.00485) 75)$.

Perhaps a more meaningful way of interpreting the regression model is by converting the dependent variable and the independent variables into natural logarithms (double-log). This provides the reader with a standard means of interpreting the data, i.e., using percentages to predict increases or decreases in the dependent variable. The previous regression model is thereby translated into the following double-log model ( $\mathrm{t}-$ stats remain unchanged for the independent variables):

$$
\ln R 360=1.970+(.336) \ln T R U S+(.307) \operatorname{lnCOMT}+(8.16) \text { EDBS }-
$$

\section{$(.247) \ln I N C$}

The double-log interpretation for the preceding model follows:

1. Every $1 \%$ increase in TRUS equates to a predicted $.336 \%$ increase in R360, keeping all other variables constant. 
2. Every $1 \%$ increase in COMT equates to a predicted $.307 \%$ increase in R360, keeping all other variables constant.

3. If an employee's highest level of education is a bachelor's degree, the model predicts an increase of $8.16 \%$ in R360 score. If an employee's highest level of education is not a bachelor's degree (i.e., if he or she has achieved a degree that is higher or lower than a bachelor's degree), this variable does not change the $\mathrm{R} 360$ score.

4. For each 1-percent increase in salary, an employee's R360 score is predicted to decrease by $.247 \%$, keeping all other independent variables constant.

\section{$\underline{\text { Missing Data }}$}

The preceding model dismissed observations with missing data when generating estimated coefficients (i.e., exclude cases method). This model dropped seven observations; one respondent did not complete the TRUSMG construct and six respondents did not submit their income. There are, however, at least two other methods for accounting for missing data, zero-order correction and first-order correction. ${ }^{3}$ The researcher generated regression models using all three methods in order to demonstrate the robustness of the findings regardless of how the data are analyzed.

Two independent variables contain missing data, TRUSMG (which affects TRUS) and $\mathrm{INC}^{4}$. Table 2 provides an overview of all three regressions (i.e., excluded cases, zero-order correction, and first-order correction ( $t$-stats for variables in parentheses):

\footnotetext{
${ }^{3}$ Zero-order correction involves substituting the sample mean for the mission observation. First-order correction uses regression estimates, from data already collected, to replace the mean. Zero-order correction produces estimated coefficients that remain unbiased, however, there tends to be a loss of precision, i.e., minimal variance is generated. First-order correction, if correctly performed, may introduce bias and a forecast error, however, it produces a more efficient set of estimated coefficients compareded to zero-order correction (see Appendix L).

${ }^{4}$ Appendix M provides a detailed explanation of calculating missing variables for TRUSMG and INC.
} 
Table 2: Estimated coefficients for dependent variable R360

\begin{tabular}{|c|c|c|c|c|c|c|c|}
\hline Method & Constant & COMT & TRUS & $\begin{array}{l}\text { INC } \\
(\$ 1,000)\end{array}$ & EDBS & $\begin{array}{l}\text { R- } \\
\text { Squared }\end{array}$ & $\begin{array}{l}\text { Adj. R- } \\
\text { Squared }\end{array}$ \\
\hline $\begin{array}{l}\text { Excluded } \\
\text { cases }\end{array}$ & $\begin{array}{r}1.970 \\
(3.150)\end{array}$ & $\begin{array}{r}.275 \\
(2.067)\end{array}$ & $\begin{array}{r}.330 \\
(2.279)\end{array}$ & $\begin{array}{r}-4.85 \mathrm{E}- \\
03 \\
(-2.267)\end{array}$ & $\begin{array}{r}.571 \\
(2.781)\end{array}$ & .420 & .375 \\
\hline $\begin{array}{l}\text { Zero- } \\
\text { order }\end{array}$ & $\begin{array}{r}1.911 \\
(3.041)\end{array}$ & $\begin{array}{r}.252 \\
(1.913)\end{array}$ & $\begin{array}{r}.363 \\
(2.634)\end{array}$ & $\begin{array}{r}-4.8 \mathrm{E}- \\
03 \\
(-2.198)\end{array}$ & $\begin{array}{r}4.58 \\
(2.31)\end{array}$ & . 381 & .338 \\
\hline $\begin{array}{l}\text { First- } \\
\text { order }\end{array}$ & $\begin{array}{r}1.888 \\
(2.983)\end{array}$ & $\begin{array}{r}.258 \\
(1.955)\end{array}$ & $\begin{array}{r}.360 \\
(2.569)\end{array}$ & $\begin{array}{r}4.79 \mathrm{E}- \\
03 \\
(-2.229) \\
\end{array}$ & $\begin{array}{r}4.69 \\
(2.363)\end{array}$ & .383 & .339 \\
\hline
\end{tabular}

It is difficult to determine which of the three methods of accounting for missing data produces the most accurate estimated coefficients. There are problematic issues associated with each method. Omitting seven observations in the excluded cases method, for example, is troublesome given the small $\mathrm{n}$. Eliminating more than $10 \%$ of the observations, therefore, exacerbates the limitation of a small sample size. Zero-order correction is a popular method to account for missing data, however there tends to be a loss of precision when generating estimated coefficients (although the coefficients remain unbiased if correctly calculated). First-order correction is often the preferred method, and may generate coefficients that are most accurate, however a limited number of observations (56) were used to calculate TRUSMG and INC in this regression. The author was forced to use a limited number of observations to calculate missing data in an already small sample, and although this first-order regression model generated an adjusted R-square of .42, there is a concern with the accuracy of the calculated INC values.

The author's preference for handling missing data, in descending order, is excluded cases, first-order correction, and finally, zero-order correction. 


\section{Organization Comparisons}

One final binary variable was included to determine if there is a difference between the estimated coefficient for employees who work for Organization 1 and employees who work for Organization 2. According to the results from this regression model, it is not possible to determine if any differences exist between the estimated coefficient for employees who work for Organization 1 and employees who work for Organization 2.

Two sample t-tests (assuming equal variances) were conducted for R360, COMT, and TRUS. This particular t-test assumes that the means of both data sets (ORG 1 and ORG 2) are equal for the constructs tested. Similar to the results discussed in the preceding paragraph, there is evidence supporting the null hypothesis for one of the three variables. Specifically, the first null hypothesis fails to be rejected; null hypotheses 2 and 3 are rejected:

1. $\mathrm{H}_{0}$ : mean of $\mathrm{R} 360(\mathrm{ORG} 1)=$ mean of $\mathrm{R} 360(\mathrm{ORG} 2)$

2. $\mathrm{H}_{0}:$ mean of $\mathrm{COMT}(\mathrm{ORG} 1)=$ mean of COMT(ORG2)

3. $\mathrm{H}_{0}$ : mean of TRUS(ORG 1$)=$ mean of TRUS $(\mathrm{ORG} 2)$

Calculated t-statistics ranged from 1.8 to 4.6 ; $\mathrm{t}$-critical values are 2.00 at the $5 \%$ level. Associated statistical data for the t-tests are provided in Table 3.

Table 3: T-tests for ORG 1 and ORG 2 (R360, COMT, TRUS)

\begin{tabular}{lrrrrrr}
\hline & \multicolumn{2}{c}{ R360 } & \multicolumn{2}{c}{ COMT } & \multicolumn{2}{c}{ TRUS } \\
\hline Mean & ORG 1 & ORG 2 & ORG 1 & ORG 2 & ORG 1 & ORG 2 \\
Variance & 5.62 & 5.09 & 6.51 & 5.75 & 6.43 & 5.15 \\
Observations & .272 & .787 & .281 & .878 & .143 & .655 \\
Hypothesized Mean & 9 & 53 & 9 & 53 & 9 & 53 \\
Difference & 0 & & 0 & & 0 & \\
df & & & & & & 60 \\
t Stat & 60 & & 60 & & 4.63 & \\
t Critical (one-tail)(5\%) & 1.76 & & 2.36 & & 2.00 & \\
\hline
\end{tabular}




\section{Multicollinearity and Heteroscedasticity}

None of the independent variables in the final regression were found to be multicollinear, however, three of the variables (COMT, TRUS, and INC) were found to be heteroscedastic. While heteroscedasticity does not bias the affected variables, it does artificially inflate the associated standard errors. Appendix J provides an overview of tests for multicollinearity and heteroscedasticity.

$\underline{\text { Outliers }}$

Due to a small $\mathrm{n}$, observations with outliers were included in all regression models. Only two possible outliers (data points with z-scores greater than or less than 3 ) were found. In one observation, the R360 standard score was 3.4, and in another observation the INC standard score was 4.2 .

\section{Data Analysis Conclusion}

A number of statistical models were generated in this section. Ultimately, four variables were found to have a statistical influence on the dependent variable, employee receptivity to 360 feedback. Two of the variables are attitudinal in nature-employee trust (which is a combination of employee trust in manager and employee trust in the organization) and employee commitment. Both variables were positively related to employee receptivity to 360 feedback and affect the dependent variable as described:

1. For each 1-point increase in employee trust (on a 7-point Likert scale), employee receptivity to 360 feedback is predicted to increase by $4.7 \%$.

2. For each 1-point increase in employee commitment (on a 7-point Likert scale), employee receptivity to 360 feedback is predicted to increase by $3.9 \%$. 
Two demographic variables were found in their regression analysis to be statistically related to the dependent variable. The first, income, has a negative relationship with employee receptivity to 360 feedback. Of the four independent variables that influence employee receptivity to 360 , income affects it the least. The other demographic variable that influences the dependent variable is discrete in nature, i.e., it is measured on a nominal scale (categories) versus an ordinal scale. Specifically, the variable relates to an employee's highest level of education. If an employee's highest level of education is a bachelor's degree, the regression model predicts a rather large increase in employee receptivity to 360 feedback. Specifically, employees with a bachelor's degree are $8.16 \%$ percent more receptive to 360 feedback than those employees without the degree. Additionally, for each $\$ 1,000$ increase in annual salary, employee receptivity to 360 feedback is predicted to decrease by $.069 \%$. Finally, if an employee's highest level of education is a bachelor's degree, it is predicted that employee receptivity to 360 will increase by $8.13 \%$. If an employee's highest level of education is greater than or less than a bachelor's degree, it is predicted that no change will occur in employee receptivity to 360.

In summation, the variables of employee trust, employee commitment, and having a bachelor's degree as the highest level of education are all positively and substantially related to employee receptivity to 360 . Income, on the other hand, has a negative and a relatively slight practical relationship with employee receptivity to 360 . 


\section{Chapter V}

Findings, Recommendations, and Conclusions

Introduction

Traditional top-down appraisal systems were commonly used by organizations for many generations. Supervisors provided feedback to direct reports, as summative or formative evaluation (or perhaps a combination of both), with the hope that the appraisal was accurate and fair. In the last several decades, however, such top-down appraisal mechanisms needed to be supplemented by a more complete feedback loop such as 360 degree feedback. One principal benefit of 360 is that it provides employees with a more comprehensive, and often a more accurate assessment of performance and behavior.

Three hundred sixty degree feedback utilizes up to a dozen, or even more, peers, direct reports, supervisors, and internal and external customers as a means to provide invaluable feedback. This feedback is intended to raise employees' awareness of their personal strengths and weaknesses. Ultimately, 360-degree feedback is designed to accelerate the growth and development of employees.

Organizations that correctly design and implement $360^{5}$ often find that it is a valuable tool, and well worth the required resources (fiscal and labor) to launch and maintain the system. Unfortunately, many 360 -degree feedback systems do not work as well as other

\footnotetext{
${ }^{5}$ Elements required for effective 360 implementation are provided in Chapter 2. Examples of best practices include using 360 as a developmental versus evaluation tool (at least for the first few feedback cycles), training must be provided to raters and employees who receive feedback, feedback must be given anonymously, the 360 system should be aligned to the organization's business plan, senior leadership must embrace the concept, and adequate resources must be provided.
} 
appraisal applications due to inappropriate implementation and maintenance. Relying on 360 as strictly a summative evaluation tool, or failing to commit required resources, for example, will likely reduce the effectiveness of the system (Peiperl, 2001).

One way of improving the likelihood of 360 success is to ensure that the organizational culture is ripe for a change that could be perceived by employees as a potential threat, i.e., establishment of an extremely personal human resource intervention. If leaders and managers attempt to introduce 360 into an organization that is not culturally mature, the probability of venture success could be significantly reduced. Employees who work in such an organization would most likely be hesitant to comply with the new mandate rather than eagerly commit; the outcome could be 360 failure. A plethora of studies (e.g., Kelly (2002); Maddi et al. (1999); Riggs and Patrick (1994)) found a positive relationship between employee motivation, organizational culture, and success levels for new organizational programs.

Ultimately, if employees are unreceptive to the process of 360 evaluation, and hesitant to consider data generated from 360 systems, the effectiveness of the appraisal process may be negatively impacted (Bernardin, Dahmus, \& Redmon, 1993). Organizations comprised predominately of employees who are not receptive to the notion of 360 , therefore, may be best served by not implementing such a costly appraisal system. Or, if leaders and managers choose to implement 360 in an organization composed of unreceptive employees, an intervention designed to improve the organizational climate would be recommended. It is necessary, therefore, for leaders and managers to first determine the level of receptivity to multi-rater feedback prior to implementing a 360 system. 
The purpose of this study was to measure employee receptivity to 360-degree feedback. The ability to predict whether individual employees will be receptive to 360 has major benefits. Human resource officials and organizational development consultants who are able to correctly make such predictions could promote 360 if it appeared that the organization was ripe for such a system. Or, the same experts could prevent tens-ofthousands of dollars from being wasted on an evaluation tool that does not currently fit the employee culture.

The significance of this study relates directly to optimizing scarce resources (fiscal and human capital). Employee resistance to particular plans, policies, and programs (e.g., 360) may generate a poor return on investment. It behooves organizations to implement these systems only if they improve productivity.

\section{Findings}

A statistically significant and positive relationship exists between the independent variable, employee receptivity to 360-degree feedback (R360), and both of the attitudinal dependent variables (employee commitment (COMT) and employee trust (TRUS)). A one percent increase in COMT translates to a .31\% increase in R360 and the same increase in TRUS equates to a rise of $.34 \%$ in R360. The attitudinal variables COMT and TRUS can theoretically be developed and improved upon and are perhaps of greatest consequence. Employee income (INC) and education level (i.e., highest education level $=$ bachelors degree $($ EDBS)) were found to influence R360. A 1 percent increase in INC leads to a $.25 \%$ decrease in R360 while employees with a bachelor's degree as the highest level of education (EDBS) increases R360 by $8.16 \%$. 


\section{Employee Commitment and Employee Trust}

A secondary finding is that employee commitment and employee trust appear to have an equivalent affect on employee receptivity to 360 -degree feedback. This is not to say that employee commitment equals employee trust (although there is a relatively high * correlation between the two), rather, both variables have a similar impact on employee receptivity to 360 . Additionally, it was determined through factor analysis that the variables employee commitment and employee trust measured different attitudinal dimensions.

The relationship between employee commitment and employee trust may have noteworthy implications. Specifically, a cause and effect relationship may exist between the two variables. The direction of causality cannot be determined from the results of this study, however the author posits one possibility. Specifically, a reinforcing system may exist between employee commitment and employee trust, and it may be likely that organizations initiate this process. In particular, organizations may nurture employee trust, and in turn employee commitment levels may rise. As employee commitment levels increase, organizations may subsequently stoutly encourage employee empowerment. If such a reinforcing loop actually exists, it behooves organizations to continue on the path of contemporary leadership practices such as servant leadership, transformation leadership, and infocracy ${ }^{6}$ (Clawson, 1999).

\footnotetext{
${ }^{6}$ Infocracy, as Clawson (1999) defines it, is the current context of leadership that is defined as the redistribution of power to key process contributors (employees at all levels) and is based on the assumption that key process contributors know best. This is in direct contrast to bureaucracy, where it is assumed the boss knows best.
} 


\section{$\underline{\text { A Comparison of Studies }}$}

The design of this study was based in part on research conducted by Funderburg and Levy (1997) (a brief overview of this study is provided in Chapter 2). Although no two constructs were common between the two studies, the author would be remiss in not comparing the calculated estimated coefficients of variables that intuitively may be related. One of the three significant variables in the Funderburg and Levy study, organizational citizenship behavior (OCB) ${ }^{7}$, appeared to be problematic early on in the study because there tended to be large discrepancies between an individual's selfreported OCB score and the OCB score provided by coworkers. This variable, therefore, will not be discussed. Additionally, a second variable in Funderburg and Levy, supervisory style ${ }^{8}$, was found to be negatively related to 360 attitude (receptivity) $(\beta=$ -.30) (a higher supervisory score indicates a supervisor who practices participative management whereas a lower score indicates a more autocratic leadership style). Funderburg and Levy contend that employees who have highly participative leaders tend to receive developmental and evaluative feedback from their supervisor and consequently may not need the additional information that 360 provides. Such reasoning may be realistic, however, another perspective is that the direct reports of highly participative leaders (versus autocratic leaders) would tend to have higher trust levels. If this were the case, there may be an inconsistency between findings. The author does not necessarily agree with the Funderburg and Levy hypothesis related to supervisory style. Specifically, the purpose of 360 is to gather employee data from multiple sources, to provide more thorough developmental feedback, regardless of supervisory style.

\footnotetext{
${ }_{8}^{7}$ OCB relates to the degree an employee helps his or her coworkers.

${ }^{8}$ Supervisory style relates to the degree of autocratic control exercised. A higher score indicates a supervisor who tends to exercise a more participative style of leadership.
} 
The third variable, perceived cost of seeking feedback ${ }^{9}$, was negatively related to 360 attitude $(\beta=-.35)$. This variable may relate directly to employee trust. Specifically, there may be a positive relationship between TRUS and perceived cost of asking for feedback. This notion may be valid because four of the twelve items that comprise TRUS relate to employee trust in supervisor.

Interestingly enough, the estimated coefficients associated with TRUS and perceived cost of asking for feedback are within .02 points $\left(\beta_{\text {TRUS }}=.33 ; \beta_{\text {perceived cost }}=-.35\right)$. The difference between the signs (positive (TRUS); negative (perceived cost of asking for feedback)) is simply due to how the items within the construct are worded. Specifically, a higher TRUS score indicates greater trust, whereas a higher perceived cost of asking for feedback score signifies a greater cost to the employee to seek feedback.

Although the estimated coefficients calculated for TRUS, COMT, and perceived costs are similar in magnitude and direction, it should be noted that different Likert scales were used to measure the constructs for each study. Specifically, Funderburg and Levy used 5-point Likert scale to measure the aforementioned variables, whereas a 7point Likert scale was used to measure R360, TRUS, and COMT.

$\underline{\text { Implications }}$

A ubiquitous question asked by leaders is how great will the return on investment (ROI) be for a particular organizational development program, policy, system, or tool. Human resource professionals strive to develop metrics to measure ROI; however they often fall short. The ROI concern, in fact, was a central issue at a recent leadership conference held at Naval Amphibious Base, Norfolk, VA, January 22-23, 2003.

\footnotetext{
${ }^{9}$ Perceived cost of seeking feedback relates to the emotional and psychological costs that an employee experiences when seeking feedback. A higher score indicates a greater cost for an employee, i.e., he or she feels embarrassed to ask a supervisor for feedback.
} 
Attendees included organizational development specialists from the armed services of the United States, Canada, and the United Kingdom, as well as representatives from private and public sector organizations who are experts in leadership and professional development. The overall opinion during this summit was that a majority of contemporary organizations know how to design and implement leadership and organizational development programs and plans; however, measuring associated results is exceptionally difficult.

Due to the extreme complexities associated with calculating leadership and professional development ROIs, it may behoove organizational leaders to first determine the degree of receptivity of workers who will be affected by a newly implemented tool. If employees are generally opposed to a new initiative, a well-crafted intervention designed to improve employee receptivity may increase the project's overall effectiveness, as well as the efficiency of implementing the program. The goal of improving employee receptivity to 360 is simply to maximize the system's ROI. Granted, leaders could simply mandate the program with little concern for the organizational climate, but as Kurt Lewin theorized, it may be more effective to first reduce the restraining forces (Hiebert \& Klatt, 2001).

Three hundred sixty degree feedback may provide exceptional information that can be used for development (formative evaluation), input as part of an appraisal system (summative evaluation), or a combination of both. The feedback tool, however, is extremely costly and time consuming to implement. Effective execution of the design and implementation of a 360 program, therefore, should be of paramount concern. One factor 
that may increase the probability of implementation success is a high level of employee receptivity to 360 .

While it is possible to successfully implement 360 in an organization regardless of the receptivity level of employees, it is assumed that organizations with higher levels of employee trust and commitment will be more effective and efficient in implementing the feedback tool compared to organizations with lower levels of trust and commitment. This "playing the odds" is true with virtually any organizational development program or tool. Sometimes a program or tool will be successful regardless, or in spite of the probability of failure, and sometimes failure is the outcome despite favorable conditions. Figure 2 provides a theoretical visual representation (not to statistical scale) of playing the odds with regard to implementing many organizational development tools, including 360.

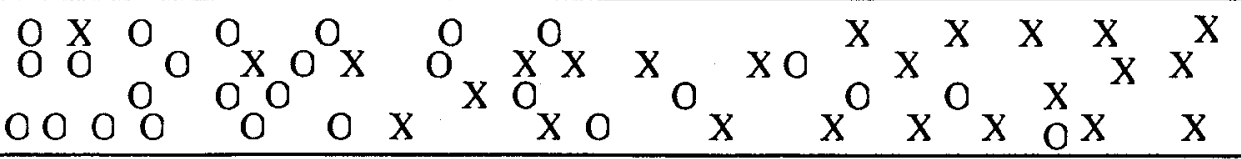

$$
\begin{aligned}
& \text { Level of Successful } 360 \text { Implementation }
\end{aligned}
$$

Figure 2. Hypothetical 360 success model
$\mathrm{X}=$ Organizations with high levels of employee commitment and employee trust $\mathrm{O}=$ Organizations with low levels of employee commitment and employee trust

Funderburg and Levy (1997) contend that more research is required to determine the components that affect an organization's willingness to accept multi-rater feedback systems. Additionally, they suggest researchers should explore "issues such as culture and climate as well as dyadic issues such as trust and communication" (p. 231). The study outlined in this dissertation focused on two dyadic issues, i.e., trust and commitment, and found both related to employee receptivity to 360 . 
The main concern of Funderburg and Levy (1997) appears to relate to the long-term appropriate use of 360 as a means to improve organizational effectiveness. One element of 360 longevity will be utilizing the system only when organizations are ripe for such an intervention. Funderburg and Levy conclude their study by stating:

Finding the best "fit" for these alternative systems will be the key' to their future success in the performance management of tomorrow. Finally, more attention must be given to reducing the social costs of 360-degree feedback systems. Investigating ways to ensure employee acceptance of these systems will guarantee the survival of 360-degree appraisal systems.

\section{$\underline{\text { Strengths and Limitations }}$}

Proven practices in survey research design and statistical theory underpin this study. Substantial time and effort was expended to ensure psychometric adequacy of the instrument and proper use of multiple regression. Multiple regression analysis generated the best linear unbiased estimators and appropriate tests were conducted to ensure model reliability.

At least three limitations exist. First and foremost, the sample size (62 respondents) was extremely small and may consequently create the phenomenon of over-fitting. Over-fitting occurs when the ratio of sample size to the number of independent variables is relatively low. Ultimately, this problem severely limits the confidence of accurate predictions or inferences made for a population based on the sample. Second, only two organizations participated. Such a small number of contributing organizations severely reduces the confidence of generalizing findings across a broad range of organization types. The limited number of ethnically diverse employees who appear to have 
participated in this research further reduces the predictive power of the study, especially considering the increase in the population of minorities in America. Third and finally, the response rate was extremely low (21.5\%). Survey findings, therefore, may be biased because it is not possible to determine if the respondent attitudes are representative of the attitudes of employees who elected to forgo the survey.

\section{$\underline{\text { Recommendations for Future Research }}$}

This study generated interesting results, however, the limited number of respondents and participating organizations raises many questions. Clearly, the most obvious recommendation is to suggest a more comprehensive study be completed (i.e., a study that incorporates several organization types and multiple organizations for each organization type, as well as including several hundred respondents). Additionally, it would be interesting to include the construct of psychological androgyny in a subsequent study. If such a study were undertaken and generated similar results, follow-up studies could be conducted in order to develop a matrix that may predict the level of probability of 360 success based on a range of R360 scores.

\section{$\underline{\text { Conclusions }}$}

It is difficult to determine if 360 will remain popular in the future. Given the present day competitive nature of business, the limited separation between countries (due to the expansion of technology and travel), and employees' thirst for professional and personal development, 360 may likely remain a reputable human resource tool. If this assumption proves valid for the years and decades to come, it will behoove organizations to utilize studies such as this to help them fully understand how and when to most effectively and efficiently employ such appraisal systems. 


\section{References}

Antonioni, D. (1994). The effects of feedback accountability on 360-degree appraisal ratings. Personnel Psychology, 47, 375-390.

Antonioni, D. (1996). Designing an effective 360-degree appraisal feedback process. Organizational Dynamics, 25, 24-38.

Ashford, S. J., \& Cummings, L. L. (1983). Feedback as an individual resource: Personal strategies of creating information. Organizational Behavior and Human Performance, $32,370-398$.

Atwater, L.E. \& Waldman, D. A. (1998). The power of 360-degree feedback. Houston, TX: Gulf.

Atwater, L. E., Waldman, D. A., Atwater, D., \& Cartier, P. (2000). An upward feedback field experiment: Supervisors' cynicism, reactions, and commitment to subordinates. Personnel Psychology, 53, 275-297.

Bass, B. M., \& Yammarino, F. J. (1991). Congruence of self and other's leadership ratings of naval officers for understanding successful performance. Applied PsychologyAn International Review, 40, 437-454.

Beck, R. C. (1990). Motivation: theories and principles ( $3^{\text {rd }}$ ed.). Englewood Cliffs, NJ: Prentice-Hall, Inc.

Bem, S. L. (1974). The measurement of psychological androgyny. Journal of consulting and clinical psychology, 42, 155-162.

Bernardin, H. J., \& Beatty, R. W. (1984). Performance appraisal: Assessing human behavior at work. Boston, MA: Kent-Wadsworth. 
Bernardin, H. J., Dahmus, S. A., \& Redmon, G. (1993). Attitudes of first-line supervisors toward subordinate appraisals. Human Resource Management, 32, 315-324.

Cann, A., \& Siegfried, W. D. (1990). Gender sterotypes and dimensions of effective leader behavior. Sex Roles, 23(7-8), 413-419).

Clawson, J. G. (1999). Level three leadership. Upper Saddle River, NJ: Prentice-Hall. Coates, D. E. (1998). Breakthroughs in mulitsource feedback software. The Human Resources Professional, 11, 7-11.

Coast Guard (1997). The U.S. coast guard officer evaluation report. Washington: GPI.

Cosentino, J., \& Nemeroff, W. F. (1979). Utilizing feedback and goal-setting to increase performance appraisal interviewer skills of appraisees. Academy of Management Journal, 22, 566-576.

Covey, S. R. (1989). The 7 habits of highly effective people. New York: Simon and Schuster.

Cummings, L. L., \& Schwab, D. P. (1973). Performance in organizations: Determinants and appraisal. Glenview, IL: Scott, Foresman, \& Co.

Cyr, D. (2002). The art of global thinking: Integrating organizational philosophies of east and west. Ashland, OH: Purdue University Press.

Daniels, A. C. (2000). Bringing out the best in people: How to apply the astonishing power of positive reinforcement. New York: McGraw-Hill.

Davis, T. \& Landa, M (2000). Changing dynamics. CMA Management, 74, 26-29.

DeNisi, A. S., \& Kluger, A. N. (2000). Feedback effectiveness: Can 360-degree appraisals be improved? The Academy of Management Executive, 14, 129-139. 
DeNisi, A. S., \& Williams, K. J. (1990). Cognitive approaches to performance appraisal. In G. R. Ferris \& K. M. Rowland (Eds.), Performance evaluation, goal setting, and feedback. (pp. 47-93). Greenwich, CT: JAI Press.

Derksen, S. \& H. J. Keselman (1992). Backward, forward and stepwise automated subset selection algorithms: Frequency of obtaining authentic and noise variables. British Journal of Mathematical and Statistical Psychology 45, 265-282.

Dillman, D. A. (1978). Mail and telephone surveys: The total design method. New York: Wiley.

Dunnette, M. D. (1993). My hammer or your hammer? Human Resource Management, 32, 373-384.

Edwards, M. R. \& Ewen, A. J. (1996). 360-degree feedback. New York: Amacom.

Fletcher, C. (1999) The implication of research on gender differences in selfassessment and 360 degree appraisal. Human Resource Management Journal: London, 9, $39-46$.

Ford, M. E. (1992). Motivating humans. Newbury Park, CA: Sage Publications, Inc.

Funderburg, S. A. \& Levy, P. E. (1997). The influence of individual and contextual variables on 360-degree feedback system attitudes. Group \& Organization Management, $\underline{22,} 210-233$.

Gilley, J. W., Maycunich, A., Ouatro, S, Whittle, D., \& Hoekstra, E. (2001). The manager as change agent. Boulder, CO: Perseus.

Gioia, D. A. \& Longnecker, C. O. (1988). Neglected at the top-executives talk about executives' appraisal. Sloan Management Review, 41, 35-40.

Greene, W. H. (1990). Econometric analysis. New York: Macmillan. 
Grote, R. C. (1996). The complete guide to performance appraisal. New York:

AMACOM.

Guba, E. G., \& Lincoln, Y. S. (1989). Fourth generation evaluation. Newbury Park: Sage.

Hackman, J. R., \& Oldham, G. R. (1980). Work redesign. Reading, MA: AddisonWesley.

Hazucha, J.F., Hezlett, S.A., \& Schneider R.J. (1993). The impact of 360-degree feedback on management skills development. Human Resource Management, 32, 325351.

Hegarty, H. H. (1974). Using subordinate rating to elicit behavioral changes in supervisors. Journal of Applied Psychology, 59, 764-766.

Henderson, R. I. (1984). Performance appraisal (2 $2^{\text {nd }}$ ed.). Reston, VA: Prentice-Hall.

Hiebert, M., \& Klatt, B (2001). The Encyclopedia of Leadership: A Practical Guide to Popular Leadership Theories and Techniques. New York, NY: McGraw-Hill.

Holliday, M (2001). Coaching, mentoring, and managing: A Coach Guidebook (2 Ed.). Franklin Lakes, NJ: Career Press.

Ilgen, D. R., Fisher, C. D., and Taylor, S. M. (1979). Consequences of individual feedback on behavior in organizations. Journal of Applied Psychology, 64, 349-368.

Johnson, A. C., Johnson, M. B., \& Buse, R. C. (1987). Econometrics. New York: MacMillan.

Katz, D. A. (1982). Econometric theory and application. Englewood Cliffs, NJ: Prentice-Hall. 
King, P. (1984). Performance planning \& appraisal: A how-to book for managers. New York: McGraw-Hill.

Kirkpatrick, D. L. (1982). How to improve performance through appraisal and coaching. New York: AMACOM.

Kluger, A. \& DeNisi, A. (1996). The effects of feedback interventions on performance: A historical review, a meta-analysis and a preliminary feedback theory. Psychological Bulletin, 119,254-284.

Landy, F. J., Barnes, J. L., \& Murphy, K. R. (1978). Correlates of perceived fairness and accuracy of performance evaluation. Journal of Applied Psychology, 65, 751-754.

Landy, F., Zedeck, S., \& Cleveland, J. (Eds.). (1983). Performance measurement and theory. Hillside, NJ: Lawrence Erlbaum Associates.

Latham, G. P. (1990). The role of goal setting in human resource management. In G. R. Ferris \& K. M. Rowland (Eds.), Performance evaluation, goal setting, and feedback. (pp. 185-215). Greenwich, CT: JAI Press.

Latham, G. P. \& Wexley, K. N. (1981). Increasing productivity through performance appraisal. Reading, MA: Addison-Wesley.

Latham, G. P., \& Wexley, K. N. (1994). Increasing productivity through performance appraisal ( $2^{\text {nd }}$ ed.). Reading, MA: Addison-Wesley.

Levinson, H. (1970). Management by whose objectives? Harvard Business Review, $125-134$

Li, J., Koh, W.k., \& Heng, S.H. (1997). The effects of interactive leadership on human resource management in Singapore's banking industry. The International Journal of Human Resource Management, 8, 710-719. 
Lindeman, M., Sundvik, L., \& Rouhiainen, P. (1995). Underestimation or overestimation of self-person variables and self-assessment accuracy in work setting. Journal of Social Behavior and Personality, 10, 123-134.

London, M., \& Smither, J. W. (1995). Can multi-source feedback change perception of goal accomplishment, self-evaluation, and performance-related outcomes? Theorybased applications and directions for research. Personnel Psychology, 48, 803-839.

Luthans, F., \& Kreitner, R. (1975). Organizational behavior modification. Glenview, IL: Scott, Foresman.

Mabe, P., \& West, S. (1982). Validity of self-evaluation of ability: A review and meta-analysis. Journal of Applied Psychology, 67, 280-296.

Maddi, S. R., Khoshaba, D. M., \& Pammenter, A. (1999). The hardy organization: Success by turning change to advantage. Consulting Psychology Journal: Practice and Research, 51, 117-124.

Maslow, A. H. (1970). Motivation and personality $\left(2^{\text {nd }}\right.$ ed.). New York: Harper \& Row.

McEvoy, G. M., \& Buller, P. F. (1987). User acceptance of peer appraisal in industrial settings. Personnel Psychology, 40, 785-797.

Mendelow, A. L. (1987). Stakeholder analysis for strategic planning and implementation. (pp. 176-191) in Strategic planning and management handbook, King, W. R., \& Cleland, D. I. (Eds.). New York: Van Nostrand Reinhold.

Milliman, J. F. \& Zawacki, R. A. (1994). Companies evaluate employees form all perspectives. Personnel Journal, 73, 99-103. 
Mitchell, T. R. (1983). The effects of social, task, and situational factors on motivation, performance and appraisal. In F. Landy, S Zedeck, \& J. Cleveland (Eds.), Performance measurement and theory. Hillside, NJ: Lawrence Erlbaum Associates.

Mohrman, A. M., Resnick-West, S. M., \& Lawler, E. E. (1989). Designing performance appraisal systems: Aligning appraisals and organizational realities. San Francisco: Jossey-Bass.

Mount, M. K., \& Judge, T. A. (1998). Trait, rater and level effects in 360-degree performance ratings. Personnel Psychology, 51, 557-576.

Nadler, D. A. (1977). Feedback and organization development: Using data-based methods. Reading, MA: Addison-Wesley Publishing.

Napier, R. W., \& Gershenfeld, M. K. (1999). Groups: Theory and experience $\left(6^{\text {th }}\right.$ ed.). Boston: Houghton Mifflin.

Nord, W. R. (1969). Beyond the teaching machine: The neglected area of operant conditioning in the theory and practice of management. Organizational Behavior and Human Performance, 4, 375-401.

Nyhan, R. C., \& Marlowe, H. A. (1997). Development of psychometric properties of the organizational trust inventory. Evaluation Review, 21, 614-637.

Patton, M.Q. (1997). Utilization-focused evaluation. Thousand Oaks, CA: Sage.

Pearce, J. L., \& Porter, L. W. (1986). Employee responses to formal performance appraisal feedback. Journal of Applied Psychology, 71, 211-218.

Peiperl, M. A. (2001). Getting $360^{\circ}$ feedback right. Harvard Business Review, 79, $142-147$.

Petri, H. L. (1986). Motivation. Belmont, CA: Wadsworth. 
Pfau, B.N. \& Kay, I.T. (2002). The human capital edge: 21 people management practices your company must implement (or avoid) to maximize shareholder value. New York: McGraw-Hill.

Pindyck, R. S., \& Rubinfeld, D. L. (1981). Econometric models and economic forecasts $\left(2^{\text {nd }}\right.$ ed.). New York: McGraw-Hill.

Pindyck, R. S., \& Rubinfeld, D. L. (1991). Econometric models and economic forecasts ( $3^{\text {rd }}$ ed.). New York: McGraw-Hill.

Porter, L. W., Steers, R. M., Mowday, R. T., \& Boulian, P. V. (1974). Organizational commitment, job satisfaction, and turnover among psychiatric technicians. Journal of Applied Psychology, 59, 603-609.

Rea, L. M. \& Parker, R. A. (1997). Designing and conducting survey research $\left(2^{\text {nd }}\right.$ ed.). San Francisco: Jossey-Bass.

Reilly, R.R., Smither, J.W., \& Vasilopoulos, N.L. (1996). A longitudinal study of upward feedback. Personnel Psychology, 49, 599-612.

Riggs, M. L., Knight, P. A. (1994). The impact of perceived group success-failure on motivational beliefs and attitudes: A causal model. Journal of Applied Psychology, 79, 755-755.

Romano, C. (1994). Conquering the fear of feedback. HR Focus, 71, 9-11.

Rogers, E., Rogers, W. W., Metlay, W. (2002). Improving the payoff from 360degree feedback. Human Resource Planning, 25.3, 44-54.

Rossi, P. H. \& Freeman, H. E. (1985). Evaluation: A systematic Approach. Beverly Hills, CA: Sage. 
Salam, S. \& Cox, J. F. (1997). In the eye of the beholder: How leadership relates to 360-degree performance ratings. Group \& Organization Management, 22, 185-209.

Schmidt, F. L. \& Hunter, J. E. (1977). Development of a general solution to the problem of validity generalization. Journal of Applied Psychology, 62, 529-540.

Schmidt, F. L., \& Hunter, J. E. (1981). Employment testing: Old theories and new research. American Psychologist, 36, 1128-1137.

Schmidt, F. L., Pearlman, K., Hunter, J. E., \& Hirsh, H. R. (1985). Forty questions about validity generalization and meta-analysis. Personnel Psychology, 38, 697-798.

Scriven, M. (1991). Beyond formative and summative evaluation. In M. W. McLaughlin \& D. C. Phillips (Eds.), Evaluation and education: At a quarter century. Chicago: University of Chicago Press.

Skinner, B. F. (1938). The behavior of organisms. New York: Appleton-Century.

Smith, P. \& Kendall, L. M. (1963). Retranslation of expectations: An approach to the construction of unambiguous anchors for rating scales. Journal of Applied Psychology, 27, 149-155.

SPSS, Inc (1999). SPSS base 10.0 applications guide. Chicago: SPSS.

Tabachnick, B. G. \& Fidell, L. S. (2001). Using multivariate statistics $\left(4^{\text {th }} \mathrm{ed}\right.$.). Needham Heights, MA: Allyn \& Bacon.

Tornow, W. W. (1993a). Editor's Note: Introduction to special issue on 360-degree feedback. Human Resource Management, v. 32, 211-219.

Tornow, W. W. (1993b). Perceptions or reality? Is multi-perspective measurement a means or an end? Human Resource Management, v. 32, 221-230. 
Tornow, W. W., London, M.. \& CCL Associates (1998). Maximizing the value of 360-degree feedback. San Francisco: Jossey Bass; Center for Creative Leadership.

Ulrich, D., Zenger, J, \& Smallwood, N (1999). Results-based leadership. Boston, MA: Harvard Business School Publishing.

Van Velsor, E., Taylor, S., \&Leslie, J. B. (1993). An examination of the relationships among self-perception accuracy, self-awareness, gender, and leaders effectiveness. Human Resource Management, 32, 249-263.

Waldman, D. A. (1997). Predictors of employee preferences for multirater and groupbased performance appraisal. Group \& Organization Management, 22, 264287).

Waldman, D. A., \& Atwater, L. E. (1998). The power of 360-degree feedback. Houston, TX: Gulf.

Walker, A. G., \& Smither, J. W. (1999). A five-year study of upward feedback: What managers do with their results matters. Personnel Psychology, 52, 393-423.

Wayne, S. J., Shore, L. M., \& Linden, R. C. (1997). Perceived organizational support and leader-member exchange: A social exchange perspective. Academy of Management Journal, 40, 82-111.

Whetzel, D. L., \& Oppler, S. H. (1997). Validation of Selection Instruments. In D. L. Whetzel \& G. R. Wheaton (Eds.), Applied measurement methods in industrial psychology. Palo Alto, CA: Davies-Black Publishing.

Whetzel, D. L., \& Wheaton, G. R. (1997). Applied measurement methods in industrial psychology. Palo Alto, CA: Davies-Black Publishing.

Wohlers, A. J. \& London, M. (1989). Ratings of managerial characteristics-evaluation difficulty, co-worker agreeement and self-awareness. Personnel Psychology, 42, 235-261. 


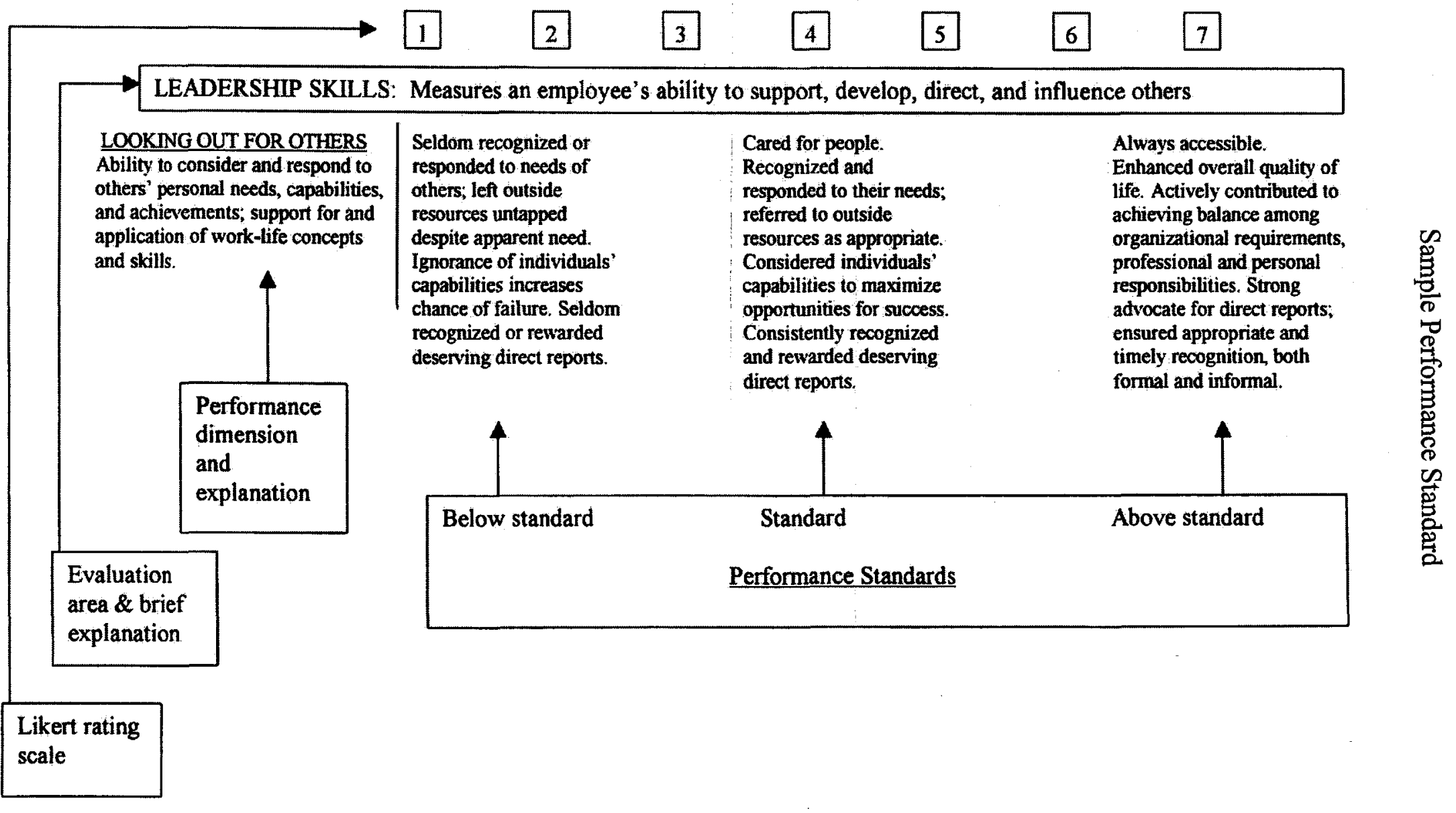


Appendix B

Performance Determinants

\section{Environment}

Job design

Supervision

Fellow workers

Compensation

Working conditions

Training

Evaluation

\begin{tabular}{|l|} 
Individual \\
\hline Ability \\
Motivation
\end{tabular}

Cummings \& Schwab, 1973 
Appendix C

Possible Effects of Feedback

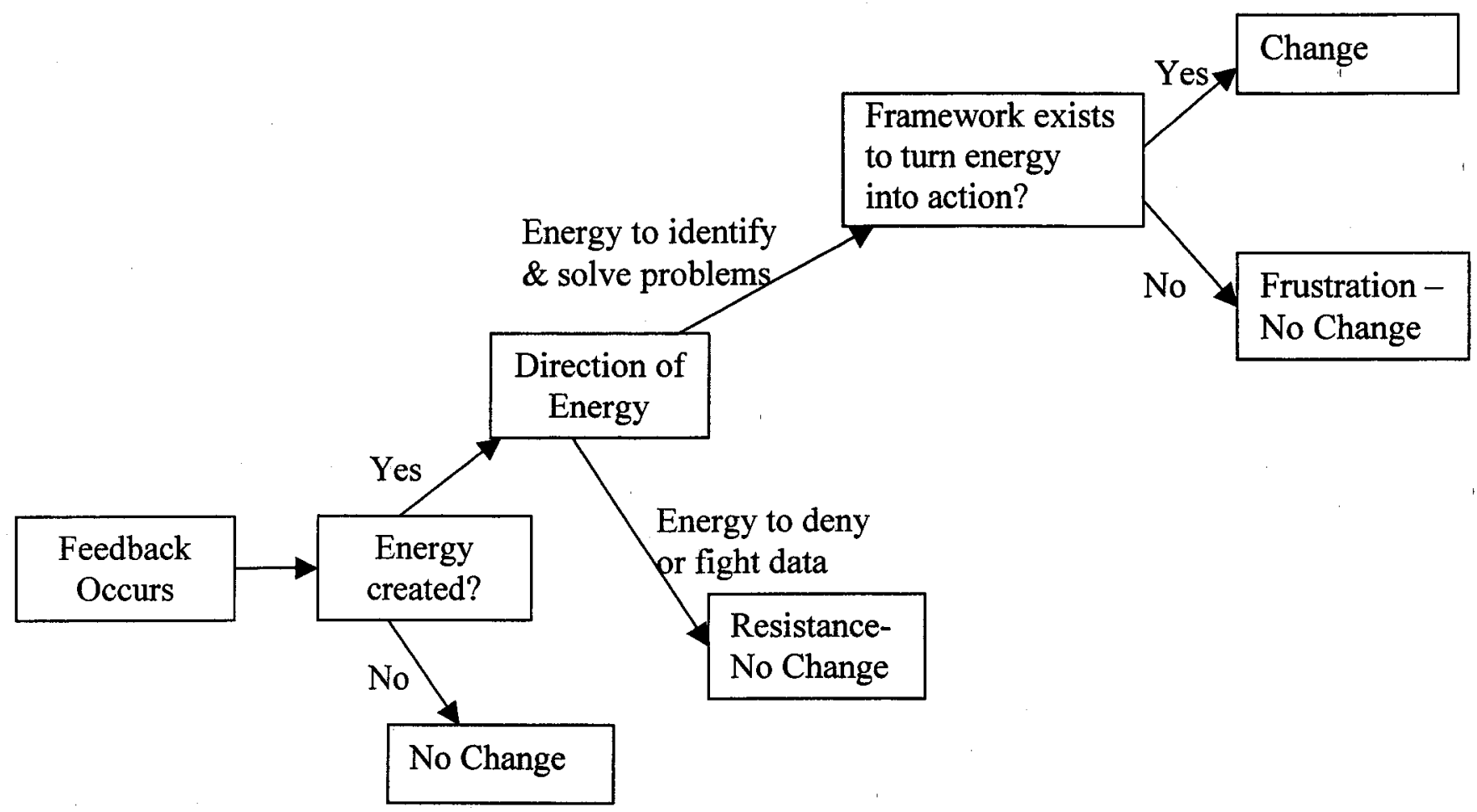

Nadler, 1977, p. 146 
Appendix D

360 Degret Fectback Orgaizational Clinate Suryey by Gres Stump

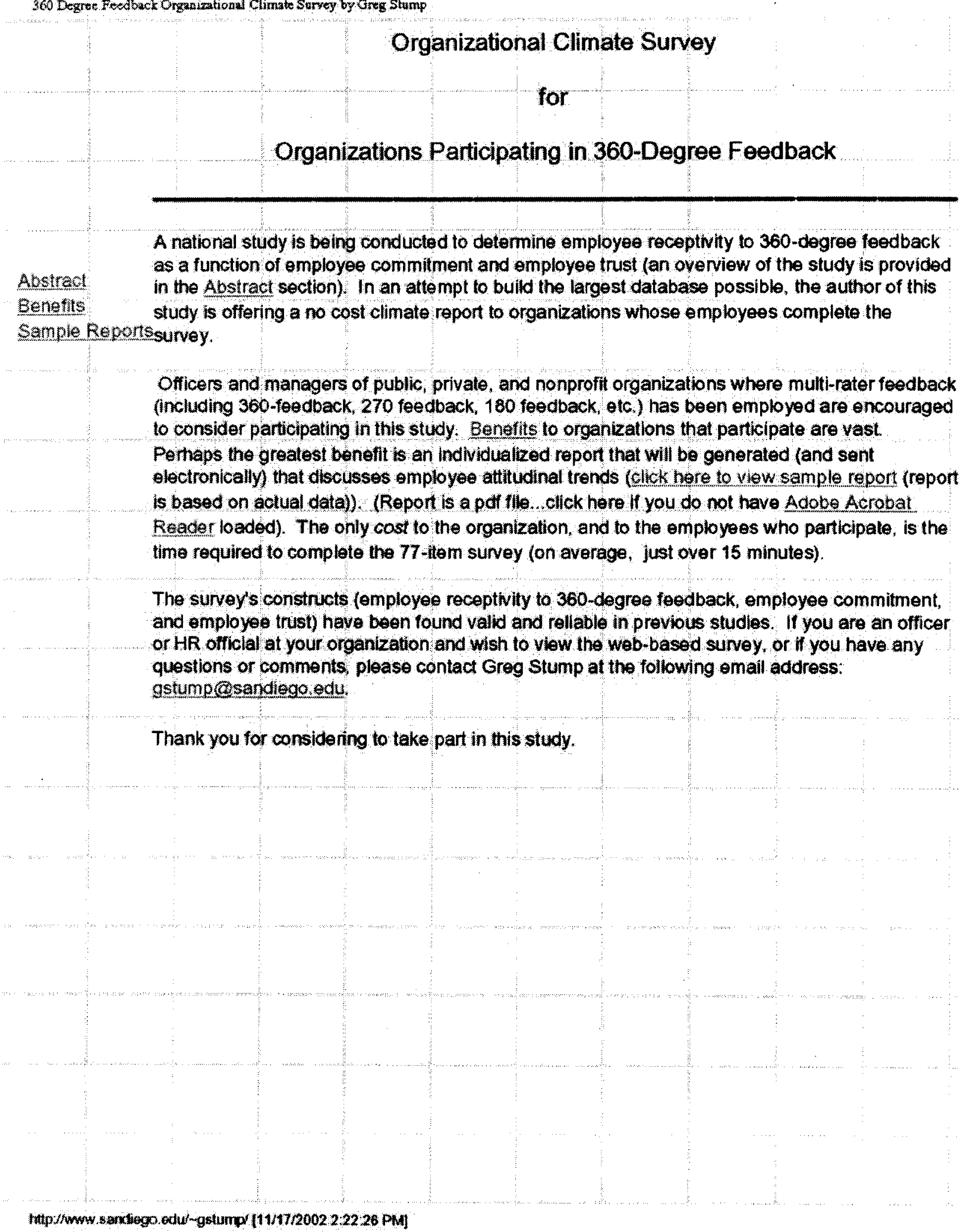




\section{Abstract}

As nations have moved from the industrial revolution to the information age, organizations have evolved as well. The structure and attitudes of current organizations no longer fit the past paradigms of bureaucracy and hierarchy. Many leaders today understand that participative management and utilization of teams will otten better cope with the incredible pace of change.

Today, one of the best examples of the organizational paradigm shift is the adoption of nontraditional appraisal systems, e.g., 360-degree feedback. Three hundred sixty degree appraisal systems, as the name implies, involve providing employees with feedback from multiple sources that may include peers, subordinates, customers, superiors, and self. This triangulation of data provides a more accurate perspective of employee performance and behavior.

This quantitative study is designed to develop a multiple regression model that will predict employee receptivity to 360 -degree feedback. The premise is that organizational cultures which are open to such an appraisal system will likely benefit from it. Receptivity will be compared using two organizational components, employee trust and employee commitment Various demographic elements will be included as independent variables.

Three hundred sixty degree systems are extremely expensive to implement if a strong relationship is found between employee receptivity to 360 -degree feedback and the aforementioned variables, an organization may better decide lf implementing such a system is worth the costs.

The alternate hypotheses are:

$H_{A 1}$. A relationship exists between the demographics (e.g., age, level of education, gender, race, income level, etc.) of an employee and his or her receptivity to 360 .

$H_{A 2}$ A relationship exists between employee trust and an employee's receptivity to 360 .

$H_{A 3}$ A relationship exists between employee commitment and an employee's receptivity to 360.

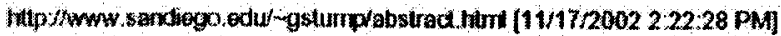


Newrige 1

\section{Benefits to Organizations}

Two types of benefits will be realized by organizations that participate in the study: Primary. benefits will occur within one month of the last survey being returned, and will allow managers to better understand how various cohorts view the organization. The power of the econometric model that will be used for this study cannot be overstated-ft will allow HR officials and managers to understand the degree of correlation between each demographic variable and two psychological variables: employee trust and employee commitment, keeping all other demographic variables constant. Secondary benefits will be realized by organizations after the study is completed. Secondary benefits will allow organizations to compare their workforce with the workforces of other organizations (the names of all organizations used in the study will be kept confidential).

Primary Benefits:

1. HR officials and managers will be able to determine overall employee commitment as a function of employee demographics (estimated coefficients will be calculated for each demographic variable). Employee commitment is measured using a 7 -item scale.

2. HR officials and managers will be able to determine overall employee trust as a function of employee demographics (same as above). Employee trust is measured using a 12item scale ( 8 items measure employee trust in supervisors; 4 items measure trust in the organization as a whole).

3. HR officials and managers will be able to determine overall employee receptivity to 360 as a function of employee demographics (same as above). Employee receptivity is measured on a 5 -item index.

\section{Secondary benefits:}

1. HR officials and managers will be able to compare the results from their organization with those of other organizations (the names of organizations and employees who take part in the study will remain confidential). The comparisons between organization types will be more reliable with a greater number of organizations taking part.

2. Organizations that take part will receive an electronic version of the study, once completed.

Note The constructs used in this research instrument (1.e, employee receptivity to 360 , employee commitment, and employee trust) have been taken from rigorous studies that were found to be psychometrically adequate (alpha factoring for the four constructs averaged above 9). Multiple regression models will be used to generate estimated coefficients, adjusted $R$ square, and $\mathrm{p}$-values for all mathematical models that would benefit organizations that take part in the survey. 
Sxuple Report (xmall organization)

Cllck here to view a sample report from a mid-sized organization model midsize.pdf

Click here to view a sample report from a small organization model small pdf

(Reports are based on actual data)

The reports are created as a PDF file. If you do not have Adobe Acrobat Reader and wish to download, click here- hitp/fwww.adobe:com/products/actobatreadstep. html

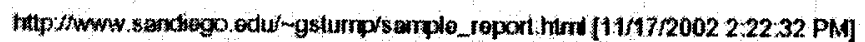




\title{
Appendix E
}

\author{
Data Interpretation \\ 360-Degree Feedback Study \\ [Company Name] - May 2002
}

Employee Receptivity to 360-Degree Feedback: The employee receptivity construct, as the name suggests, measures the degree of employee receptivity to 360-feedback. Employees are asked to answer five questions relating to performance improvement, skill improvement, faimess, accuracy of feedback, etc. as they relate of feedback provided from various entities, including supervisor, peers, direct reports, self, internal and external customens.

Following, a matrix provides the number of respondents who answered questions relating to each type of feedback source $(n)$, and the average score for each source $(1=$ least receptive to 360 feedback, 7 = most receptive to 360 feedback). For example, twelve employees indicated that a supervisor provides feedback, and the employees averaged a receptivity score of 5.9 out of a possible 7 .

\begin{tabular}{|c|c|c|c|c|c|c|c|}
\hline & Supervisor & Peers & \begin{tabular}{|l|} 
Direct \\
Reports
\end{tabular} & $\begin{array}{l}\text { Internal } \\
\text { Customers }\end{array}$ & $\begin{array}{l}\text { Extemal } \\
\text { Customers }\end{array}$ & $\begin{array}{l}\text { Self } \\
\text { Report }\end{array}$ & 360 \\
\hline$n=$ & 12 & 13 & 6 & 5 & & 13 & \\
\hline $\begin{array}{l}\text { Average } \\
\text { Score }\end{array}$ & 5.9 & 5.7 & 4.9 & 4.9 & & $5: 1$ & 5.6 \\
\hline $\begin{array}{l}\text { Standard } \\
\text { Deviation }\end{array}$ & .7 & . & 1.3 & 1.0 & & 7 & 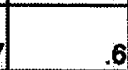 \\
\hline
\end{tabular}

- indieates fewer
than 3 respondents
answered questions
pertaining to this
element. In order to
maintain
confidentidity, results
will not be provided.

The data indicate employees are more receptive to feedback from supervisors and peers, and less receptive to feedback from internal customers and direct reports. The reader should be wary of data derived from feedback sources where $n$ is small (e.g., internal customers). Although $n$ is relatively small for all feedback sources, the reader may be well served to consider the overall size of [Company Name] (i.e, an $n$ of 12 or 13 is a large percentage of [Company Name]).

A standard distribution exists within the employee receptivity to 360 -feedback data. Please see histogram 1 on the following page.

There is a relatively minor relationship between employee receptivity and demographic variables such as education level, income, and the number of years participating in 360 . Only one demographic variable, age, was found to be significant $(p=.06$, adjusted $R-S q u a r e=38)$. The relationship between employee receptivity to 360 and age, in the case of [Company Name], is negative-the older the employee, the less receptive he or she will be to 360 feedback. Specifically: Employee receptivity $=6.74-.029$ (age). An employee who is 30 , for example, would generally score a $5.87(6.74-.029(30))$ where a 50 year-old employee would generally score a $5.29(6.74-(.029)(50))$. 


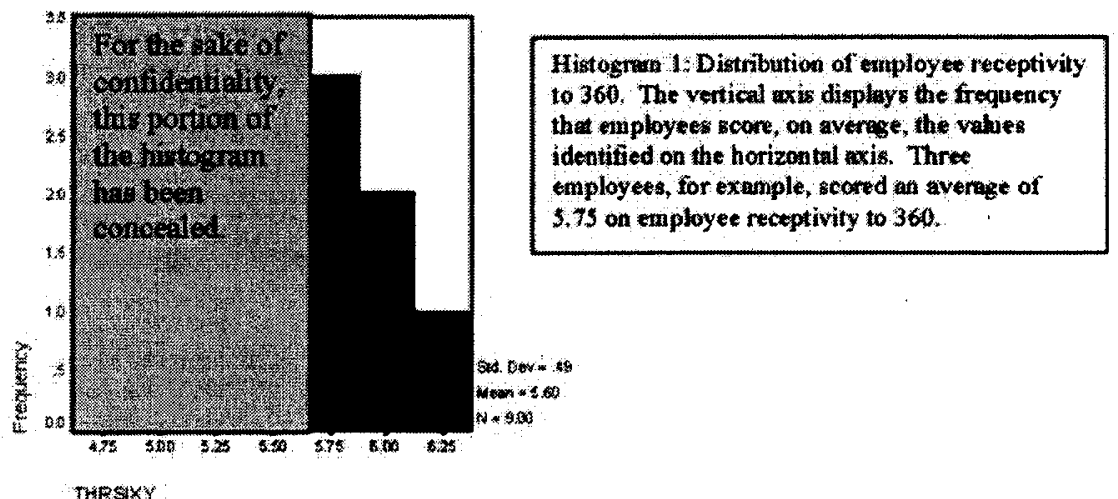

Employee Commitment: Employee commitment uses a 7-item construct to measure the level of commitment an employee has to hiv or her organization. Two of the items in this construct indude, "I am willing to pat in a great deal of effort beyond that normally expected in order to help my organization be snccessful", and, "I find that my valu and the values of $\mathrm{my}$ organization are very similar?. A 7.tem scale is used to measure responses $(1=$ strongly disagree, $7=$ strongly agree).

[Company Name] scored very high, on average, in employee commitment. The average score yas 62 with a 26 atandard deviation $(n=9)$. Due to the relatively high scores for all employees, no relationships were found between any demographic variable and employee commitment In order to maintain confidentially, no additional data or charts are provided.

Employee Trust: Employee trust is a 12-item construct that comprises two sub-constructs, employee trust in the supervisor ( 8 items) and employee tnus in the organization ( 4 items). The trust in supervisor subscale represents employee trust in what may be one of the most critical mediators of organizational complexity, an employee's immediate supervisor. The organizational trust subseale is designed to differentiate attitudes of trust toward the entire organization. An example of the trust in supervisor construct is, My level of confidence that (supervisor) is technically competent at the critical elements of his or her job is ". An example of the trust in organization construct is, "My level of confidence that this organization will treat me farly is "Scores are rated on a 7 -item scale ranging from 1 (nearly zero) to 7 (near 100\%).

The following matrix provides an overview of trust scoring:

\begin{tabular}{|l|r|r|r|}
\hline & frust (Supervisor) & Trust (Organization) & Trust (Total) \\
\hline $\mathrm{n}=$ & 6 & 9 & \\
\hline Average Score & 6.22 & 6.56 & 6.39 \\
\hline Standard Deviation & 0.45 & 0.51 & 0.39 \\
\hline
\end{tabular}

[Company Namel scored very high, on average, in trust. It appears that employees fend to tnust the organization more than their supervisor. Due to the relatively high scores provided by all employees, no relationships were found between any demegraphic variable and employee commitment. The following histograms may be used to compare trust (supervisor), inust (organization) and trust (overall - the total of both supervisor and organization) 


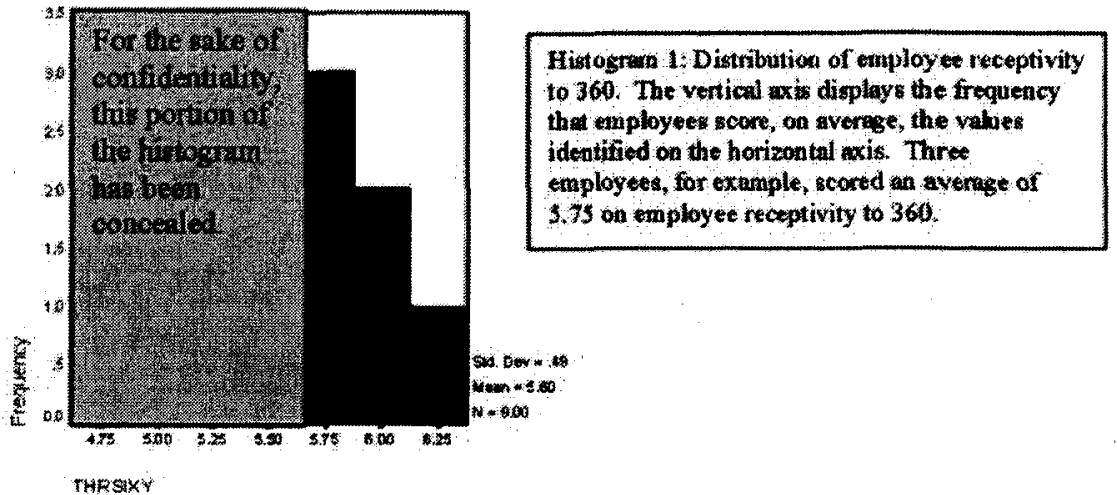

Employee Commitment: Employee commitment uses a 7 -item construct to neasure the level of commitment an employee has to lis or her organzation. Two of the items in this construct include, 4 am willing to put in a great deal of effort beyond that nomally expected in order to help my organization be snocessful", and, "I find that my value and the values of my organization are very similar". A 7 ittem seale is used to measure responses $(1=$ strongly disagree, $7=$ strongly agree).

[Company Name] sconed very high, on average, in employee commitnent. The average score was 62 with a 26 standard deviation $(n=9)$. Due to the relatively high scores for all employees, no relationships were found between any demographic variable and employee commitment. In order to maintain confidentially, no additional data or charts are provided.

Employee Trust: Employee trust is a 12-iten construct that comprises two sub-constructs, employee trust in the supervisor ( 8 items) and employee trust in the organization ( 4 items). The trust in supervisor subscale represents employee trust in what may be one of the most critical mediators of organzational complexity, an employee's immediate supervisor. The organizational trust subseale is designed to differentiate attitudes of trust toward the entire organization. An example of the trast in supervisor construct is, My level of confidence that (supervisor) is technically competent at the critical elements of his or her job is ". An example of the trust in organization construct is, My level of confidence that this onganization will treat me fairly is ". Scores are rated on 7 -item scale ranging from 1 (nearly zero) to 7 (near 100\%).

The following matrix provides an overview of trust scoring:

\begin{tabular}{|l|r|r|r|}
\hline & Trust (Supervisor) & Trust (Organization) & Trust (Total) \\
\hline Average Score & 8 & 9 & \\
\hline Standard Deviation & 6.22 & 6.56 & 6.39 \\
\hline
\end{tabular}

[Company Name] seored very high, on average, in trust. It appears that employees tend to trust the organization more than their sapervisor. Due to the relatively high scores provided by all employees, no relationships were found between any demographic variable and employee commitment. The following histograms may be used to compare trust (supervisor), trust (organization) and trust (overall - the total of both supervisor and organization): 


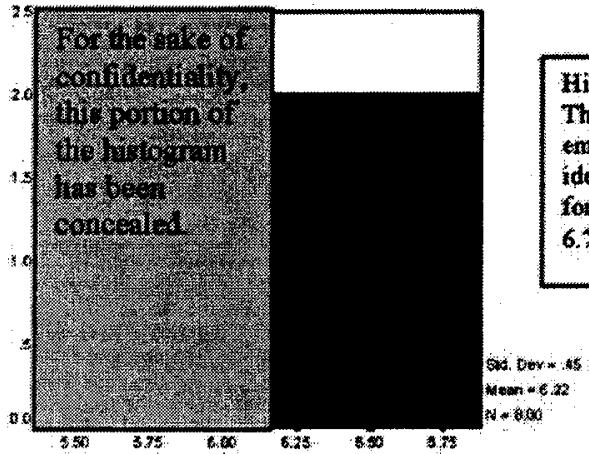

Histogran 2. Distribution of trust for aupervisor. The vertical axis diepleys the frecpuency that employees score, on averase, the values

identified on the trorizontal axis Two employees, for example, scored an werrige of $6.25,6.5$, and 6.75 on employee thist for supervisor.

TRUstMon

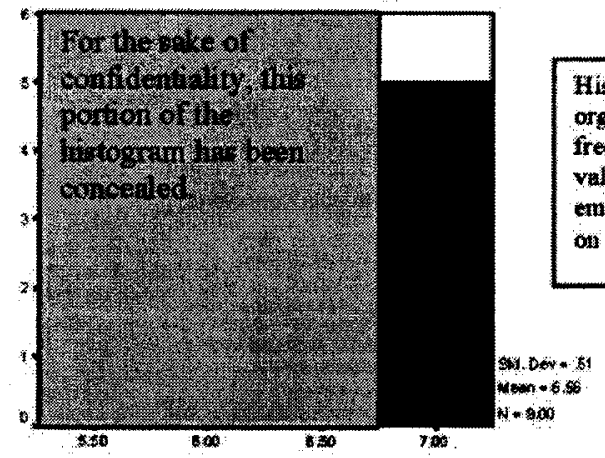

Histogram 3: Distribution of trust for reanization. The vertical axis displays the frequency that employ ees score, on nverage, the values identified on the horizontal axis. Five employ ees, for example scored wh average of 7.0 on employet trust for organization.

Telsonec

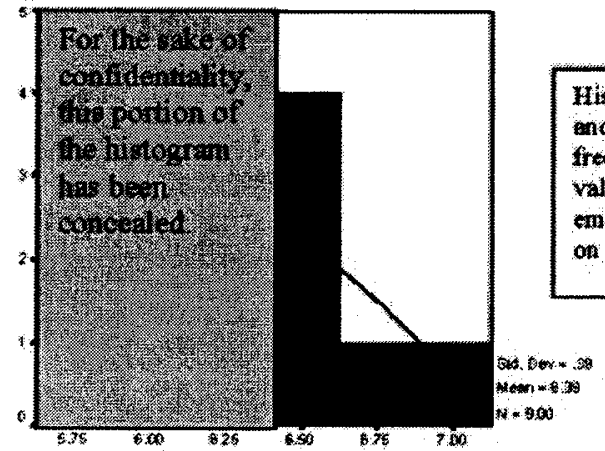

Histogran 4 /Distribution of trust for wapervisor nd organtion. The vertical ax is displays the frequency that eaployees sore, on averase, the values identified on the horizontal ax is. "Three. employees, for example, scered an average of 6.3 on employec trust for crganization

raustort 
Points to consider about employee commitment and employee trust:

Employees may be divided into three categories-committed, non-committed, and actively uncommitted. Committed employee are mentally, emotionally, and cognitively present. They are the $20 \%$ of your organization who complete $80 \%$ of the work (world class workgroups, however, often have a higher percentage of committed employees). Non-committed employees are productive some days, and not productive on others. Their performance varies. Actively uncommitted employees are psychological absent, but physically present. Often they are disruptive and do more harm than good. Analogously speaking, committed employees are owners, non-committed employees are renters, and actively uncommitted employees simply exist.

With tremendous resources, it is possible to convert approximately one-half of actively uncommitted employees into non-committed or committed employees. Often, however, it better serves an organization to attempt to help employees move from non-committed to committed. This may be done through various employee development tools (e.g., individual development plans, mentoring, coaching, etc.) and through open, honest communication.

A positive and significant relationship exists between employee commitment and both profitability and productivity.

Employee trust, for this study, was divided between two constructs -employee trust in supervisor and employee trust in organization. A positive and significant relationship exists between trust in supervisor and both employee innovative behavior and satisfaction with supervisor. A positive and significant relationship exists between organizational trust and both organizational commitment and retention. A supervisor's competence, benevolence, and integrity are the best predictors of employee trust for the supervisor. Employee trust in organization is correlated with perceived organizational support and justice. 


\title{
Appendix F
}

\author{
Data Interpretation \\ 360-Degree Feedback Study \\ [Organization]- Survey conducted August 2002
}

This report consists of three sections. The first section is a report of quantitative survey results for [Organization]. The second section provides an overview of how employee trust and employee commitment may relate to your organization. The final section is a qualitative overview of survey data statements offered by [Organization] employees who participated in the Intemet based 360 -degree feedback survey.

A total of 53 respondents took part in the survey. The response rate for the survey is approximately $19 \%$. Survey results, therefore, may not accurately portray general tendencies among [Organization] employees.

\section{Section I}

Employee Receptivity to 360-Degree Feedback: The employee receptivity construct, as the name suggests, measures the degree of employee receptivity to 360-feedback. Employees are asked to answer five questions relating to performance improvement, skill improvement, faimess, accuracy of feedback, etc. as they relate to feedback provided by various entities, including supervisor, peers, direct reports, self, internal and external customers. An employee who has three feedback sources, for example, would answer a total of 15 questions relating to receptivity to 360 ( 3 sources $X 5$ question/source $=15$ questions).

The following table provides the number of respondents who answered questions relating to each type of feedback source, and the average score for each source $(1=$ least receptive to 360 feedback, $7=$ most receptive to 360 feedback). For example, 52 employees indicated that a supervisor provides feedback, and the average receptivity score for these employees was a 5.0.

\begin{tabular}{|c|c|c|c|c|c|c|}
\hline & Supervisor & Peers & \begin{tabular}{|l|} 
Direct \\
Reports
\end{tabular} & $\begin{array}{l}\text { Internal } \\
\text { Customers }\end{array}$ & $\begin{array}{l}\text { Extemal } \\
\text { Customers }\end{array}$ & $\begin{array}{l}\text { Self } \\
\text { Report }\end{array}$ \\
\hline$n$ & 52 & 31 & 27 & 22 & 10 & 40 \\
\hline $\begin{array}{l}\text { Average } \\
\text { Score }\end{array}$ & 5.0 & 4.9 & 5.7 & 5.1 & 5.4 & 5.0 \\
\hline $\begin{array}{l}\text { Standard } \\
\text { Deviation }\end{array}$ & 12 & 14 & .8 & 1.0 & .8 & 8 \\
\hline
\end{tabular}

The data indicate employees are more receptive to feedback from direct reports and external customers, and less receptive to feedback from peers.

Figure 1, shown on the next page, provides the frequency of receptivity to 360 -degree feedback scores. The receptivity scores are calculated by averaging the receptivity scores, of all feedback sources, for each respondent. A respondent's receptivity score in this histogram, for example, would be a 5.0 if s/he provided answers that generated receptivity scores of $4.4,4.6,5.0$, and 6.0 for his or her feedback sources. 
Figure 1

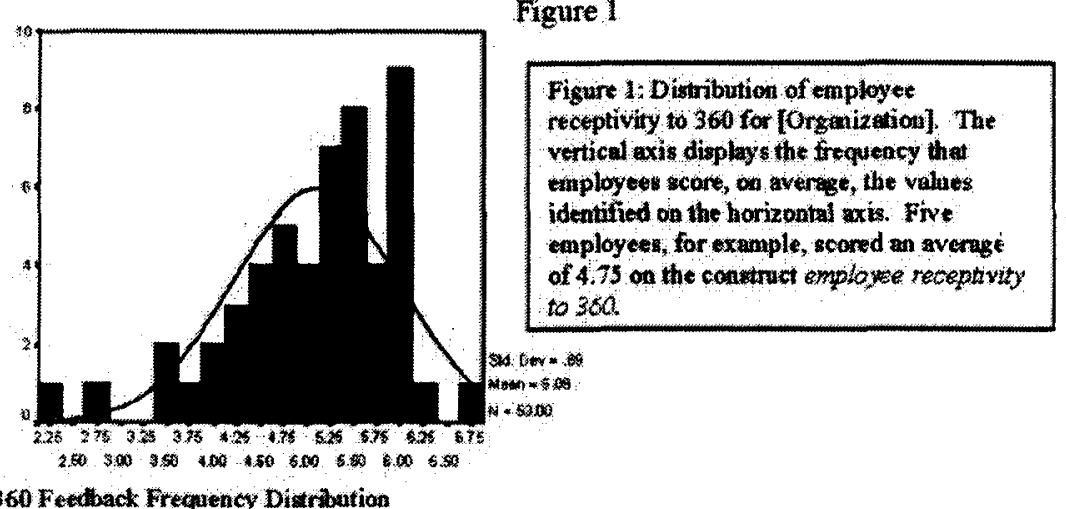

360 Feedlact: Frequency Diturbution

Eight multiple regression models were generated using employee receptivity to 360 -degree feedback as the dependent vanable. Nine independent variables were included in one or more of the multiple regression models, including, employee trust, employee commitment, age, gender, income, education level, position (e.g., executive management, middle managernent, etc), years participating in 360 , and year employed at [Organization]. The constructs employee trust and enployee commitment were measured using a seven point Likert index.

The best fitting multiple regression model used two of the nine independent variables, employee commitnent and income. Although employee commitment and income variables were statistically significant, only employee commitment was practically significant (i.e. small changes in employee commitment accounted for relatively large change in employee receptivity of 360-degre feedbach). For this model, adjusted R-Square $=344$ and p-values aqual .006 for income, and 000 for employee commitment: The model follows:

Employee receptivity to 360 feedback $=2.71-(.5 E-03($ income $($ in thousands $))+.5($ employee commitment)

The generated ooefficients may be read as follows. For every thousands of dollars in eamed income, a respondent's employee receptivity to 360 score decreases by .0075 (kecping all other variables constoni). Additionally, for every 1 point increase in employee commitment, employee receptivity to 360 scores will increase by 5 point (keeping all other wariables constomit.

If a respondent, for example eaned $\$ 65,000$ year and scored 5,8 on employee commitnent, we wolld estimate she would ecore 5.12 on employee receptivity to 360 (Employee receptivity to $360=2.71-(7.5 \mathrm{E}-03)(65))+.5(5.8)=2.71-.488+2.9=5.12)$.

Employee Commitment: Employee commitment consists of a 7-item construct that measure the level of commitment an employee has to his or her onganization. Two of the items in this eonstruct, for example, include, "I am willing to put in a great deal of effort beyond that normally expected in order to help my organization be successful", and, "I find that my values 
and the values of my organization are very similar". A 7-item scale is used to measure responses $(1=$ strongly disagree, 7 = strongly agree).

On average, survey respondents scored 5.75 on the employee commitment construct (standard deviation $=.94$ )

A total of two correlation matrices and sixteen multiple regression models were generated during employee commitment data interpretation. Four independent variables were found to be statistically significant (i.e., $p$-value $=<.15)$. They include income $(p$-value $=009)$, receptivity to 360 score $(p$-value $=.000)$ employee category $(p$-value $=.008)$, and education ( $p$-value $=$ .135). Adjusted R-square for this model $=.325$.

Income and receptivity to 360 feedback questions were asked in such a way as to produce continuous data. Specifically, respondents provided the year in which they were born and their income, versus selecting their age and income from a range of possible ages and income. Employee category and education, on the other hand, are discrete variables. Discrete variables are much less fluid; possible responses for discrete variables are not as smooth compared to continuous variables. An income (a continuous variable in this study) of $\$ 50,000$, for example, is exactly one-half of an income of $\$ 100,000$. It's typically less intuitive to compare discrete variables in econometric modeling, for example, discussing the difference in education (e.g., a BS vs. an MS), or a position of middle management vs. an entry-level management position. Unlike the income example, it's very difficult to quantify differences between a BS and an MS.

Binary or "dummy" variables must be used when including discrete variables in econometric modeling. Unfortunately; the limited number of observations (i.e., survey responses) precluded the use of each response possibility for the employee category and education variables. The employee calegory construct, which comprised a total of 7 possible responses (i.e., executive management, middle management, entry-level management, clerical, production (including trade or craft), professional (professor, doctor, teacher, nurse, etc.), and other), had to be reduced to two binary variables-management and non-management employees. Management employees include executive, middle, and entry level. Non-management employees consist of all other categories listed above. The education variable, which initially comprised a total of 8 possible responses, was reduced to three binary variables. They include less than a bachelors degree, a bachelors degree, and more than a bachelors degree. The final employee commitment multiple regression model is as follows:

$\mathrm{EMPCOM}=1.67+.64(360 \mathrm{score})+9.95 \mathrm{E}-03(\mathrm{NNC})+.54(\mathrm{MGT})-.43(\mathrm{BS})-.57(\mathrm{BS}+)$

Where:

EMPCOM = Employee commitment

360 score $=$ average employee receptivity to 360 score

$\mathrm{INC}=$ annually income (in thousands)

MGT $=1$ if manager (executive, mid, entry level), 0 if not

$\mathrm{BS}=1$ if highest education equals bachelors degree, 0 if not (i.e., highest education level is less

than or more than a bachelors)

$\mathrm{BS}+=1$ if highest education equals a masters or higher, 0 if not 
In general terms, this model tells os that a higher scores in receptivity, and the greater the income of a respondent, the greater the employee commitment score. Additionally, managers tend to have higher employee commitment scores compared to other employees. Finally, the greater the edncation, the lower employee commitment scores tend to be.

To better understand this model, it may be best to provide an example. Let's assume, for example, that an employee scored a 5.5 on the receptivity to 360 constnet, made $\$ 45,000$ in salary last year, was a mid-level manager, and has a bachelors degree. We would calculate this employee would score a 53 on the employee commitment construct (EMPCOM $=1.67+$ $.64(5.5)+.00995(45)+.54(1)-.43(1) \cdot .57(0)=1.67+3.52+.54-.43=5.3)$.

Employee Trust: Employee trust is a 12-item construat that comprises two sub-construets, employee trust in the supervisor (8 items) and employee trust in the organization ( 4 items). The trust in supervisor subscale represents employee triat in what may be one of the most critical mediators of organizational complexity, an employee's immediate supervisor. The organizational trust subscale is designed to differentiate attitudes of trust toward the entire organization. An example of the trust in supervisor construct is, My level of confidence that (supervisor) is technically competent at the critical elements of his or her job is ".". An example of the trust in organization construct is, My level of confidence that this organization will treat me fairly is ". Scores are rated on a 7 -iten scale ranging from 1 (nearly zero) to 7 (near 100\%).

The following matrix provides an overvew of trust sconing:

\begin{tabular}{|l|r|r|r|}
\hline & Trust (Supervison & Trust (Oroanization) & Trust (Tota) \\
\hline $\mathrm{n}=$ & 53 & 53 & 53 \\
\hline Average Score & 54 & 4.9 & 5.2 \\
\hline Standard Deviation & 111 & 8 & 0.8 \\
\hline
\end{tabular}

It appeare [Organization] employees tend to trust supervisors more than the organization. No relationships were found between any demographic variable and employee trust. The following histograms may be used to compare trust (supervison), trust (organization) and trust (overall - the total of both supervisor and organization):

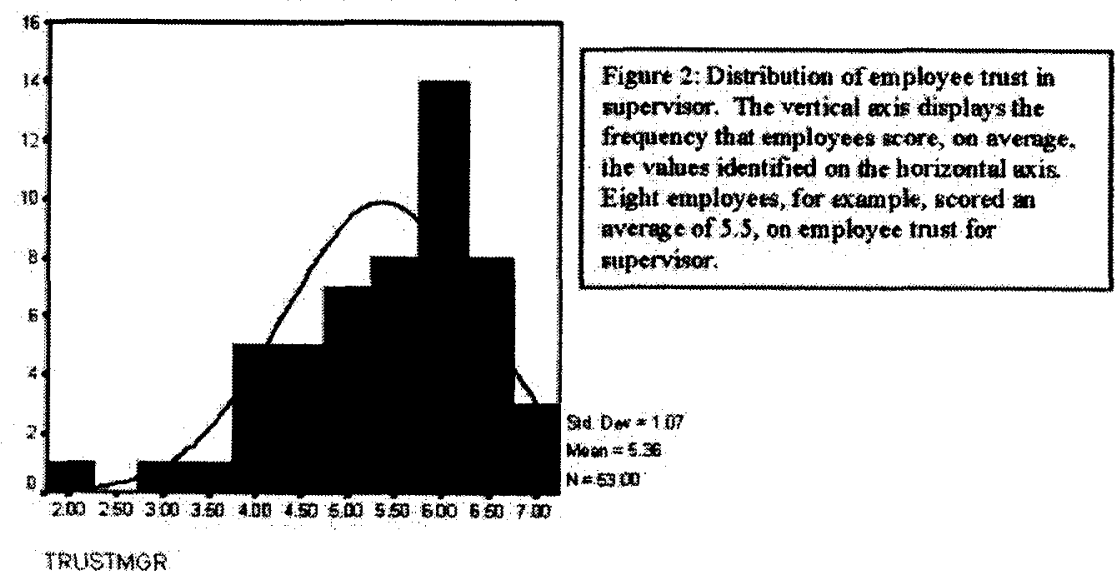



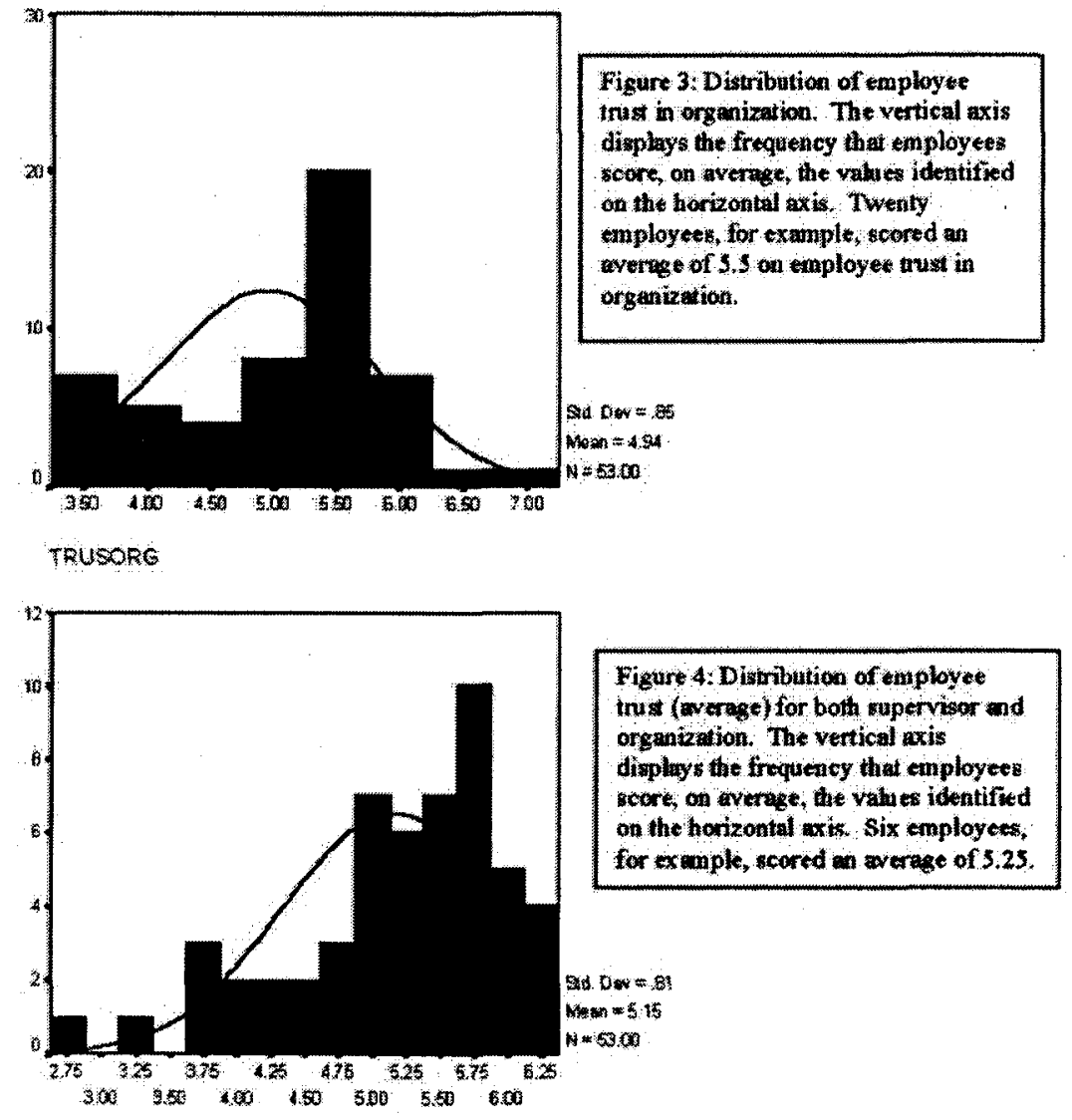

TRuston

Section II: How employee commitment and employee trust relate to organizations.

Emplove Commitment: Employees can be divided into three categories-committed, not committed, and actively uncommitted. Committed employees are emotionally, mentally, and intellechally connected to the orgarization. they go above and beyond what is expected. Typically, committed employes comprise $20 \%$ of the onganization, and they complete $80 \%$ of the work. World-class workgroups, however, generally have a higher percentage of employees who are committed. Employees who are not committed typically may or may not be productive - their performance fluctuates depending on the day. Actively uncommitted employee are generally disconnected from the organization-they are physically present but cognitively and enotionally absent. 
Generally speaking, approximately one-half of actively uncommitted employees can develop a heal thy, organizationally committed mentality. Such a transformation, however, typically requires tremendous resources on the part of the organization and much effort on the part of the employee. In many cases, it better serves an organization to provide interventions that will help non-committed employees transform into committed employees. Individual development planning, mentoring, and other human resources interventions, as well as honest communication with non-committed employees, may help such employees become more engaged in the workplace.

There is a direct link between employee commitment and both profitability and productivity.

Emplovee Trust: Trust; in this study, is considered from two perspectives-employee trust as it relates to the supervisor, and employee trust as it relates to the organization. A positive relationship exists betwen employee trust in supervisor and increased innovative behavior and satisfaction with supervisor. A positive relationship exists between employee trust in organization and both organizational commitment and lower retention. $A$ positive and significant relationship exists between trust in ones supervisor and trust in organization. Trust in supervisor relates more to a supervisor's ability, benevolence, and integrity, whereas trust in organization relates to perceived organizational support and justice.

Employee trust does not simply occur. An environment conducive to trust must exist in order for employees to increase trust in both the supervisor and the organization.

Section III: Qualitative data.

The following comments were provided by [Organization] employees who participated in this research. Certain words were deleted to help ensure anonymity among respondents.

-I have only undergone a 360-feedback for myself once in 19 [deleted]. This year starts a new organizational requirement of having a personal skills assessment (very similar to a 360 ) at least once every 2 years

-I am quite opposed to the use of 360 data that is required to be shared with ones supervisor. This seems like a poor mechanism to receive input, especially initial input, from one's peers, etc. In an organization with a high level of trust, it might work, but I have not had contact with any organization that has that across the board.

-There are always personnel and personal issues that interfere and affect the input one receives.

-360 data given confidentially to the individual can be quite helpful. The surveys need to be designed by those who know how to do it and know what information needs to be obtained. Instead, it seems that organizations think anyone can do the survey form, which can make the results meaningless or frustrating.

-Until people employ processes like the 360 or staff development process with the right (honorable) motives, it is only another process than is exploited for the greater good of the few who use it for their advantage. 
-360 feed back has been a great improvenent, however I get frustrated when I am asked for my feedback on an individual and then see no change if I have a frustration. It would be good if somehow it could be commmicated that your concems were dicussed and are being addressed or were not chosen as a prionity. because there are times when completing these that I think "what's the use nothing will change any way"!

for me, this has been a wonderful and challenging place to be, including every position I have held in more than [deleted] years. The folks here largely competent, open and well balanced in life.

-The 360 is a good concept if the data is actually used to improve things, but when it is used repeatedly and nothing ever changew it becomes more of a hindrance to the organization than a useful tool. "ve seen employee moral plummet each time they are asked to do the 360 because they have come to expect that nothing will be done to address the "poop piles" that exist within the organization.

-It was difficult to answer one of the questions becanse the first time the 360 is just for yon to see, the following times the data is "owned" by both you and your supervisor.

-What does the year I was born and how much money I make have anything to do with the 360 ? Answer: This is a good quextion. Please visit my website (wow sandiego.edu gsamp) if you wish to see the relotionships I'm exploring. Basically, I'm attempting to see if there are relationships between receptivity to 360 and the following atems amployee commitment employee trixt, achucation lewel, age, income, ethicity, years participating in 360 , gender, etc.

1 would be interested in the results.

-1 work for an Office that is part of a Department that is part of a Division that is part of a Unversity. The Offic is $A O K$, even tops. The Department is not. The Division is adequale. The Unversity is top noteh In answering the questions I tended to relate my evaluations to the bottom two tiers, difficult since I an quite positive aboul one and quite negative about the other.

-360 feed back is usefil but; I believe too much personality conflict and hidden agendas from management can cloud the feedback and render it useless. Hidden agendas will supercede any good feedback and accentuate any negative for whatever purpose management has in mind at the time. One [mistake] will wipe out 10 [superior accomplishment] and become major fodder for hidden agendas, especially at raise time. Long-term employees are discriminated against and not revered for their wealth of knowledge. At times they are shumed by much younger supervisors who think they "know it all".

The Organization preaches tras, honesty, etc, however what they preach and put into action isn't the same.

END OF REPORT ****** I extend a dep felt "thank you" to [Organization] and the employe who participated in this survey. If you have comments or questions, please contact me at. gstumplosandiego.edu. With warmest regards, Greg Stump. 


\section{Appendix G}

\section{Psychological Androgyny}

\section{The Construct of Psychological Androgyny}

Psychological Androgyny is a leadership style construct that is measured by a sexrole inventory that treats masculinity and femininity as two independent dimensions. The concept of masculinity and femininity as it relates to sex-role inventory, however, is not gender specific. Using this concept, it is possible to characterize a person as masculine, feminine, or neutral as a function of the difference between his or her masculine and feminine characteristics (Bem, 1974).

The leadership style construct consists of three sex types (masculine, feminine, and neutral), each represented by 12 traits. The original psychological androgyny construct comprised 20 traits each for the three sex types, and was introduced as the Bem Sex-Role Inventory (BSRI) (Bem, 1974). The 36 traits used for this study (12 traits $\mathrm{X} 3$ sex types) all relate to leadership activities, and have been found to be statistically reliable and valid (Cann \& Siegfried, 1987; Cann \& Siegfried, 1990). The construct uses a 7-point scale for 36 traits (i.e., items) that describe the participant. The scale ranges from 1 ("Never or almost never true") to 7 ("Always or almost always true"). Respondents receive three major scores: a masculine score, a feminine score, and a neutral score. Scoring was calculated by totaling the responses of the 12 items in each of the three categories. Reliability scores in Cann \& Siegfried studies $(1987,1990)$ range between .75 and .86 .

Demographic information was used as independent variables in the mathematical model (age, gender, years of 360 participation, job position, education, race, and 
income). The author collapsed several of the discrete demographic variables (e.g., education) in order to preserve degrees of freedom in the regression models.

\section{Deletion of Psychological Androgyny}

The construct of psychological androgyny was deleted as an independent variable for two reasons. The first reason was purely practical; the construct increased the instrument length by 36 items, and managers simply would not permit it to be introduced into their workforce. In order to increase the probability of securing organizations to participate, the survey had to be shortened.

The second reason psychological androgyny was deleted was because the pilot group thought some of the words used in the instrument, to describe personal behaviors, were difficult to self score. More importantly, a factor analysis performed on the responses provided by the pilot group yielded disturbing results. Specifically, only four or fewer of the 12 items that were part of each of the three elements of the construct (masculine, feminine, and neutral) hung together. The masculine element of psychological androgyny, for example, generated factor analysis correlation scores from .919 to -.0468 for the first correlation loading. Three of the items, independent, assertive, and confident, generated factor analysis scores that were high and positive $(.919, .822$, and .945 , respectively). In this same loading, however, the attributes aggressive, forceful, and autocratic generated negative correlation scores $(-.0468,-.204$, and -.021$)$.

Once a factor analysis matrix was generated, three additional steps determined that four or fewer items in each of the three psychological androgyny elements were statistically related. The three steps include (SPSS, 1999): 
1. Eliminate variables with less than a .75 correlation value with any other single variable.

2. Calculate factor loading

3. Generate a rotated component matrix to determine items that were related Consequently, the psychological androgyny construct was deleted from this study. 
Appendix $\mathrm{H}$

300-Dogret Fetalack Surrey

\section{0-Degree Feedback Survey}

\section{Thank You in Advance for Completing this Survey}

As mentioned in the email you received, your anonymity regarding this survey is guaranteed. It is not possible to link respondents with individual surveys that are submitted.

To whom do you provide 360-degree feedback? (Please mark "Yes", "No", or "Not applicable" for each response listed. Please write a response for number 5, if applicable.):

1. Your supervisor or boss?
O Yes
O No
O Not applicable

2. Your peers?
$O$ Yes
O No
O Not applicable

3. Your direct reports (direct reports are those employees whom you supervise or manage)? 


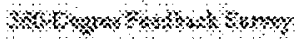
Oें\%:
1. Wis

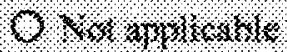

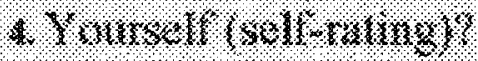
$0 \%:$
oxos

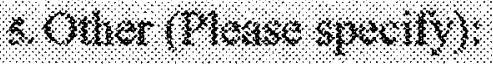

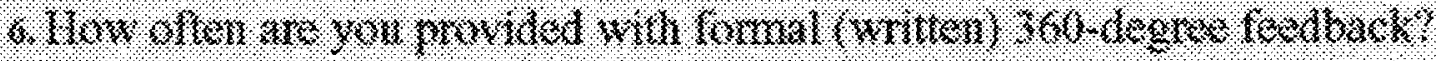

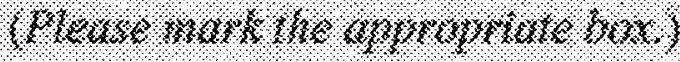

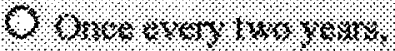

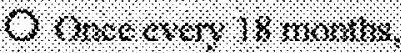

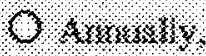

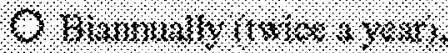

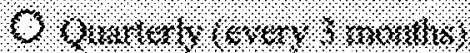
O $0: \mathrm{m}: \mathrm{s}$

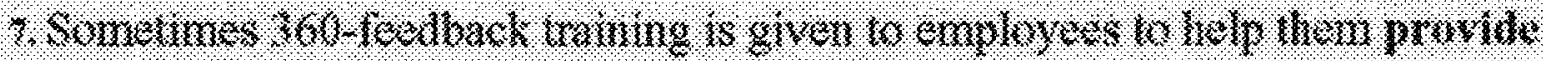

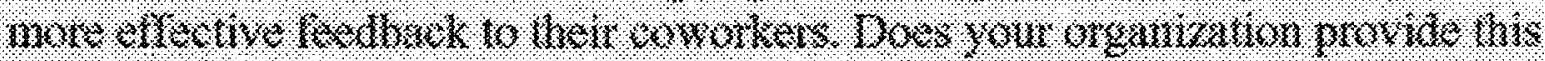

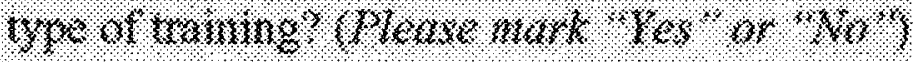
$0 \times 1 \times 8$
O *is:

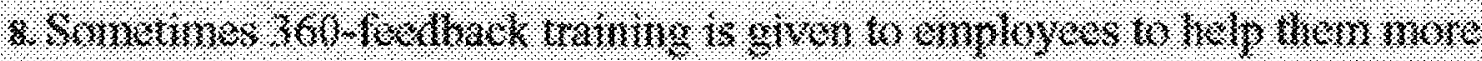

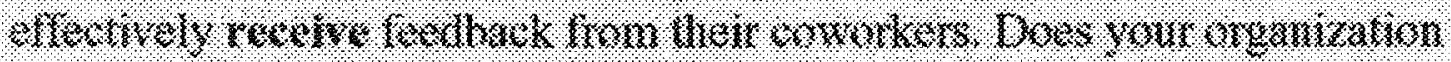

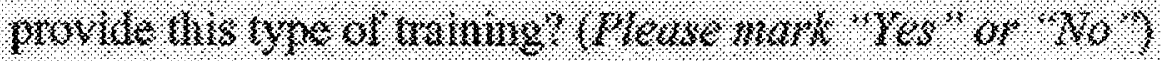

0 \%ex

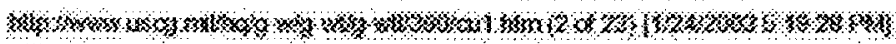


360-Degree fendback survey

O No

9. Does your organization use the results of 360-degree feedback as justification for human resource actions such as pay increases, promotions, transfers, terminations, etc?
O Yes
O No

10. Does your supervisor or manager have access to your 360 -degree results?
O Yes
O No
Not applicable, I don't have a supervisor or manager

I am interested in knowing how much you agree or disagree with several statements that follow. A 7-point scale follows each statement. Please identify your response for each question.

11. Does your supervisor evaluate you? (Please mark "Yes", "No", or "Not applicable")

$O$ Yes (Ifyes, please proceed to question 12)

O No (If no, please proceed to question 17 )

O Not applicable, I have no supervisor (If not applicable, please proceed to question 17)

The following 5 items relate to your supervisor. Please read each statement and respond accordingly.

12. The appraisal data I received from my supervisor will help improve my

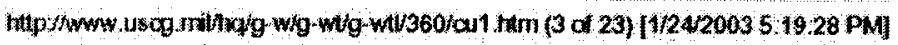


30 -Degrete Feduack Survey.

performance:
O Strongly Disagree
$O$ Disagree
O Slightly Dísagree
O Neutral
O Slightly Agree
O Agree
O strongly Agree

13. The appraisal data that I received from my supervisor will help improve my skills:
O Strongly Disagree
O Disagree
O Slightly Disagree
$O$ Neutral
O slightly Agree
$O$ Agree
O Strongly Agree

14. My supervisor is in the best position to evaluate certain aspects of my performance:
Strongly Disagree
O Disagree
O Slightly Disagree
O Neutral
$O$ slightly Agree
O Agree
O Strongly Agree

15. The use of my supervisor to appraise my performance is a fair method of appraisal for this job:

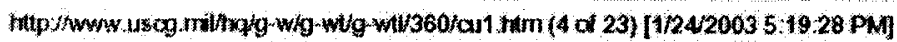




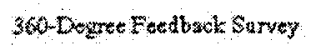

Strongly Disagree

O Disagree

Slightly Disagree

Neutral

O Slightly Agree

$O$ Agree

O Strongly Agree

16. The appraisal feedback I received from my supervisor accurately reflects my performance on the job:
Strongly Disagree
O Disagree
O slightly Disagree
O Neutral
O Slightly Agree
O Agree
Strongly Agree

17. Do your peers evaluate you? (Please mark "Yes", "No", or "Not applicable")

Yes (I/yes, please proceed to question 18)

$O$ No (If no, please proceed to question 23 )

Not applicable, I have no peers (If not applicable, please proceed to question 23)

The following 5 items relate to your peers. Please read each statement and respond accordingly.

18. The appraisal data I received from my peers will help improve my performance:
O Strongly Disagree
Disagree
Slightly Disagree

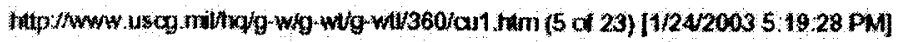


360-Dezer Feaduak Survey

O Neutral

O slightly Agree

O Agree

O Strongly Agree

19. The appraisal data that I received from my peers will help improve my skills:
O strongly Disagree
O Disagree
O slightly Disagree
O Neutral
O Slightly Agree
O Agree
Strongly Agree

20. My peers are in the best position to evaluate certain aspects of my performance:
Strongly Disagree
O Disagree
0 slighily Disagree
O Neutral
O slightly Agree
O Agree
O Strongly $A$ gree

21. The use of my peers to appraise my performance is a fair method of appraisal for this job:
Strongly Disagree
O Disagree
0 slightly Disagree
$O$ Neutral
O slightly Agree
$O$ Agree

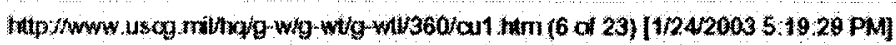




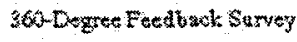

O Strongly Agree

22. The appraisal feedback I received from my peers accurately reflects my performance on the job:
Strongly Disagree
O Disagree
O slightly Disagree
O Neutral
O slightly Agree
O Agree
$O$ strongly Agree

23. Do your direct reports evaluate you (direct reports are employees whom you supervise or manage)? (Please mark "Yes", "No", or "Not applicable")
Yes (If yes, please proceed to question 24 )
$\mathrm{O}$ No (If no, please proceed to question 29)
O Not applicable, thave no direct reports (If not applicable, please proceed to question 29)

\section{The following 5 items relate to your direct reports. Please read each statement and respond accordingly.}

24. The appraisal data I received from my direct reports will help improve my performance:
O Strongly Disagree
O Disagree
O slightly Disagree
O Neutral
O Slightly Agree
O Agree
$O$ strongly Agree

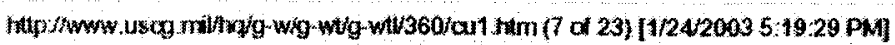


300-Dogre Fetatadk Survey

25. The appraisal data that I received from my direct reports will help improve my skills:
O Strongly Disagree
$O$ Disagree
O Slightly Disagree
O Neutral
O Slightly Agree
$O$ Agree
$O$ Strongly Agree

26. My direct reports are in the best position to evaluate certain aspects of my performance:
S Strongly Disagree
O Disagree
$O$ slightly Disagree
O Neutral
$O$ slightly Agree
$O$ Agree
O Strongly Agree

27. The use of my direct reports to appraise my performance is a fair method of appraisal for this job:
O Strongly Disagree
$O$ Disagree
O slightly Disagree
$O$ Neutral
$O$ slightly Agree
O Agree
O Strongly Agree

28. The appraisal feedback I received from my direct reports accurately reflects my performance on the job:

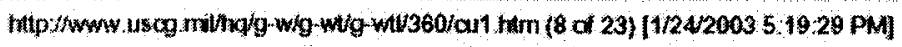


360-Degref Fetilack Survey
O Strongly Disagree
O Disagree
Slightly Disagree
O Neutral
O slightly Agree
O Agree
O Strongly Agree

29. Do your internal customers evaluate you? (Internal customers in this case are coworkers for whom you provide a service or product, but who do not work in your department or division.) (Please mark "Yes", "No", or "Not applicable")

Yes (Ifyes, please proceed to question 30 )

No (If no, please proceed to question 35 )

Not applicable, I have no internal customers (If not applicable, please proceed to question 35)

\section{The following 5 items relate to your internal customers. Please read each statement and respond accordingly.}

30. The appraisal data I received from my internal customers will help improve my performance:
Strongly Disagree
O Disagree
O Slightly Disagree
O Neutral
O Slightly Agree
$O$ Agree
$O$ Strongly Agres

31. The appraisal data that I received from my internal customers will help improve my skills: 
360 Dogrec Feedbed Survey
O strongly Disagree
O Disagree
O Slightly Disagree
O Neutral
O Slightly Agree
O Agree
O strongly Agree

32. My internal customers are in the best position to evaluate certain aspects of my performance:
O Strongly Disagree
O Disagree
O slightly Disagree
O Neutral
O slightly Agree
O Agree
O strongly Agree

33. The use of my internal customers to appraise my performance is a fair method of appraisal for this job:
Strongly Disagree
$O$ Disagree
O slightly Disagree
O Neutral
O slightly Agree
$O$ Agree
Strongly Agree

34. The appraisal feedback I received from my internal customers accurately reflects my performance on the job:
$O$ Strongly Disagree
O Disagree

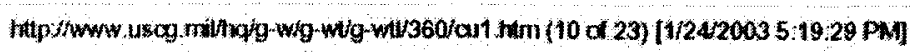


$360-$ begree Fetdvack Survey
0 slightly Disagree
O Neutral
O slightly Agree
O Agree
O Strongly Agree

35. Do your external customers evaluate you? (External customers in this case are customers who do not work in your organization, and who purchase products or senvices from your organization.) (Please mark "Yes", "No", or "Not applicable")

O Yes (f yes, please proceed to question 36 )

$\mathrm{O}$ No (I/ no, please proceed to question 4I)

O Not applicable, I have no extemal customers (If not applicable, please proceed to question 4I)

\section{The following 5 items relate to your external customers. Please read each statement and respond accordingly.}

36. The appraisal data I received from my external customers will help improve my performance:
O Strongly Disagree
O Disagree
O Slightly Disagree
O Neutral
O Slightly Agree
O Agree
$O$ Strongly Agree

37. The appraisal data that I received from my external customers will help improve my skills:

$$
\text { O Strongly Disagree }
$$


360-1Xegrec Fetdiack Survey

O Disagree

O Slightly Disagree

O Neutral

Slightly Agree

O Agree

O Strongly Agree

38. My external customers are in the best position to evaluate certain aspects of my performance:
$O$ Strongly Disagree
O Disagree
O slightly Disagree
O Neutral
Slightly Agree
O Agree
O Strongly Agree

39. The use of my external customers to appraise my performance is a fair method of appraisal for this job:
O Strongly Disagree
O Disagree
Slightly Disagree
$O$ Neutral
O Slightly Agree
$O$ Agree
$O$ strongly Agree

40. The appraisal feedback I received from my external customers accurately reflects my performance on the job:
$O$ strongly Disagree
0 Disagree
Slightly Disagree

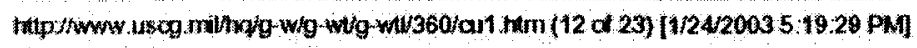


360 - Degre Fetdiack Survey

O Neutral

Slightly Agree

$O$ Agree

Strongly Agree

41. Do you evaluate yourself (a self rating)? (Please mark "Yes" or "No")

0 Yes (Ifyes, please proceed to question 42)

O No (I no, please proceed to question 47 )

The following 5 items relate to you. Please read each statement and respond accordingly.

42. The appraisal data that I provide for myself will help improve my performance;
Strongly Disagree
O Disagree
$O$ slightly Disagree
O Neutral
$O$ Slightly Agree
O Agree
Strongly Agree

43. The appraisal data that I provide for myself will help improve my skills:
S Strongly Disagree
$O$ Disagree
O Slightly Disagree
O Neutral
S Slightly Agree
O Agree
O Strongly Agree

44. I am in the best position to evaluate certain aspects of my performance: 
360-Degre Futdhack Survey:
Strongly Disagree
O Disagree
O Slightly Disagree
O Neutral
O Slightly Agree
$O$ Agree
Strongly Agree

45. The use of self-ratings to appraise my performance is a fair method of appraisal for this job:
Strongly Disagree
O Disagree
O slightly Disagree
O Neutral
O slightly Agree
O Agree
O strongly Agree

46. The appraisal feedback I provide for myself accurately reflects my performance on the job:
Strongly Disagree
$O$ Disagree
Slightly Disagree
O Neutral
O slightly Agree
O Agree
Strongly Agree

The following seven items use a 7-point scale. Please read each statement, all of which relate to the organization for which you work, and mark one response that best indicates 
360-Degree Fetdhack Survey

how strongly you disagree or agree with the statement.

47. I am willing to put in a great deal of effort beyond that normally expected in order to help my organization be successful.
Strongly Disagree
O Disagree
O Slightly Disagree
O Neutral
O slightly Agree
Agree
O Strongly Agree

48. I really care about the fate of my organization.
Strongly Disagree
O Disagree
O slightly Disagree
$O$ Neutral
O slightly Agree
O Agree
O Strongly Agree

49. I am extremely glad that I chose my organization for which to work over others that I was considering at the time I joined.
Strongly Disagree
Disagree
$O$ slightly Disagree
O Neutral
O slightly Agree
O Agree
O Strongly Agree

50. I talk up my organization to my friends as a great organization for which to

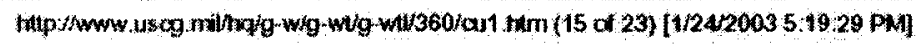




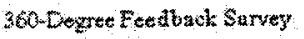

work.
O Strongly Disagree
O Disagree
O Slightly Disagree
0 Neutral
S Slightly Agree
O Agree
Strongly Agree

51. I am proud to tell others that I am a part of my organization.
O Strongly Disagree
O Disagree
0 Slightly Disagree
Neutral
$O$ Slightly Agree
O Agree
O strongly Agree

52. I find that my values and the values of my organization are very similar.
Strongly Disagree
$O$ Disagree
O Slightly Disagree
$O$ Neutral
O slightly Agree
O Agree
O Strongly Agree

53. For me, my organization is the best of all possible organizations for which to work.
Strongly Disagree
O Disagree

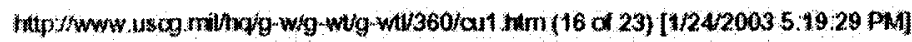


360-Degree Feedback Survey
O slightly Disagree
O Neutral
O Slightly Agree
O Agree
O Strongly Agree

Please complete each of the following 8 statements by reading the name of your supervisor in the first blank. After reading the statement, mark the response that is closest to your opinion.

54. My level of confidence that_(my supervisor)_is technically competent at the critical elements of his or her job is
O Nearly Zero
O Very Low
O Low
O $50-50$
$O$ High
$O$ Very High
O Near $100 \%$

55. My level of confidence that (my supervisor)_will make well thought out decisions about his or her job is
Nearly Zero
$O$ Very Low
O Low
050.50
$O$ High
$O$ Very High
O Near $100 \%$

56. My level of confidence that (my supervisor) will follow through on an 
360-Degree Fedbatek Survey:

assignment is
O Nearly Zero
$O$ Very Low
O Low
$050-50$
0 High
$O$ Very High
$O$ Near $100 \%$

57. My level of confidence that (my supervisor) has an acceptable level of understanding of his/her job is
O Nearly Zero
0 Very Low
O Low
O $50-50$
0 High
$O$ Very High
Near $100 \%$

58. My level of confidence that (my supervisor) will be able to do his or her job in an acceptable manner is
O Nearly Zero
0 Very Low
O Low
O 50.50
High
$O$ Very High
Near $100 \%$

59. When (my supervisor) tells me something, my level of confidence that 1 can rely on what he/she tells me is 


$$
\begin{aligned}
& \text { 360. Degree Feedback Survey } \\
& \text { O Nearly Lero } \\
& \text { O Very Low } \\
& \text { O Low } \\
& 0 \text { 50-50 } \\
& \text { O High } \\
& \text { O very High } \\
& \text { O Near } 100 \%
\end{aligned}
$$

60. My confidence in (my supervisor) to do a job without causing other problems is
Nearly Zero
Verylow
O Low
050.50
O High
Very High
O Near $100 \%$

61. My level of confidence that (my supervisor) will think through what he or she is doing on the job is
Nearly Zero
O Very Low
O Low
$0.50-50$
High
$O$ Very High
O Near $100 \%$

Each of the following 4 statements refers to your department. After reading the statement, please mark the response that

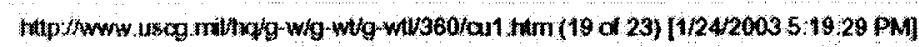


360-Degret Fodback Saryey.

\section{is closest to your opinion.}

62. My level of confidence that this organization will treat me fairly is
$O$ Nearly Zero
$O$ Very Low
O Low
O $50-50$
$O$ High
$O$ very High
O Near 100\%

63. The level of trust between supervisors and workers in this organization is
O Nearly Zero
$O$ Very Low
O Low
O $50-50$
$O$ High
$O$ very High
O Near $100 \%$

64. The level of trust among the people I work with on a regular basis is
O Nearly Zero
O Very Low
$O$ Low
O $50-50$
$O$ High
$O$ Very High
O Near $100 \%$

65. The degree to which we can depend on each other in this organization is

O Nearly Zero

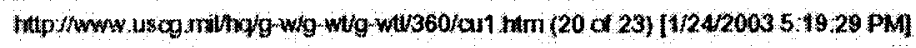


360-Dogree Feetback Servey.
O Very Low
O Low
O $50-50$
High
$O$ Very High
Near $100 \%$

66. In what year did you begin working for your current employer? (Please type in the year)

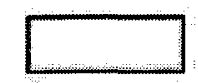

67. How many years have you participated in 360-degree feedback while working for your current employer? (Please type in the number of years)

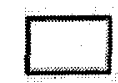

68. How many years did you participate in 360-degree feedback prior to working for your current employer? (Please type in the number of years)

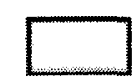

69. What category best describes your current position? (Please mark the correct box). If your position doesn't correspond to any of the following options, please proceed to question 70.

Executive management, or equivalent,

O Middle management, or equivalent,

Entry-level management, or equivalent,

Clerical, or equivalent,

O Production, trade, or craft (mechanic, electrician, technician, etc), or equivalent

$O$ Professor, doctor, teacher, nurse, etc.

$O$ Other (please go to question 70)

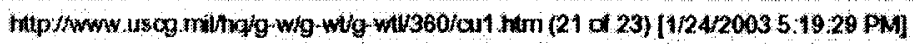


70. If your current job position isn't listed above, please us the space below to type in your response. (Please specify)

71. Are you male or female? (Please mark the correct box)
O Male
O Female

72. What is the highest degree/level of school you have completed? (Please mark the correct box)
$\bigcirc$ Less than High School Graduate,
High School Graduate (or equivalency),
O Trade School
O some college credit, but no degree,
O Associate degree (for example, AA, AS),
Bachelor's degree (for example, BA, AB, BS),
O Master's degree (for example, MA, MS Meng, MEd, MSW, MBA),
O Doctorate or professional degree (for example, PhD, EdD, MDD, JD, DDS, DVM, LLB)

73. Which of the following best describes you? (Please mark the correct box) If none of the responses below adequately describes you, please proceed to question 74.
White, not Hispanic,
O Black, not Hispanic,
$O$ Hispanic,
O Asian/Pacific Islander,
Alaskan Native or Native American, not Hispanic,
Other (please go to question 74) 
$360-D e g r e$ Feedback Survey

74. If none of the responses above adequately describe you, please type your response below.

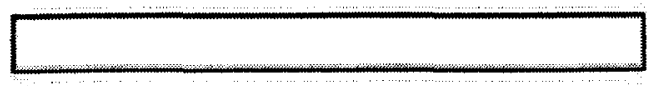

75. In what year were your born? (Please type in the year)

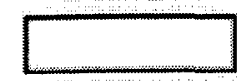

76. What was your approximate total income last year? (Please type in the amount in U.S. Dollars)

$\$$

77. Is there anything else that you would like to offer? If so, please feel free to use this space.

\section{THANK YOU for completing this survey}

Submit Survey.

This questionnaire was ereated using Porseus SurveySolutions. 


\section{Appendix I}

\section{Multiple Regression Assumptions}

The concept of multiple regression producing the best, linear, unbiased estimators compared to all other linear, unbiased estimators is proven by the Gauss-Markov Theorem. The theorem is based on five assumptions. Problems may arise if the assumptions are not met, i.e., the regression model may no longer produce the best, linear, unbiased estimators if the assumptions are found to be violated (although it is possible to correct for violations of the assumptions). It is important, therefore, to discuss the assumptions to determine the importance of each one, and to develop plans to help correct associated errors.

The first assumption is the relationship between $\mathrm{X}$ and $\mathrm{Y}$ is linear and is described by the equation: $Y_{i}=\beta_{0}+\beta_{1} X_{1}+\beta_{2} X_{2}+\cdots+\beta_{K} X_{K}+$ ų where $u$ is the error or disturbance term (the vertical distance between a data point and the fitted regression line, Y) (Greene, 1990; Pindyck \& Rubinfeld, 1991). The casual observer, however, could argue that in some circumstances, such as in the proposed study, a quadratic or reciprocal relationship may exist between $\mathrm{X}$ and $\mathrm{Y}$, therefore multiple regression will not produce the best estimators $\alpha$ and $\beta$. These nonlinear cases, however, can be considered special linear cases because the linearity assumption is made with regards to estimators $\alpha$ and $\beta$, not the variables $Y$ and $X$. For example, the quadratic equation $Y=\beta_{0}+\beta_{1} X+\beta_{2} X^{2}$ in nonlinear with respect to the variable $\mathrm{X}$, however, the regression model applies. If the squared term is moved to the variable $X$, the model becomes non linear $\left(Y=\beta_{0}+\beta_{1} X+\right.$ $\left.\beta_{2}^{2} \mathrm{X}\right)(\mathrm{Katz}, 1982)$. 
The second assumption that lays the foundation for the Gauss-Markov Theorem is that the values of $\mathrm{X}$ are fixed and nonrandom (nonstochastic). Similarly, although not directly related to this concept, the values of $Y$ are random (stochastic) (Katz, 1982). The primary point regarding this assumption is multiple regression uses an error term that is measured vertically along the $\mathrm{Y}$-axis. Researchers are concerned with measuring error terms for $\mathrm{Y}$ as a function of $\mathrm{X}$, not $\mathrm{X}$ as a function of $\mathrm{Y}$.

The third assumption is on average, the error term is equal to zero, i.e., $\mathrm{E}(\mathcal{C})=0$. Specifically, the average disturbance associated with $\mathrm{X}$ is zero (Johnson \& Johnson, 1987). This assumption is commonsensical if we consider a scatter plot and an associated fitted line, $\hat{Y}$. If we consider the positive and negative error terms for all data points, they should cancel each other thereby giving an average disturbance term equal to zero.

The fourth assumption is the error term has a constant variance for all observations throughout the range of $X$ values $\left(E\left(\epsilon^{2}\right)=\sigma^{2}\right.$, where $\sigma^{2}$ equals a constant). This is the assumption of homoscedasticity. Of all underlying assumptions associated with the Gauss-Markov Theorem, this assumption generally causes the most problem because it is possible that this assumption is violated.

The fifth assumption is the error term of any given observation is not linearly related with any other error term, i.e., there is no serial or autocorrelation. Another way of stating this assumption is there is no linear relationship between error terms, or $E\left(\epsilon_{i} C_{j}\right)=0$ for $i$ $\neq \mathrm{j}$. Generally speaking, autocorrelation is a phenomenon that occurs more frequently in time-series versus cross-section studies. Autocorrelation may be either negative (i.e., each subsequent error term falls on the opposite side of the fitted regression line) or positive (i.e., many error terms lie above or below the fitted regression line (Greene, 1990; Katz, 
1982). The study will use cross-sectional data, therefore, autocorrelation should not present any problems in the model.

The sixth and final assumption is no perfect relationship exists between independent variables. During regression analysis, it is not allowable, for example, to include weight in kilograms and weight in pounds since there is an exact relationship between the two. 


\section{Appendix J}

Multicollinearity and Homoscedasticity

The final regression model generated the best linear unbiased estimators (BLUEs), however, the Gauss-Markov theorem that underpins the concept of BLUE comprises six assumptions in multiple regression modeling. In cross sectional studies such as this one, two assumptions may be violated and must be checked. Specifically, multicollinearity and heteroscedasticity are problems that can weaken a researcher's analysis (Tabachnick \& Fidell, 2001; Johnson et al, 1987).

\section{Multicollinearity}

At least two tests for multicollinearity exist. The first is to simply compare the bivariate correlations of all independent variables. If a correlation of .9 or higher exists among any of the independent variables, multicollinearity may exist (Tabachnick \& Fidell, 2001). All independent variables in this study pass this initial test as illustrated in the following Pearson's correlation matrix.

\begin{tabular}{|l|l|l|l|l|}
\hline & COMT & TRUS & INC & EDBS \\
\hline COMT & - & .657 & .205 & -.016 \\
\hline TRUS & .657 & - & .113 & -.170 \\
\hline INC & .202 & .113 & - & .013 \\
\hline EDBS & -.016 & -.170 & .013 & - \\
\hline
\end{tabular}

The second option to test for multicollinearity is to calculate the collinearity statistics tolerance (CST) and variance inflation factor (VIF). CST is calculated for each independent variable as follows:

$$
\mathrm{CST}=1-\mathrm{R}_{\mathrm{i}}^{2}
$$

where $\mathrm{R}^{2}$ is the squared multiple correlation (SMC). SMC is calculated for each independent variable by moving the independent variable to the left side of the 
regression model (i.e., in essence turning it into a dependent variable), and running a regression using the remaining dependent variables (SPSS, 2001; Tabachnick \& Fidell, 2001). In the final regression model above, three SMCs were generated:

$\mathrm{R}^{2}$ COMT for COMT regressed on TRUS and INC and EDBS

$\mathrm{R}_{\text {TRUS }}^{2}$ for TRUS regressed on COMT and INC and EDBS

$\mathrm{R}^{2}{ }_{\text {NNC }}$ for INC regressed on COMT and TRUS and EDBS

$\mathrm{R}^{2}{ }_{\text {INC }}$ for EDBS regressed on COMT and TRUS and INC

CST values range between 0 and 1 . The closer the CST is to 0 , the greater the correlation between two or more variables. Any variable with a CST value of .0001 is suspect of being too closely correlated with one or more variables in the regression.

The VIF is the reciprocal of CST. Variables that produce large VIF values, therefore, should also be suspect. The independent variables in the final model do not appear to be highly correlated. The following table provides CST and VIF values for each variable (SPSS, 2001).

\section{Coefficients}

\begin{tabular}{|c|c|c|c|c|c|c|c|c|}
\hline \multirow[b]{2}{*}{ Model } & & \multicolumn{2}{|c|}{$\begin{array}{l}\text { Unstandardized } \\
\text { Coefficients }\end{array}$} & \multirow{2}{*}{$\begin{array}{c}\begin{array}{c}\text { Standardized } \\
\text { Coefficients }\end{array} \\
\text { Beta }\end{array}$} & \multirow[b]{2}{*}{$t$} & \multirow[b]{2}{*}{ Sig. } & \multicolumn{2}{|c|}{ Collinearity Statistics } \\
\hline & & B & Std. Error & & & & Tolerance & VIF \\
\hline & (Constant) & 1.970 & .625 & & 3.150 & .003 & & \\
\hline & TRUS & .330 & .145 & .336 & 2.279 & .027 & .523 & 1.911 \\
\hline & COMT & .275 & .133 & .307 & 2.067 & .044 & .515 & 1.941 \\
\hline & EDBS & .571 & .205 & .300 & 2.781 & .008 & .977 & 1.024 \\
\hline & INC & $-4.85 E-03$ & .002 & -.247 & -2.267 & .028 & .956 & 1.046 \\
\hline
\end{tabular}

a. Dependent Variable: R360

\section{Homogeneity of Variance (Homoscedasticity)}

The next potential problem in cross sectional research is heteroscedasticity (described earlier in Chapter 4). Several tests may be utilized to determine if 
heteroscedasticity is present between the dependent variable and independent variables. Prior to performing any tests, however, it is possible to see if error terms in the three scatter plots (employee receptivity to 360 variable vs. each of the three identified independent variables) appear to be constant (see Figures A4 though A6). Additionally, residual error term plots may help to identify non-uniformity (i.e., a heteroscedastic scenario)(Figures A7 through A9). Unfortunately, it is difficult to determine whether constant error terms exist by visually examining the scatter plots and residual error term plots. The only variable that appears to exhibit heteroscedastic tendencies, in both the scatter plot and residual error term plot is trust (TRUS). A more formal method will help to determine homoscedasticity, or lack thereof.

The Goldfeld-Quant test for heteroscedasticity is used in bivariate analysis. It is a relatively simple test that requires 7 steps (Johnson \& Johnson, 1987):

1. Determine which independent variable may be presenting the problem of heteroscedasticity.

2. Generate a matrix that includes dependent variable value and the values of the independent variables in question.

3. Restructure the matrix in ascending value order.

4. Delete $20 \%$ to $30 \%$ of the middle value observations.

5. Generate two regression models, one for small values and one for large values.

6. Calculate the residual sum of squares (RSS) for each model, and divide RSS low into $\mathrm{RSS}_{\text {high. }}$ This is the calculated F stat.

7. Determine degrees of freedom and compare calculated F stat to F critical. The null hypothesis assumes homoscedasticity. 
The first independent variable to be considered for the Goldfeld-Quant test is employee commitment. The dataset was sequenced so that employee receptivity to 360 scores were in ascending order. The middle 18 observations were removed, leaving 22 small value observations and 22 large value observations. A regression model was generated giving residual sum of square values as follows: $\mathrm{RSS}_{\text {small }}=9.335, \mathrm{RSS}_{\text {large }}=$ 1.198; $\mathrm{RSS}_{\mathrm{smal}} / \mathrm{RSS}_{\mathrm{large}}=7.8$. There are 20 degrees of freedom in each subset (22 observations -2 variables estimated). The critical value of $F(20,20)$ is 2.12 at the .05 level, so we reject the null hypothesis of homoscedasticity $\left(F_{\text {calculated }}(7.8)>F_{\text {critical }}\right.$ (2.12)).

The Goldfeld-Quant test for the other independent variables yielded similar results. The following table provides a comparison of 22 observations for small and large RSS values for all independent variables:

\begin{tabular}{|l|l|l|l|l|l|}
\hline & $\mathrm{RSS}_{\text {small }}$ & $\mathrm{RSS}_{\text {large }}$ & $\mathrm{RSS}_{\text {small }} / \mathrm{RSS}_{\text {large }}$ & $\mathrm{F}(20,20)$ & $\begin{array}{l}\text { Null } \\
\text { Hypothesis }\end{array}$ \\
\hline COMT & 9.335 & 1.198 & 7.8 & 2.12 & Reject \\
\hline TRUS & 7.317 & 1.093 & 6.7 & 2.12 & Reject \\
\hline INC & 8.555 & 1.095 & 7.8 & 2.12 & Reject \\
\hline
\end{tabular}

All independent variables in our final model appear to be heteroscedastic. Although this unfortunate phenomenon fails one of the six assumptions related to the GaussMarkov theorem, the analysis is weakened but not invalidated. Actually, heteroscedasticity is common and many scientists attempt to remedy the situation from the start of data analysis. Heteroscedasticity increases the standard error in the regression model (Johnson \& Johnson, 1987).

The heteroscedastic remedy is simply to divide the dependent variable and all independent variables by the coefficient of the heteroscedastic independent variable. 
Unfortunately, all three independent variables suffer from heteroscedasticity. In this case, the independent variable that appears to suffer from the greatest degree of heteroscedasticity will be treated as the problem variable. Specifically, TRUS (see Figure A8) appears to have the least uniform residual plot. The transformed equation becomes:

$360 /$ TRUS $=\beta_{0} /$ TRUS $+\beta_{1}$ COMT/TRUS $+\beta_{2}$ TRUS $/$ TRUS $+\beta_{3}$ INC/TRUS 


\section{Appendix K}

Two Tests to Determine if COMT $=$ TRUS

Test 1

$\mathrm{H}_{\mathrm{A}}: \mathrm{COMT} \neq \mathrm{TRUS}$

$\mathrm{H}_{0}: \mathrm{COMT}=\mathrm{TRUS} ;$ or COMT-TRUS $=0$

Test using a standard t-test (i.e., $\left.\left[\left(b_{1}-b_{2}\right)-0\right] / S_{b 1-b 2}\right)$ :

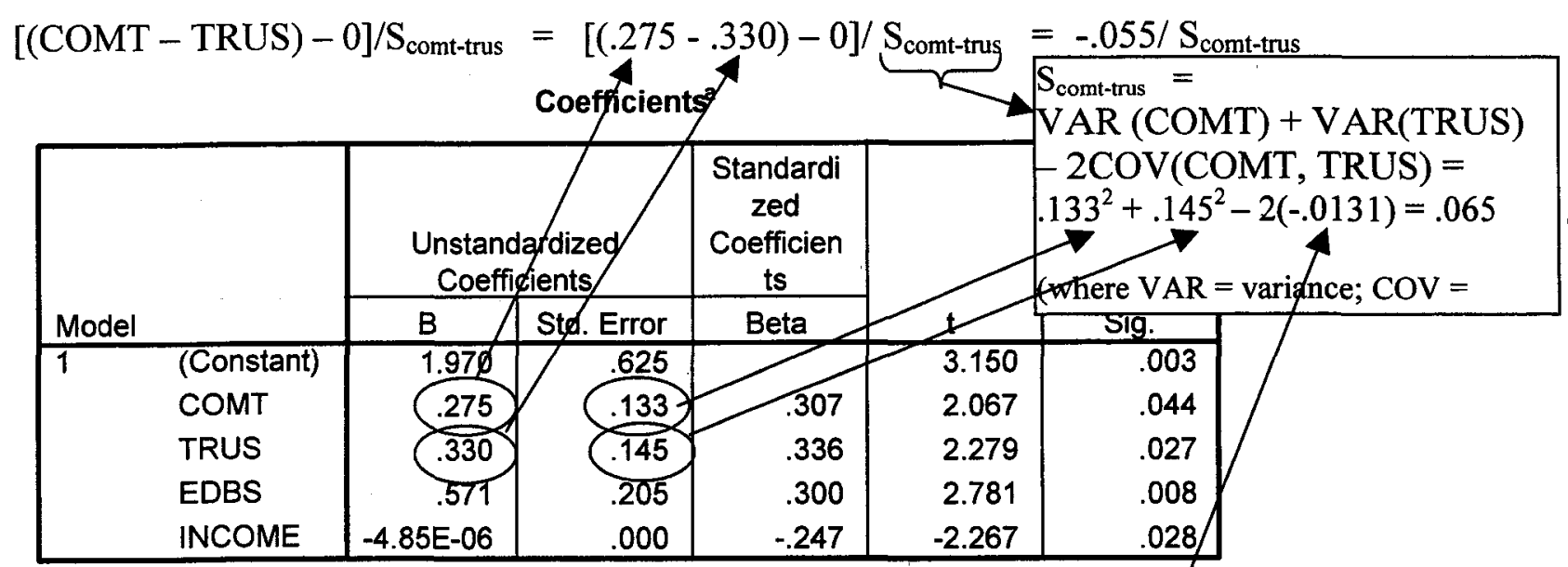

a. Dependent Variable: R360

\begin{tabular}{|c|c|c|c|c|c|c|}
\hline \multicolumn{7}{|c|}{ Coefficient Correlations } \\
\hline Model & & & INCOME & EDBS & TRUS & СOMT \\
\hline \multirow{8}{*}{1} & Correlations & INCOME & 1.000 & -.011 & .035 & -.175 \\
\hline & & EDBS & -.011 & 1.000 & .150 & -.090 \\
\hline & & TRUS & .035 & .150 & 1.000 & -.680 \\
\hline & & COMT & -.175 & -.090 & -.680 & 1.000 \\
\hline & Covariances & INCOME & $4.578 \mathrm{E}-12$ & $-4.71 E-09$ & $1.099 \mathrm{E}-08$ & $-4.98 \mathrm{E}-08$ \\
\hline & & EDBS & $-4.71 E-09$ & 4.219E-02 & 4.464E- -03 & $-2.47 E-03$ \\
\hline & & TRUS & $1.099 \mathrm{E}-08$ & 4.464E-03 & $2.0948-02$ & $-1.31 \mathrm{E}-02$ \\
\hline & & СOMT & $-4.98 E-08$ & $-2.47 \mathrm{E}-03$ & $-1.31 \mathrm{E}-02$ & $1.775 \mathrm{E}-02$ \\
\hline
\end{tabular}

a. Dependent Variable: R360

$[(\mathrm{COMT}-\mathrm{TRUS})-0] / \mathrm{S}_{\text {comt-trus }}=-.055 / .065=-.850=\mathrm{t} \quad \mathrm{t}_{\text {critical }} \approx 2.7$ (for .01$)$

$\mathrm{t}(-.85)<\mathrm{t}_{\text {critical }} \therefore$ fail to reject null COMT $=$ TRUS 


\section{Test 2}

Given (from Pindyck \& Rubinfeld (1991)):

$$
\begin{aligned}
\mathrm{Y}_{\mathrm{i}} & =\mathrm{B}_{1}+\mathrm{B}_{2}\left(\mathrm{X}_{2 \mathrm{i}}+\mathrm{X}_{3 \mathrm{i}}\right)+\gamma \mathrm{X}_{3 \mathrm{i}}+\cdots+\mathrm{B}_{\mathrm{k}} \mathrm{X}_{\mathrm{ki}}+\varepsilon_{\mathrm{i}} \\
& =\mathrm{B}_{1}+\mathrm{B}_{2} \mathrm{X}_{2 \mathrm{i}}+\left(\mathrm{B}_{2}+\gamma\right) \mathrm{X}_{3 \mathrm{i}}+\cdots+\mathrm{B}_{\mathrm{k}} \mathrm{X}_{\mathrm{ki}}+\varepsilon_{\mathrm{i}}
\end{aligned}
$$

$\mathrm{H}_{0}: \gamma=0$

This test requires running a new regression where TRUS is omitted, and a new variable, COMT + TRUS (labeled as COMTRUS), is added. This regression generated the following results:

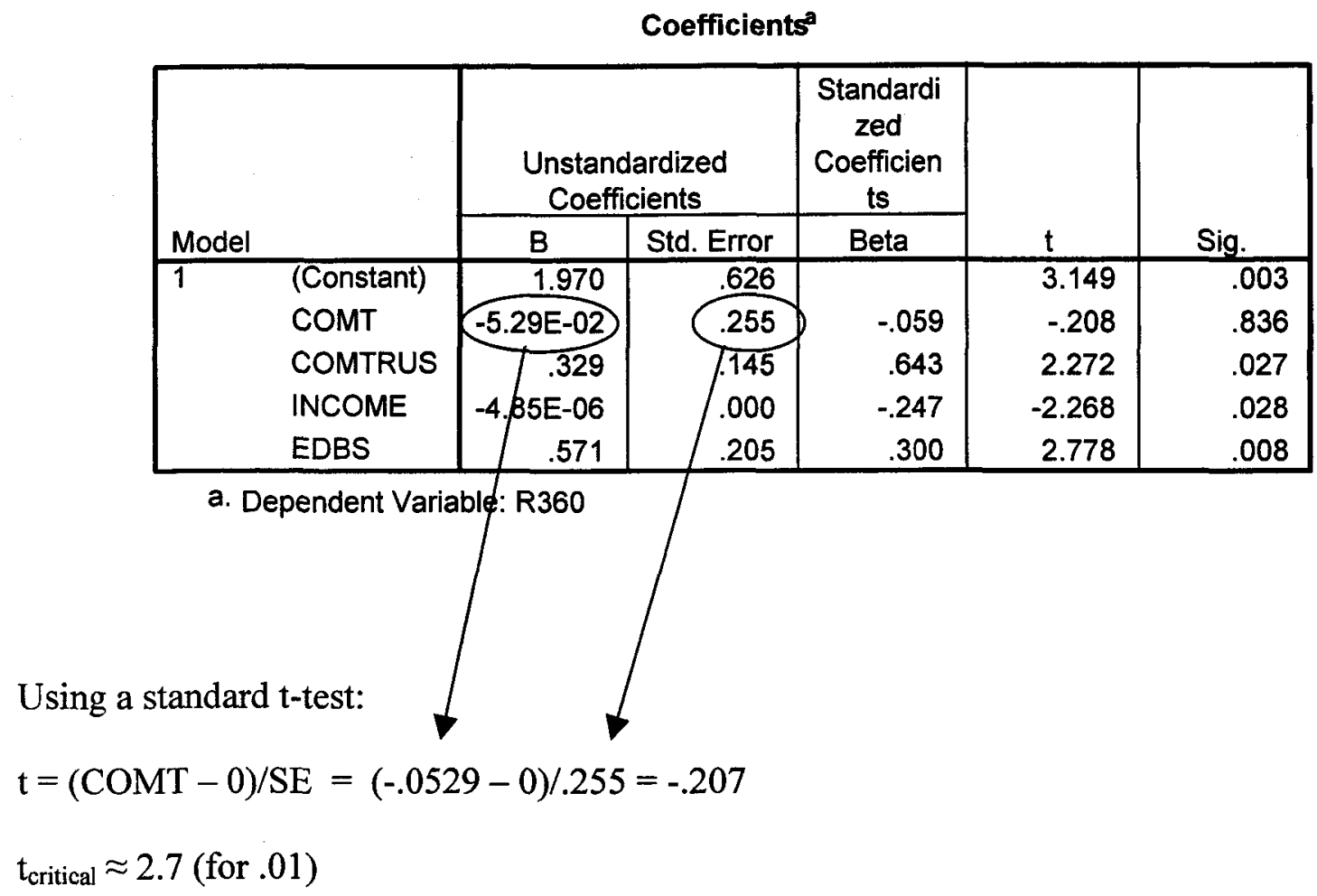

$\mathrm{t}(-.207)<\mathfrak{t}_{\text {critical }}(2.7) \therefore$ fail to reject null $\gamma=0$ 


\section{Appendix L}

\section{Determining Values for First-Order Correction}

\section{$\underline{\text { Trust in Manager }}$}

One data point is missing for TRUSMG (i.e., one respondent did not answer items associated with TRUSMG). In order to estimate the missing data value, a new regression model must be generated. The dependent variable, therefore, becomes TRUSMG. The independent variables used in this model are those that best predict trust in manager values. Several regression models were generated yielding two independent variables that relate to trust in manager; frequency of 360 feedback (in months) (FREQ) and COMT. The following model was generated (adjusted R-Squared $=.187 ; \mathrm{t}$-stats in lower parentheses):

$$
\text { TRUSMG }=4.896+(.305) \text { COMT }-(5.93 \mathrm{E}-02) \mathrm{FREQ}
$$

Therefore, the single missing data point may be calculated as follows:

$$
\text { TRUSMG }=4.896+(.305)(6.27)-(5.93 \mathrm{E}-02)(12)=6.10
$$

\section{Income}

A total of six respondents did not provide income data. In order to utilize first-order correction, income will become the dependent variable. The best fitting first-order correction model for income included three independent variables; education (EDU), job category (JCAT), and gender (SEX). The following regression will generate values for missing incomes (adjusted R-Squared $=.420, \mathrm{R}$-Squared $=.453 ; \mathrm{t}$-stats in lower parentheses):

$$
\mathrm{INC}=31.881+(16.001) \mathrm{EDU}-8.926(\mathrm{JCAT})+25.433(\mathrm{SEX})
$$


The following first-order correction model generated an adjusted R-Squared of .293 and a R-Squared of .328 (t-stats in lower parentheses):

$$
360=2.177+(.291) \mathrm{COMT}+(.297) \mathrm{TRUS}-(4.89 \mathrm{E}-3) \mathrm{INC}
$$


Table A1

Variable Nomenclature \& Variable Measurement

\begin{tabular}{|c|c|c|c|}
\hline Variable Name & $\begin{array}{l}\text { Variable } \\
\text { Symbol }\end{array}$ & Scale & Comments \\
\hline $\begin{array}{l}\text { Employee Receptivity to } \\
360^{\circ} \text { Feedback }\end{array}$ & R360 & $\begin{array}{l}\text { Likert (lequates to the } \\
\text { lowest possible score, } 7 \\
\text { equates to the highest } \\
\text { possible score) }\end{array}$ & 5 item construct \\
\hline Employee Commitment & COMT & Same & 7 item construct \\
\hline Employee Trust in Manager & TRUSMG & Same & 8 item construct \\
\hline $\begin{array}{l}\text { Employee Trust in } \\
\text { Organization }\end{array}$ & TRUSOR & Same & 4 item construct \\
\hline Employee Trust (Total) & TRUS & Same. & $\begin{array}{l}\text { Calculated by } \\
\text { averaging TRUMG } \\
\text { and TRUSOR }\end{array}$ \\
\hline $\begin{array}{l}\text { Frequency of } 360^{\circ} \\
\text { Feedback }\end{array}$ & FREQ & Continuous Variable & Months \\
\hline Income & INC & Continuous Variable & Thousands of \$'s \\
\hline Highest Level of Education & $\mathrm{EDU}$ & Discrete Variable & $\begin{array}{l}\text { Variable originally } \\
\text { containing } 8 \text { possible } \\
\text { responses, reduced to } 4\end{array}$ \\
\hline Job Category & JCAT & Discrete Variable & $\begin{array}{l}\text { Variable originally } \\
\text { containing } 7 \text { possible } \\
\text { responses, reduced to } 4\end{array}$ \\
\hline Sex & SEX & Binary Variable & \\
\hline Ethnicity & $\overline{\mathrm{ETH}}$ & Binary Variable & $\begin{array}{l}\text { Variable originally } \\
\text { containing } 6 \text { possible } \\
\text { responses, reduced to } 2 \\
\text { (white, non white) }\end{array}$ \\
\hline $\begin{array}{l}\text { Employment Period with } \\
\text { Present Employer }\end{array}$ & YRSWK & Continuous Variable & Years \\
\hline $\begin{array}{l}\text { Years Participating in } 360 \\
\text { with Present Employer }\end{array}$ & YRS360 & Continuous Variable & Years \\
\hline $\begin{array}{l}\text { Employer Provides } \\
\text { Training to Better Give } \\
\text { Feedback? }\end{array}$ & GIVE & Binary Variable & \\
\hline $\begin{array}{l}\text { Employer Provides } \\
\text { Training to Better Give } \\
\text { Feedback? }\end{array}$ & REC & Binary Variable & \\
\hline
\end{tabular}


Table A2

Organization 1 - Descriptive Statistics

\begin{tabular}{lrrrrr}
\hline \multicolumn{1}{c}{ Variables } & \multicolumn{2}{l}{ n Minimum Maximum } & Mean & $\begin{array}{r}\text { Standard } \\
\text { Deviation }\end{array}$ \\
\hline Receptivity to 360 feedback from SUPERVISOR & 8 & 4.40 & 6.60 & 5.82 & .73 \\
\hline Receptivity to 360 feedback from PEERS & 9 & 3.40 & 6.40 & 5.60 & .90 \\
\hline Receptivity to 360 feedback from DIRECT REPORTS & 4 & 4.80 & 6.20 & 5.60 & .63 \\
\hline Receptivity to 360 feedback from INTERNAL CUST & 3 & 4.00 & 6.00 & 5.26 & 1.10 \\
\hline Receptivity to 360 feedback from EXTERNAL CUST & 0 & & & & \\
\hline Receptivity to 360 feedback from SELF & 9 & 3.80 & 6.60 & 5.42 & .83 \\
\hline Receptivity to 360 feedback TOTAL (R360) & 9 & 4.64 & 6.27 & 5.62 & .52 \\
\hline COMMITMENT (COMT) & 9 & 5.29 & 7.00 & 6.50 & .53 \\
\hline TRUST in MANAGER (TRUSMG) & 8 & 5.50 & 6.75 & 6.21 & .45 \\
\hline TRUST in ORGANIZATION (TRUSOR) & 9 & 5.50 & 7.00 & 6.55 & .51 \\
\hline TRUST TOTAL Manager \& Organization) (TRUS) & 9 & 5.81 & 7.00 & 6.43 & .37 \\
\hline Years with CURRENT EMPLOYER (YRSWK) & 9 & 2 & 12 & 6.22 & 3.11 \\
\hline Years Participating in 360 w/ CURRENT EMPLOYEER & 9 & 1 & 6 & 3.33 & 1.66 \\
(YRS360) & & & & & \\
\hline Age (AGE) & 9 & 28 & 62 & 42.78 & 10.77 \\
\hline Income (INCOME) & 8 & 18000 & 200000 & 62250 & 60144 \\
\hline
\end{tabular}

Gender: 8 female, 1 male

Ethnicity: 9 white, 0 non-white 
Table A3

Organization 2 - Descriptive Statistics

\begin{tabular}{lrrrrr}
\hline \multicolumn{1}{c}{ Variables } & \multicolumn{2}{c}{$\mathrm{n}$ Minimum Maximum } & \multicolumn{2}{c}{ Mean Standard } \\
& & & & & \multicolumn{3}{c}{\begin{tabular}{l} 
Deviation \\
\hline Receptivity to 360 feedback from SUPERVISOR
\end{tabular}} & 52 & 2.00 & 6.80 & 5.02 & 1.21 \\
\hline Receptivity to 360 feedback from PEERS & 31 & 1.60 & 6.60 & 4.90 & 1.36 \\
\hline Receptivity to 360 feedback from DIRECT REPORTS & 27 & 3.60 & 7.00 & 5.76 & .75 \\
\hline Receptivity to 360 feedback from INTERNAL CUST & 22 & 2.60 & 6.80 & 5.07 & .97 \\
\hline Receptivity to 360 feedback from EXTERNAL CUST & 10 & 4.20 & 6.20 & 5.44 & .75 \\
\hline Receptivity to 360 feedback from SELF & 40 & 2.60 & 7.00 & 5.06 & 1.09 \\
\hline Receptivity to 360 feedback TOTAL (R360) & 53 & 2.20 & 6.70 & 5.08 & .89 \\
\hline COMMITMENT (COMT) & 53 & 3.14 & 6.86 & 5.75 & .94 \\
\hline TRUST in MANAGER (TRUSMG) & 53 & 2.00 & 7.00 & 5.36 & 1.07 \\
\hline TRUST in ORGANIZATION (TRUSOR) & 53 & 3.25 & 7.00 & 4.94 & .85 \\
\hline TRUST TOTAL (Manager \& Organization) (TRUS) & 53 & 2.63 & 6.25 & 5.15 & .81 \\
\hline Years with CURRENT EMPLOYER (YRSWK) & 52 & 1 & 36 & 13.77 & 9.0 \\
\hline Years Participating in 360 w/ CURRENT EMPLOYEER & 52 & 0 & 11 & 4.60 & 3.08 \\
(YRS360) & & & & & \\
\hline Age (AGE) & 50 & 27 & 67 & 46.6 & 9.23 \\
\hline Income (INCOME) & 52 & 30000 & 250000 & 62377 & 41838 \\
\hline
\end{tabular}

Gender: 25 female, 28 male

Ethnicity: 49 white, 4 non-white 
Table A4

Combined (Organization 1 and Organization 2 - Descriptive Statistics

\begin{tabular}{lrrrrr}
\hline \multicolumn{1}{c}{ Variables } & \multicolumn{2}{l}{ NMinimumMaximum } & Mean & $\begin{array}{r}\text { Standard } \\
\text { Deviation }\end{array}$ \\
\hline Receptivity to 360 feedback from SUPERVISOR & 60 & 2.00 & 6.80 & 5.13 & 1.1900 \\
\hline Receptivity to 360 feedback from PEERS & 40 & 1.60 & 6.60 & 5.05 & 1.2935 \\
\hline Receptivity to 360 feedback from DIRECT REPORTS & 31 & 3.60 & 7.00 & 5.74 & .7307 \\
\hline Receptivity to 360 feedback from INTERNAL CUST & 25 & 2.60 & 6.80 & 5.09 & .9668 \\
\hline Receptivity to 360 feedback from EXTERNAL CUST & 10 & 4.20 & 6.20 & 5.44 & .7531 \\
\hline Receptivity to 360 feedback from SELF & 49 & 2.60 & 7.00 & 5.12 & 1.0530 \\
\hline Receptivity to 360 feedback TOTAL (R360) & 62 & 2.20 & 6.70 & 5.16 & .8622 \\
\hline COMMITMENT (COMT) & 62 & 3.14 & 7.00 & 5.85 & .9265 \\
\hline TRUST in MANAGER (TRUSMG) & 61 & 2.00 & 7.00 & 5.47 & 1.0454 \\
\hline TRUST in ORGANIZATION (TRUSOR) & 62 & 3.25 & 7.00 & 5.17 & .9921 \\
\hline TRUST TOTAL (Manager \& Organization)(TRUS) & 62 & 2.63 & 7.00 & 5.33 & .8855 \\
\hline Years with CURRENT EMPLOYER (YRSWK) & 61 & 1 & 36 & 12.66 & 8.80 \\
\hline Years Participating in 360 w/ CURRENT & 61 & 0 & 11 & 4.41 & 2.93 \\
EMPLOYEER (YRS360) & & & & & \\
\hline Age (AGE) & 59 & 27 & 67 & 46.02 & 9.48 \\
\hline Income (INCOME) & 56 & 18000 & 250000 & 62358 & 44228.95 \\
\hline Gender (SEX) (female) & 33 & & & & \\
\hline \hline
\end{tabular}

Gender: 33 female, 29 male

Ethnicity: 58 white, 4 non-white 
Table A5

Pearson Correlation - Continuous Variables

\begin{tabular}{l|l|l|l|l|l|l|l|l}
\hline & R360 & COMT & TRUS & TRUSMG & TRUSOR & YRSWK & AGE & INC \\
\hline R360 & 1.0 & $.464^{* *}$ & $.484^{* *}$ & $.458^{* *}$ & $.359^{* *}$ & .062 & .069 & -.142 \\
COMT & $.464^{* *}$ & 1.0 & $.657^{* *}$ & $.475^{* *}$ & $.652^{* *}$ & .132 & .082 & .205 \\
TRUS & $.484^{* *}$ & $.657^{* *}$ & 1.0 & $.870^{* *}$ & $.856^{* *}$ & -.087 & .103 & .113 \\
TRUSMG & $.458^{* *}$ & $.475^{* *}$ & $.870^{* *}$ & 1.0 & $.474^{* *}$ & .020 & .105 & -.904 \\
TRUSOR & $.359^{* *}$ & $.652^{* *}$ & $.856^{* *}$ & $.474^{* *}$ & 1.0 & -.175 & .079 & .209 \\
YRSWK & .062 & .132 & -.087 & .020 & -.175 & 1.0 & $.509 * *$ & .234 \\
AGE & .069 & .082 & .103 & .105 & .079 & $.509 * *$ & 1.0 & $.324 *$ \\
INC & -.142 & .205 & .113 & -.094 & .209 & .234 & $.324 *$ & 1.0 \\
\hline
\end{tabular}


Figure A1. Combined Frequency Distribution (Organization 1 \& 2) - Employee Receptivity to 360 (R360)

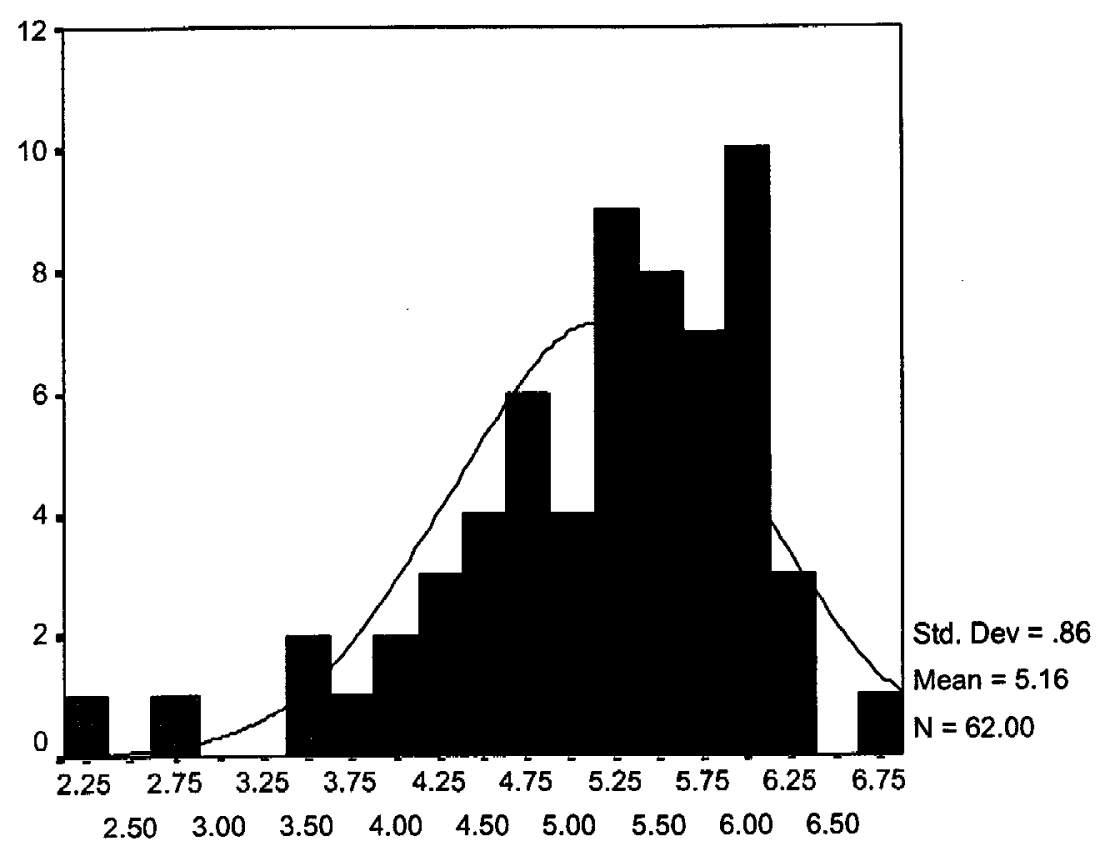

Combined - Total 360 
Figure A2. Combined Frequency Distribution (Organization $1 \& 2$ ) - Employee Commitment (COMT)

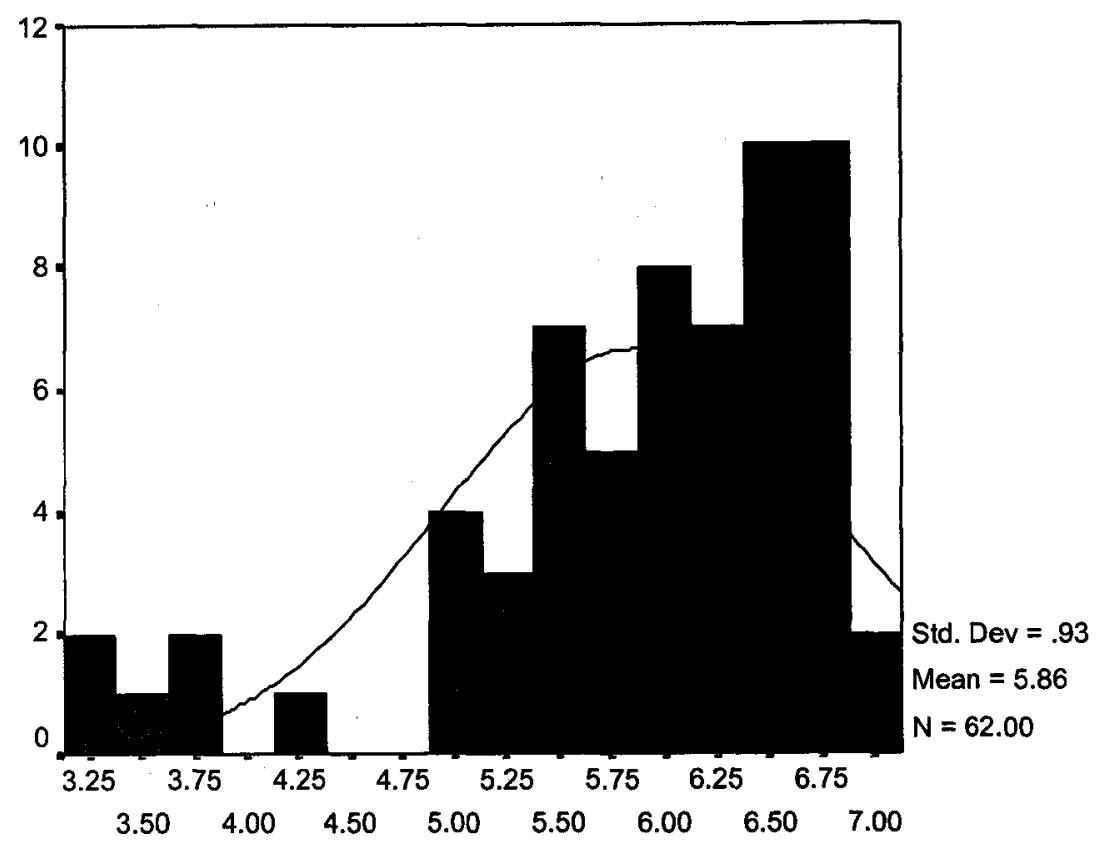

Commitment 
Figure A3. Combined Frequency Distribution (Organization 1 \& 2) - Employee Trust (manager \& organization combined) (TRUS)

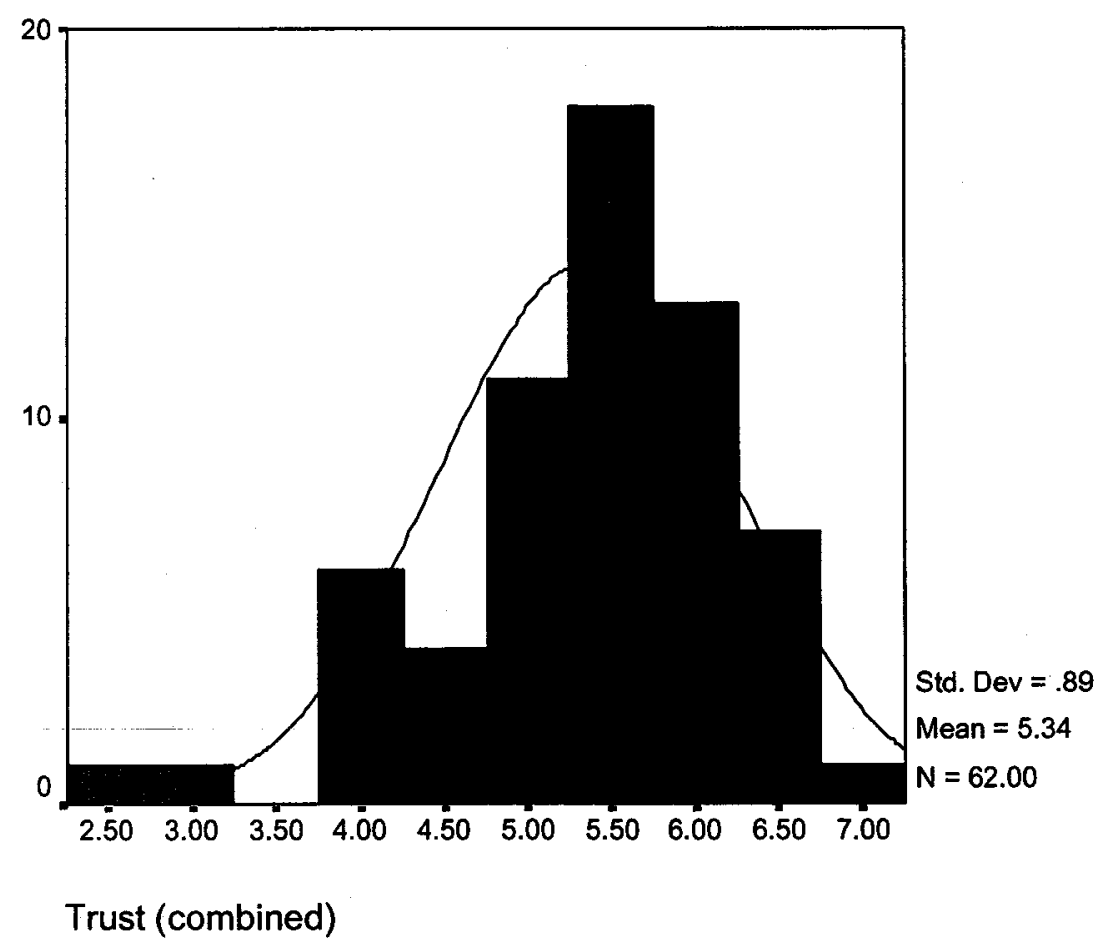


Figure A4. Scatter plot: 360 Receptivity (R360): Trust (total) (TRUS)

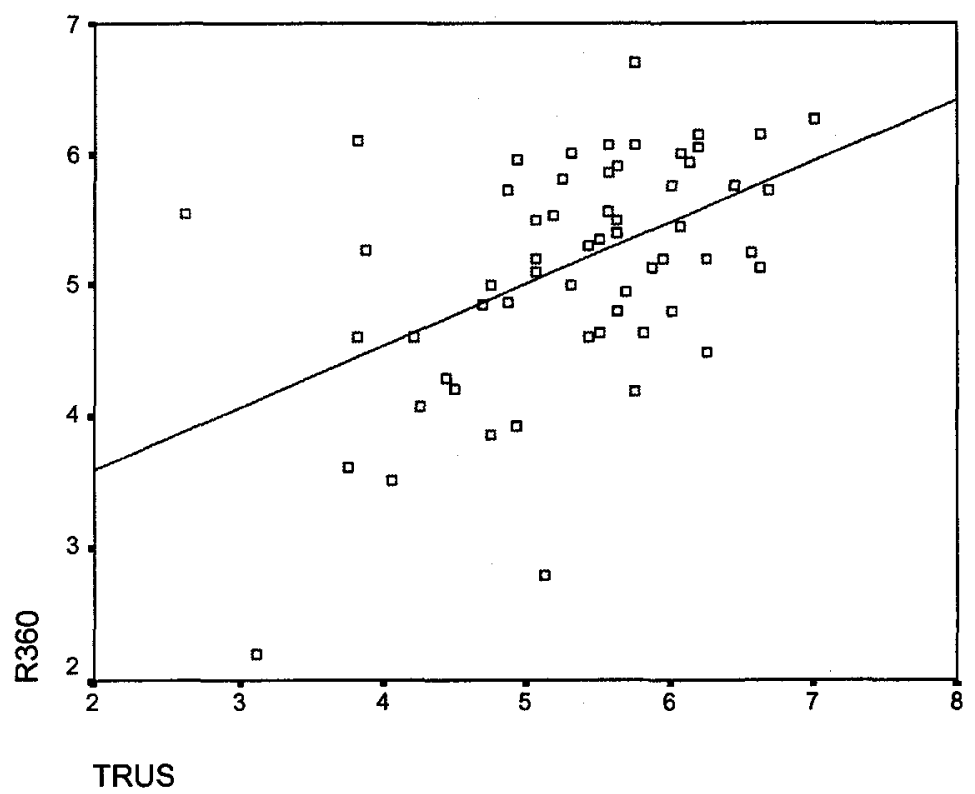


Figure A5. Scatter plot: 360 Receptivity (R360): Employee Commitment (COMT)

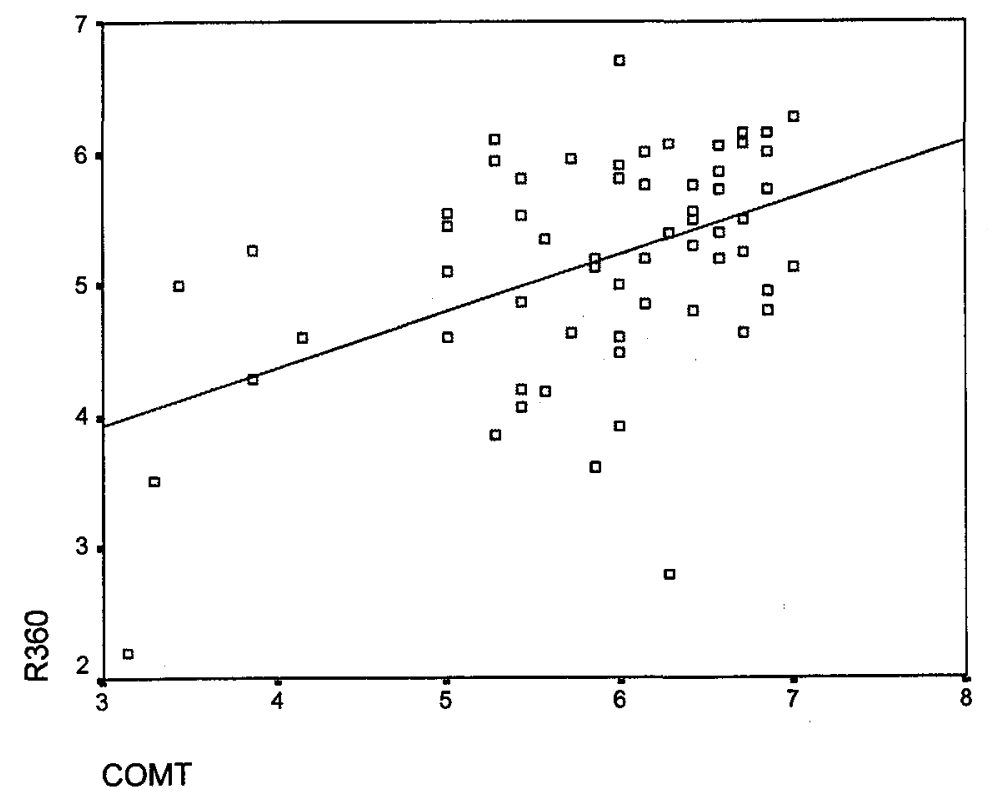


Figure A6. Scatter plot: 360 Receptivity (R360): Income (INC)

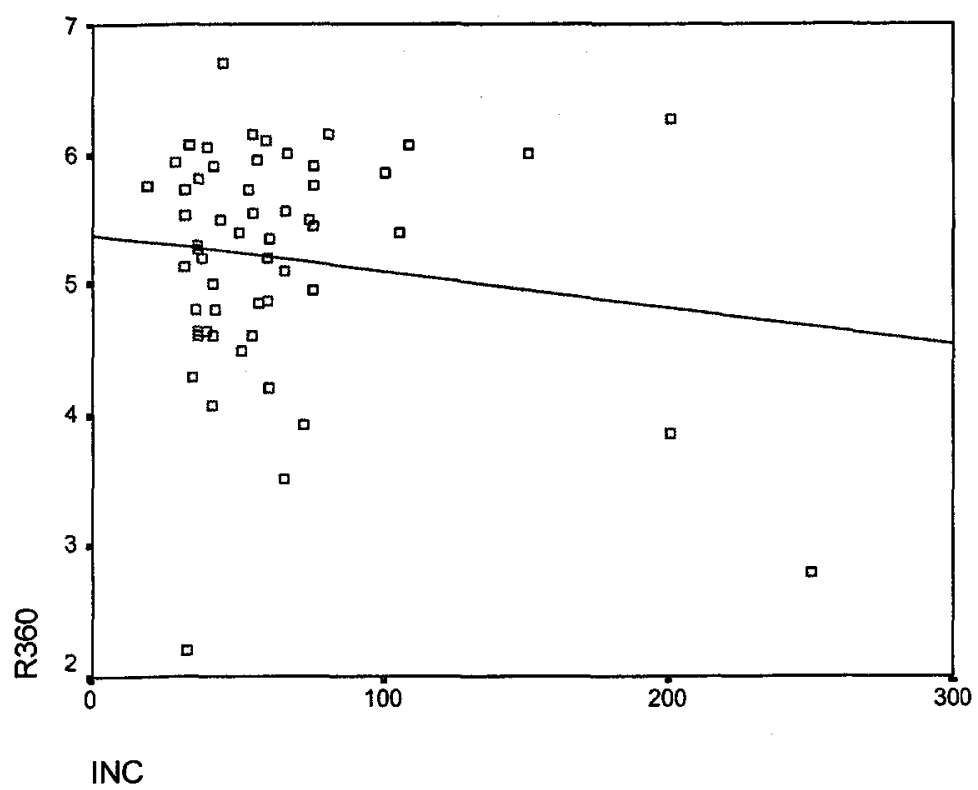

Reproduced with permission of the copyright owner. Further reproduction prohibited without permission. 
Figure A7. Residual Error Terms Related to Employee Commitment (COMT)

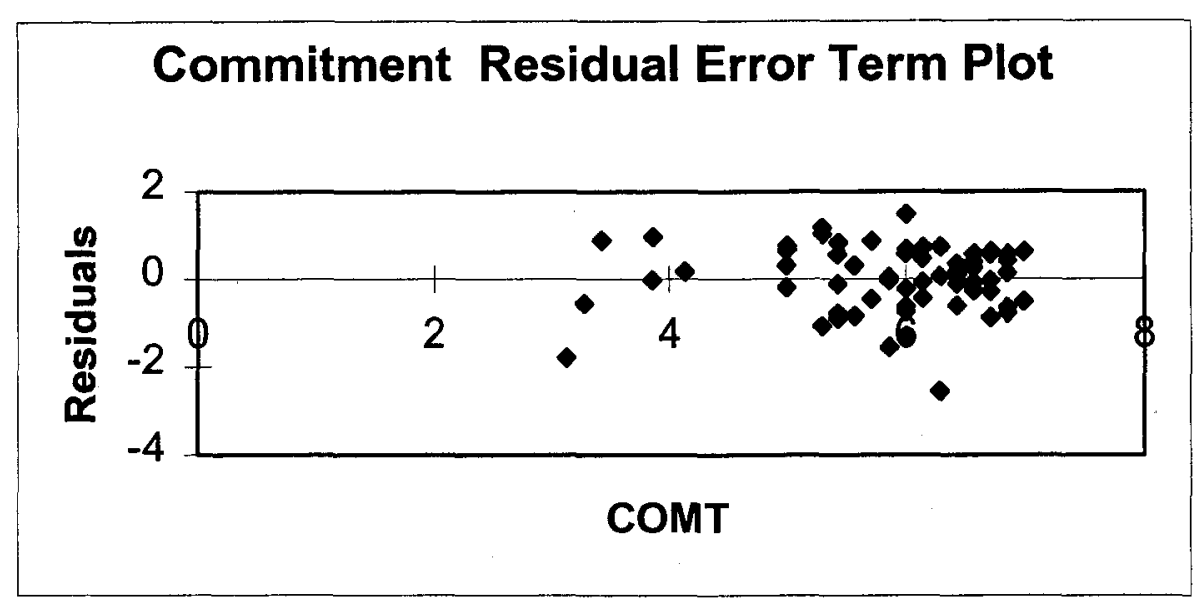


Figure A8. Residual Error Terms Related to Employee Trust (TRUS)

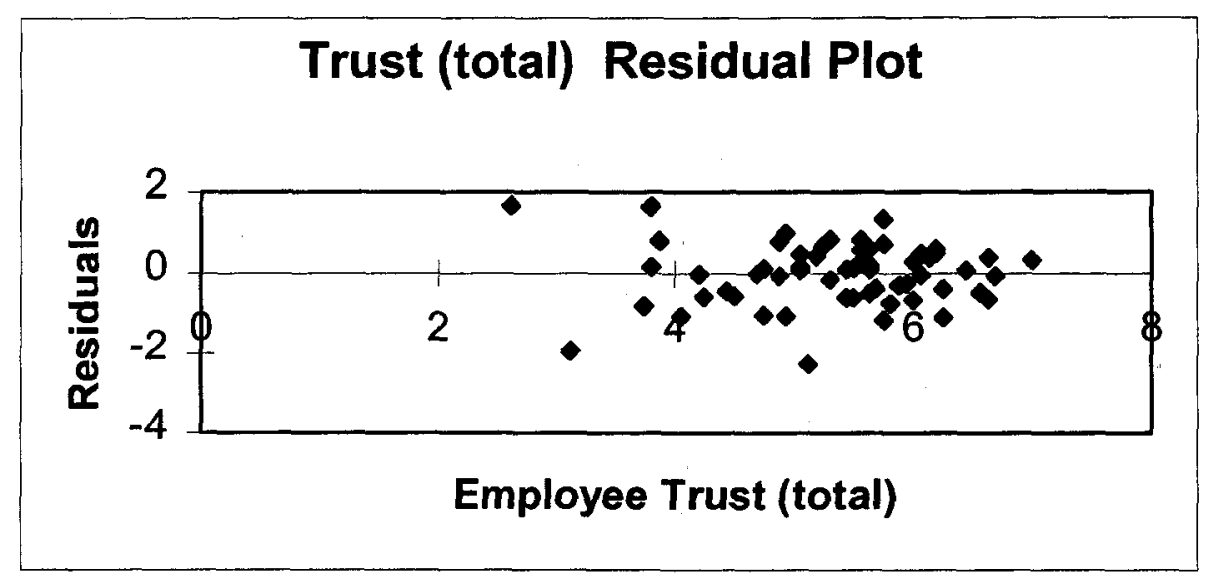


Figure A9. Residual Error Terms Related to Income (INC)

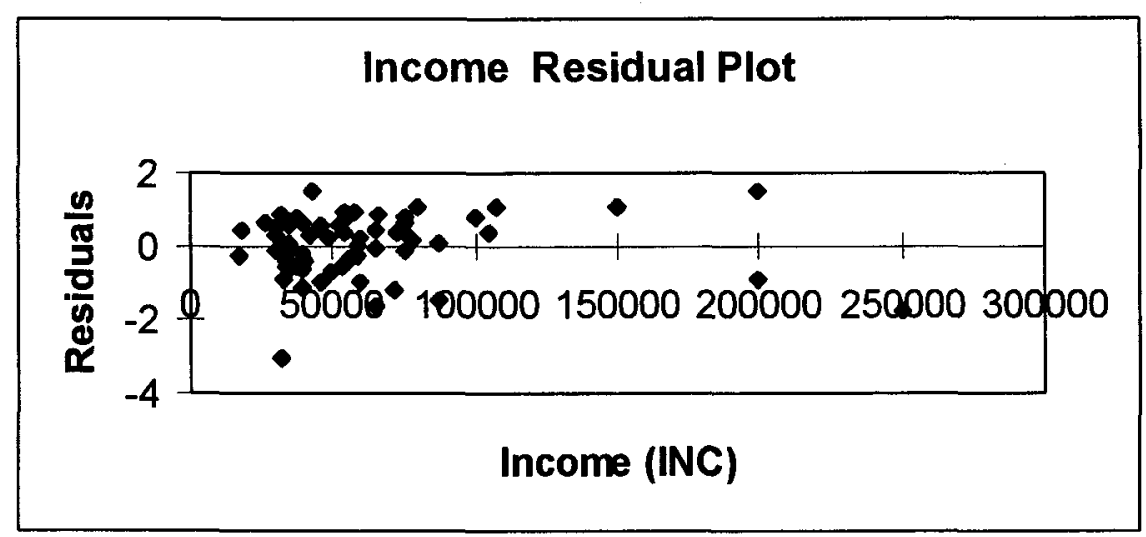

